\title{
Living at a green care farm
}

Citation for published version (APA):

de Boer, B. S. (2017). Living at a green care farm: An innovative alternative for regular care in nursing homes for people with dementia. [Doctoral Thesis, Maastricht University]. Datawyse / Universitaire Pers Maastricht. https://doi.org/10.26481/dis.20171019bdb

Document status and date:

Published: 01/01/2017

DOI:

10.26481/dis.20171019bdb

Document Version:

Publisher's PDF, also known as Version of record

\section{Please check the document version of this publication:}

- A submitted manuscript is the version of the article upon submission and before peer-review. There can be important differences between the submitted version and the official published version of record.

People interested in the research are advised to contact the author for the final version of the publication, or visit the DOI to the publisher's website.

- The final author version and the galley proof are versions of the publication after peer review.

- The final published version features the final layout of the paper including the volume, issue and page numbers.

Link to publication

\footnotetext{
General rights Owners
rights.

- You may freely distribute the URL identifying the publication in the public portal. please follow below link for the End User Agreement:

www.umlib.nl/taverne-license

Take down policy

If you believe that this document breaches copyright please contact us at:

repository@maastrichtuniversity.nl

providing details and we will investigate your claim.
}

Copyright and moral rights for the publications made accessible in the public portal are retained by the authors and/or other copyright owners and it is a condition of accessing publications that users recognise and abide by the legal requirements associated with these

- Users may download and print one copy of any publication from the public portal for the purpose of private study or research.

- You may not further distribute the material or use it for any profit-making activity or commercial gain

If the publication is distributed under the terms of Article $25 \mathrm{fa}$ of the Dutch Copyright Act, indicated by the "Taverne" license above, 


\section{Living at a green care farm}

\section{An innovative alternative for regular care in nursing homes for people with dementia}

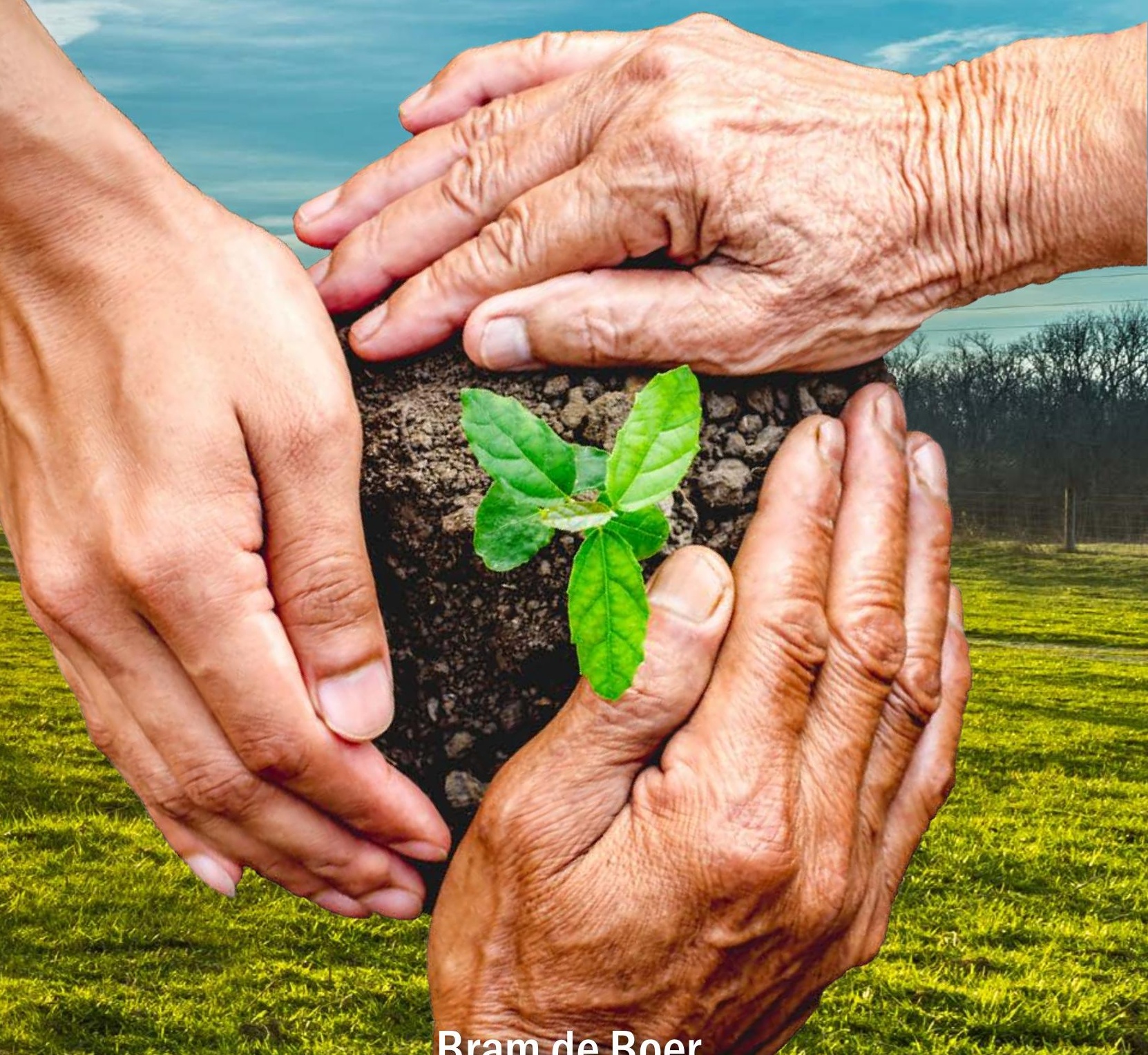

W. 7 aram de Boer

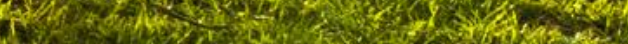

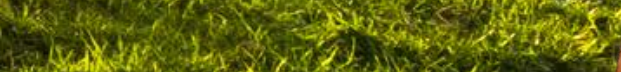

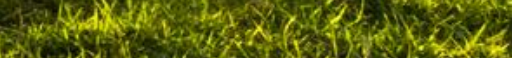

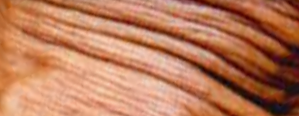

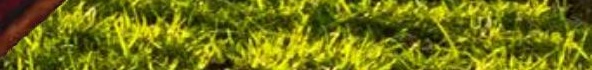

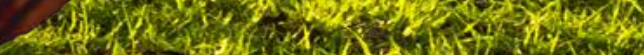

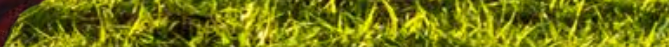

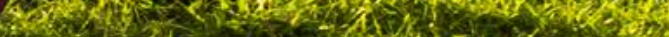


The research presented in this dissertation was conducted at the CAPRHI Care and Public Health Research Institute, department of Health Services Research, Maastricht University. CAPHRI is part of the Netherlands School of Primary Care Research (CARE), which has been acknowledged by the Royal Netherlands Academy of Science (KNAW). This research was funded under a grant from the Netherlands Organisation for Health Research and Development (ZonMw), project number: 728010002, Maastricht University, and the Province of Limburg.

Printing + Cover: Datawyse | Universitaire Pers Maastricht

(C) Copyright Bram de Boer, Maastricht 2017

ISBN: 9789461597465

Financial support for printing this thesis has been kindly provided by Alzheimer Nederland.

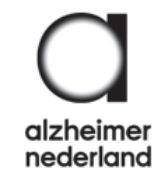




\title{
Living at a green care farm
}

\section{An innovative alternative for regular care in nursing homes for people with dementia}

\author{
PROEFSCHRIFT \\ to obtain the degree of Doctor at Maastricht University, \\ on the authority of the Rector Magnificus, Prof. dr. Rianne M Letschert, \\ in accordance with the decision of the Board of Deans, \\ to be defended in public \\ on Thursday October $19^{\text {th }}, 2017$, at 16.00 hours
}

by

Bram Sybrandus de Boer 
SUPERVISOR

Prof. dr. JPH Hamers

\section{CO-SUPERVISORS}

Dr. H. Verbeek

Dr. S.M.G. Zwakhalen

\section{ASSESSMENT COMMITTEE}

Prof. dr. G Kok (chair)

Prof. dr. JMGA Schols

Prof. dr. FRJ Verhey

Prof. dr. KG Luijkx (Tilburg University)

Prof. dr. K Wolf-Ostermann (Bremen University, Germany) 


\section{CONTENTS}

CHAPTER 1 General introduction

CHAPTER 2 Living at the farm, innovative nursing home care for people with dementia - study protocol of an observational longitudinal study

BMC geriatrics, 2015

CHAPTER 3 Daily lives of residents with dementia in nursing homes:

development of the Maastricht Electronic Daily Life Observation Tool

International Psychogeriatrics, 2016

CHAPTER 4 Green care farms as innovative nursing homes, promoting activities and social interaction for people with dementia

Journal of the American Medical Directors Association, 2017

CHAPTER 5 The association between aspects of daily life and quality of life of people with dementia living in long-term care facilities: a

momentary assessment study

International Psychogeriatrics, 2016

CHAPTER 6 Quality of Care and Quality of Life of People with Dementia Living at Green Care Farms: a cross-sectional study

BMC Geriatrics, 2017

CHAPTER 7 Positive and Negative Experiences of Informal Caregivers of People with Dementia Living in Green Care Farms, Small-scale Living Facilities, and Traditional Nursing Homes.

\section{Submitted for publication}

CHAPTER 8 General discussion

Summary

Samenvatting

Valorization

Dankwoord

About the author

List of publications

Living lab in ageing and long -term care 

CHAPTER ـ

General introduction 


\section{GENERAL INTRODUCTION}

In the Netherlands, as in many other countries, the aim is to allow people with dementia to live at home as long as possible. However, a substantial proportion will be admitted into a nursing home because they require complex care that cannot be provided in the home situation. ${ }^{1-3}$ When a nursing home admission is required, people with dementia and their informal caregivers can go to a wide spectrum of different types of nursing homes which vary in terms of physical and organizational environment. There are more traditional, large-scale nursing homes, and small-scale, homelike facilities. In addition, there are several innovative types of nursing homes developing in the Netherlands. In 2013 the first green care farm providing 24-hour nursing home care for people with dementia has opened and, since then, more green care farms have gradually started up and now provide nursing home care.

Although there has been some research on green care farms providing daycare for different client groups, no studies have been done on the concept of 24-hour nursing home care at green care farms. It is unknown whether it is possible to provide this type of care in such a new and unique environment. Furthermore, there is no knowledge on the effects green care farms have on their residents, the quality of care they provide, and the experiences with this new concept.

The aim of this dissertation is to study the effects of green care farms that provide 24-hour nursing home care for people with dementia on the daily lives of residents, quality of care, quality of life, and experiences of informal caregivers. This first chapter provides information on dementia, developments within nursing home care, green care farms, daily life at nursing homes, and the relevance of the studies described in this dissertation.

\section{Dementia}

Dementia is characterized by a decline in memory or other cognitive skills severely enough to reduce a person's ability to perform everyday activities. It is often accompanied by impaired function in communication, attention, reasoning, or visual perception. Dementia is progressive, meaning that symptoms gradually get worse over time. ${ }^{1}$ Alzheimer's disease is the most common type of dementia, accounting for 60 to 80 percent of the cases.

The number of people worldwide with dementia is expected to grow from 9.95 million in 2010 to 18.65 million in 2050. In The Netherlands, the number of people with dementia will increase from 260,000 to 500,000 in 2050. This increasing number of people with dementia will put more strain on long term care services in the near future and will lead to a larger demand for nursing homes in the Netherlands. 


\section{Developments within nursing home care for people with dementia}

The development of nursing homes in the Netherlands stems from demographic changes in the population and the need to solve the issue of long-term stay by an increasing number of elderly patients in hospitals. ${ }^{4}$ Nursing homes were developed based on a medical model of care focusing on physical care needs and keeping residents safe. Therefore, many nursing homes have an institutional character and still work according to this medical model of care. Care is often delivered in large-scale facilities and routines of the nursing staff determine daily life at the nursing home. Nowadays, there is a worldwide movement towards a more psychosocial care concept ${ }^{5-7}$ aiming to provide person-centered care in small-scale, homelike care environments. ${ }^{8}$ Traditional nursing homes are being redesigned into smaller group homes that provide a more homelike and familiar atmosphere for their residents. Furthermore, various alternative facilities are developing across the world. Examples are small-scale living facilities on the terrain of larger nursing home, stand-alone units in the neighborhood, and recently, green care farms that provide 24-hour nursing home care for people with dementia. These new facilities are aimed at allowing people to continue the life they had before admission for as long as possible. They try to achieve this by focusing on engaging residents in activities, giving them feelings of meaning in life and allowing them to express themselves and interact with other people. ${ }^{8,9}$ Aspects such as autonomy and quality of life are increasingly becoming more important. Care staff has integrated tasks and basically form a household together with the residents. This means that tasks such as cooking, cleaning, doing the laundry, setting the table, doing the dishes, and other daily activities are performed by staff together with residents.

This change in care concept can also be seen in policies, strategies and frameworks launched in many countries aimed at improving the quality of care and quality of life for people with dementia living in nursing homes. This also means that the way quality of care is assessed will change in the future. Quality of care in nursing homes is often debated and negative outcomes such as adverse drug events, pressure ulcers, falls, and use of restraints are increasingly reported in recent studies. ${ }^{10,11}$ The focus used to be on these health care problems that occurred. However, problems such as passivity, boredom, loneliness, and social exclusion are getting more and more attention. ${ }^{12,13}$

Whether residents of nursing homes can maintain feelings of meaning in their life, have social interactions, and can make their own choices is difficult to measure, and has received little attention in research. This emphasizes the importance of developing new ways of looking at how nursing home residents spend their days, which is why the daily life of residents is an important focus in this dissertation.

Furthermore, there is an increased emphasis on the role of informal caregivers of people with dementia living in nursing homes. They play a key role in the decision process for a particular type of nursing home and are involved more and more in social as well as care-related activities with their relative with dementia. ${ }^{14-16}$. Research shows 
that the active participation of family members contributes to a better quality of life of people with dementia in term of social relationships and social isolation. ${ }^{17}$ Having a match between the person with dementia and the care environment can promote the delivery of person centered care. ${ }^{18}$ Therefore, it is important to investigate why people choose a particular type of nursing home and what their experiences are with these different care environments. To provide such person-centered care for residents, it is vital to offer meaningful activities, and to allow them to maintain their quality of life as much as possible. This leads to a high demand for a broad selection of innovative nursing homes that meet individual desires and needs. Green care farms providing 24hour nursing home care for people with dementia are a new type of small-scale living facility that is developing in the Netherlands.

\section{Green care farms}

The development of green care farms not only stems from developments within the health care sector, but also from developments within the agricultural sector. ${ }^{19}$ There is an increasing demand for multifunctional agriculture in order to increase revenue for farmers. Most green care farms provide daycare services for a wide range of client groups (e.g. people with learning disabilities, psychological problems, addiction problems, and people with dementia. ${ }^{20,21}$ Green care farms that provide daycare are developing in many parts of world with Norway, the Netherlands, France and Italy being the leading countries. ${ }^{22,23}$ All green care farms have some degree of farming and of care, but the ratio between farming and care may differ across settings. ${ }^{24}$ Some of these green care farms are actual farms that have agricultural production, while for others, providing care is the main source of income and agricultural production is a byproduct. In the Netherlands, there are over a thousand green care farms, and approximately 200 provide care for people with dementia. A handful of them are now providing 24-hour nursing home care, meaning that people actually live on the farm (in the same way as people live in other nursing homes). This is unique in the world.

These green care farms have many characteristics of small-scale living facilities for people with dementia. A small group of residents live together in a home-like and noninstitutional house on the terrain of a farm. Daily activities include domestic activities, work-related activities, social activities, and leisure/recreational activities. This wide range of activities is incorporated into normal daily care practices. ${ }^{21}$ The physical environment of green care farms is different from existing nursing homes. Residents of green care farms have the opportunity to go outdoors and to take care of gardens or animals. In addition, the environment is open and residents are free to move around as they please. The aim of green care farms is to provide a stimulating environment that encourages people with dementia to be active, and to initiate daily activities themselves. By providing care in such an innovative environment, green care farms 
offer the possibility of having an active and meaningful daily life, which is difficult to achieve in more traditional nursing homes.

In traditional nursing homes, several interventions are used to provide residents with activities (animal-assisted therapy, nature based interventions, recreational activities, other social and physical interventions). As at regular day-care services for people with dementia, these interventions are not continuously present in the environment of the nursing home. ${ }^{25}$. This is in contrast with green care farms, where many elements of the mentioned interventions naturally occur in the environment. Besides the recognizable and activating environment, the environment has the potential to stimulate the senses of people with dementia by means of odors, sounds, touch, and tastes (animals, hay, tractors, fresh fruit and vegetables). Therefore, sensory stimulation interventions are not necessary. The same applies to interventions aimed at physical activity; instead of offering interventions aimed at physical activity, the environment and possibilities for activities stimulate people to be physically active (walking in the garden, getting milk from the cows, or vegetables from the yard). Thus, several interventions are incorporated in the environment and therefore continuously and simultaneously present. ${ }^{25}$ The goal of green care farms is to provide residents with a meaningful daily life within a familiar and open environment.

\section{Daily life at nursing homes}

Studies show that residents of nursing homes spend the majority of their daily life doing little or nothing while remaining in a lying or sitting position, without social interaction. $^{26-28}$ They are rarely engaged in meaningful activities. This is problematic because having something to do is important for nursing home residents as it allows them to connect with other people and to experience feelings of pleasure during their day. ${ }^{29,} 30$ Participation in activities is an important indicator of nursing home quality. However, daily life is a dynamic and multidimensional concept, and is constituted by more than activities alone. The physical environment of nursing homes is also important for the daily lives of their residents. For instance, the provision of outdoor areas accommodates activity, and may reduce levels of agitation. ${ }^{31}$ Furthermore, possibilities for social interaction are important for people with dementia since having social contacts is a basic human need. Therefore, it is important to take into account all relevant aspects of daily life for people with dementia living in a nursing home.

\section{Relevance, aim and outline}

The International Association of Gerontology and Geriatrics and the World Health Organization have stated that there is a pressing need for innovative care models to improve the quality of care in nursing homes. ${ }^{32}$ However, a recent review on the impact of homelike residential care models indicated that evidence on the effectiveness of 
these models is limited and that more comparative research is needed to justify the uptake of more homelike residential care models such as green care farms. ${ }^{9}$ Evidence regarding these care models is important for health policy makers, care providers, and (potential) residents of nursing homes.

In a time where person-centered care is being advocated as a way to provide high quality care, insight is needed into the needs, possibilities, and environmental aspects that are important for individual nursing home residents. Gaining insight into the daily lives of residents allows nursing home staff and researchers to tailor interventions for individuals. Furthermore, knowledge on quality of care, and experiences with the care provided at green care farms, in comparison with other types of nursing homes can lead to a better understanding of which lessons can be learned from this kind of innovative small-scale homelike nursing homes. Up until now, research on green care farms providing 24-hour nursing home care for people with dementia is lacking.

The aim of this dissertation is to investigate the effects of green care farms that provide 24-hour nursing home care for people with dementia. It is investigated whether there are differences between green care farms, traditional nursing homes, and regular small-scale living facilities in terms of the daily lives of residents, quality of care, quality of life, and experiences of informal caregivers. Furthermore, the development of a new observation tool to measure the daily lives of people with dementia living in a nursing home is described.

Chapter 2 presents the study protocol of the main study into the effects of green care farms as innovative nursing homes for people with dementia. The main research questions are formulated and the design of the study is described. Furthermore, the sample, settings, measurement methods, and procedures are discussed. Chapter 3 describes the development of the Maastricht Electronic Daily Life Observation tool (MEDLO-tool). This is a freely accessible, easy to use, electronic observation tool for assessing relevant aspects of daily life for nursing home residents with dementia. The chapter shows the development process, the tool that was created, and a first exploration of the inter-rater reliability and feasibility of the tool. Chapter 4 shows the effects of a longitudinal observational study investigating the daily lives of people with dementia living in green care farms in comparison with residents of traditional nursing homes and regular small-scale living facilities. Chapter 5 provides the results of a study on the association between aspects of daily life which were observed using the MEDLOtool and quality of life. Chapter 6 reports on the findings of a study on quality of care, quality of life, and related outcomes at green care farms and other types of nursing homes. Structure, process, and outcome indicators of quality of care are discussed and different perspectives on quality of life are covered. Chapter 7 shows the results of a qualitative study which explores the experiences of informal caregivers with green care farms, small-scale living facilities, and traditional nursing homes. Topics discussed are: reasons of choice for a particular type of nursing home, positive, and negative 
experiences with the nursing home. Chapter 8 summarizes the main findings and discusses implications for both research and practice. Strengths and limitations of the studies are considered and possibilities for future directions are discussed. 


\section{REFERENCES}

1. Alzheimer's Association, 2017 Alzheimer's disease facts and figures. Alzheimer's \& Dementia 2017;13: p. 325-373.

2. Gaugler, J.E., et al., Predictors of nursing home admission for persons with dementia. Medical Care 2009;47(2): p. 191-198.

3. Luppa, M., et al., Prediction of institutionalization in the elderly. A systematic review. Age and Ageing 2009;p. afp202.

4. Schols, J.M., H.F. Crebolder, and C. van Weel, Nursing home and nursing home physician: the Dutch experience. Journal of the American Medical Directors Association, 2004;5(3): p. 207-212.

5. Flicker, L., Dementia reconsidered: The person comes first. BMJ 1999;318(7187): p. 880.

6. Taft, L.B., et al., A psychosocial model of dementia care: Theoretical and empirical support. Archives of Psychiatric Nursing 1997;11(1): p. 13-20.

7. Buron, B., Levels of personhood: A model for dementia care. Geriatric Nursing 2008;29(5): p. 324-332.

8. Verbeek, H., et al., Small, homelike care environments for older people with dementia: a literature review. International Psychogeriatrics 2009;21(02): p. 252-264.

9. Ausserhofer, D., et al., "There's No Place Like Home": A Scoping Review on the Impact of Homelike Residential Care Models on Resident-, Family-, and Staff-Related Outcomes. Journal of the American Medical Directors Association 2016;17(8): p. 685-693.

10. Handler, S.M., et al., Epidemiology of medication-related adverse events in nursing homes. The American Journal of Geriatric Pharmacotherapy 2006;4(3): p. 264-272.

11. Horn, S.D., et al., Description of the National Pressure Ulcer Long-Term Care Study. Journal of the American Geriatrics Society 2002;50(11): p. 1816-1825.

12. Knight, T. and D. Mellor, Social inclusion of older adults in care: Is it just a question of providing activities? International Journal of Qualitative Studies on Health and Well-being 2007;2(2): p. 76-85.

13. Cahill, S. and A.M. Diaz-Ponce, 'I hate having nobody here. I'd like to know where they all are': Can qualitative research detect differences in quality of life among nursing home residents with different levels of cognitive impairment? Aging \& Mental Health 2011;15(5): p. 562-572.

14. Cohen, L.W., et al., Dementia in relation to family caregiver involvement and burden in long-term care. Journal of Applied Gerontology 2014;33(5): p. 522-540.

15. Butcher, H.K., et al., Thematic analysis of the experience of making a decision to place a family member with Alzheimer's disease in a special care unit. Research in Nursing \& Health 2001;24(6): p. 470-480.

16. Caron, C.D., F. Ducharme, and J. Griffith, Deciding on institutionalization for a relative with dementia: the most difficult decision for caregivers. Canadian Journal on Aging 2006;25(02): p. 193-205.

17. Gräske, J., et al., Family visits in shared-housing arrangements for residents with dementia-a crosssectional study on the impact on residents' quality of life. BMC Geriatrics 2015;15(1): p. 14.

18. Lawton, M.P., The physical environment of the person with Alzheimer's disease. Aging \& Mental Health 2001;5(sup1): p. 56-64.

19. Haubenhofer, D.K., et al., The development of green care in western European countries. EXPLORE: the Journal of Science and Healing 2010;6(2): p. 106-111.

20. Hassink, J., et al., Care farms in the Netherlands: Attractive empowerment-oriented and strengths-based practices in the community. Health \& Place 2010;16(3): p. 423-430.

21. De Bruin, S., et al., The concept of green care farms for older people with dementia An integrative framework. Dementia 2010;9(1): p. 79-128.

22. Hassink, J. and M. van Dijk, Farming for health across Europe: Comparison between countries, and recommendations for a research and policy agenda, in Farming for health 2006; Springer. p. 345-357.

23. Hassink, J., W. Hulsink, and J. Grin, Care Farms in the Netherlands: An Underexplored Example of Multifunctional Agriculture-Toward an Empirically Grounded, Organization-Theory-Based Typology. Rural Sociology 2012;77(4): p. 569-600.

24. Roest, A., et al., Kijk op multifunctionele landbouw, omzet en impact 2007-2009. 2010, LEI/PPO. 
25. de Bruin, S.R., Sowing in the autumn season: exploring benefits of green care farms for dementia patients. 2009.

26. Ice, G.H., Daily life in a nursing home: Has it changed in 25 years? Journal of Aging Studies 2002;16(4): p. 345-359.

27. den Ouden, M., et al., Daily (In) Activities of nursing home residents in their wards: an observation study. Journal of the American Medical Directors Association 2015;16(11): p. 963-968.

28. Winblad, B., et al., Defeating Alzheimer's disease and other dementias: a priority for European science and society. The Lancet Neurology 2016;15(5): p. 455.

29. Hancock, G.A., et al., The needs of older people with dementia in residential care. International Journal of Geriatric Psychiatry 2006;21(1): p. 43-49.

30. Vernooij-Dassen, M., Meaningful activities for people with dementia. Aging \& Mental Health 2007;11:4, 359-360,

31. Whear, R., et al., What is the impact of using outdoor spaces such as gardens on the physical and mental well-being of those with dementia? A systematic review of quantitative and qualitative evidence. Journal of the American Medical Directors Association 2014;15(10): p. 697-705.

32. Tolson, D., et al., International Association of Gerontology and Geriatrics: A global agenda for clinical research and quality of care in nursing homes. Journal of the American Medical Directors Association 2011;12(3): p. 184-189. 



\section{CHAPTER}

Living at the farm, innovative nursing home care for people with dementia - study protocol of an observational longitudinal

study

This chapter was published as: de Boer B, Hamers J, Beerens H, Zwakhalen S, Tan F, Verbeek $\mathrm{H}$. Living at the farm, innovative nursing home care for people with dementiastudy protocol of an observational longitudinal study. BMC geriatrics 2015; 15(1): 144 . doi: 10.1186/s12877-015-0141-x 


\section{ABSTRACT}

Background: In nursing home care, new care environments directed towards small-scale and homelike environments are developing. The green care farm, which provides $24-$ hour nursing home care for people with dementia, is one such new care environment. Knowledge is needed on the relation between environmental features of green care farms such as nature, domesticity and offering care in small groups and the influence on the daily lives of residents. The aim of this study is to explore (1) the daily lives of residents, (2) the quality of care and (3) the experiences of caregivers on green care farms compared with other nursing home care environments.

Methods/design: An observational longitudinal study including a baseline and a sixmonth follow-up measurement is carried out. Four types of nursing home care environments are included: (1) large scale nursing home ward, (2) small scale living facility on the terrain of a larger nursing home (3) stand-alone small scale living facility and (4) green care farm. Quality of care is examined through structure, process and outcome indicators. The primary outcome measure is the daily life of residents, assessed by ecological momentary assessments. Aspects of daily life include (1) activity (activity performed by the resident, the engagement in this activity and the degree of physical effort); (2) physical environment (the location of the resident and the interaction with the physical environment); (3) social environment (the level and type of social interaction, and with whom this social interaction took place) and (4) psychological well-being (mood and agitation). In addition, social engagement, quality of life, behavioral symptoms and agitation are evaluated through questionnaires. Furthermore, demographics, cognitive impairment, functional dependence and the severity of dementia are assessed. Semi-structured interviews are performed with caregivers regarding their experiences with the different nursing home care environments.

Discussion: This is the first study investigating green care farms providing 24-hour nursing home care for people with dementia. The study provides valuable insight into the daily lives of residents, the quality of care, and the experiences of caregivers at green care farms in comparison with other nursing home care environments including small-scale care environments and large scale nursing home wards.

Keywords Activities, daily life, dementia, green care farms, institutional long-term care, nursing home care environments, quality of care, quality of life, social engagement 


\section{BACKGROUND}

The number of people living with dementia worldwide is expected to increase from 24 million in 2001 to 81 million in 2040. ${ }^{1}$ This trend can also be seen in the Netherlands where the number of people suffering from dementia is expected to double to over 500,000 people in $2040{ }^{2}$ Most of the people with dementia live at home. However, as the dementia progresses, living at home is often not possible and approximately $30 \%$ get admitted to nursing homes as they require complex care., ${ }^{3,4}$

Nursing home care used to be primarily organized according to a medical care concept $^{5-7}$ in traditional large-scale wards with an institutional character. Physical care needs are the main focus of attention and care for people with dementia is organized around routines of the nursing staff. ${ }^{8,9}$ In many countries, current nursing homes are increasingly organized according to a psychosocial and more homelike care concept. ${ }^{10,}$ ${ }^{11}$ Here, the care is often organized in smaller units, usually with 6-8 residents. ${ }^{8}$ The residents live together in a homelike and recognizable environment in which striving to achieve a situation closest to home is the priority. ${ }^{12,13}$ Personal care and daily routines are integrated, meaning that care staff performs tasks such as cooking and cleaning together with the residents. This psychosocial care concept strives to allow people to continue the life they had before admission, as much as possible, and promotes person centered care and quality of life. In addition, this type of care involves the provision of autonomy for residents, letting them make their own choices and encouraging social interaction and participation in activities. ${ }^{14,15}$

The change in care concept and the exponential growth of the number of people with dementia lead to a high demand for a broad selection of innovative and efficient nursing home care facilities that meet individuals' desires and requirements ${ }^{1}$. In the Netherlands, a variety of small scale, homelike living facilities have been developed; some are stand-alone units in the neighbourhood built as an archetypical house while others are units situated on the terrain of a larger nursing home. ${ }^{16}$ New type of smallscale, homelike care facilities are green care farms for people with dementia. Originally developed as day-care only centres, nowadays some green care farms have started to provide 24-hour care as a new alternative for regular nursing homes.

\section{What are green care farms?}

Green care farms come in different forms, and are referred to in a variety of terms, such as social farming, multifunctional agriculture and farming for health. ${ }^{17}$ The development of green care farms not only stems from the health care sector, but also from developments within the agricultural sector. ${ }^{18}$ Here, there is an increasing demand for multifunctional agriculture in order to increase revenue for farmers. ${ }^{19}$ Green care farms mostly provide day care for different client groups (e.g., people with learning disabilities, psychological problems, addiction problems and people with dementia) and 
are aimed at promoting individual's social, mental, and educational wellbeing. ${ }^{18,20-22}$ Green care farms that provide day care are developing in many parts of the world. ${ }^{19}$ Leading countries include: Norway (approximately 1,100 green care farms), the Netherlands (1,000), France (900), Italy (675), Belgium (300), Austria (250), the UK (230), Germany (160) and Ireland (100). ${ }^{17-19,23}$ Some of these green care farms are actual farms that have agricultural production while for others, providing care is the main source of income and gaining agricultural production is a byproduct. ${ }^{24}$

In the Netherlands, approximately 200 green care farms provide day care for people with dementia. ${ }^{21}$ Findings of a study investigating the effects of day care on Dutch green care farms suggest that there are differences in the daily lives between people spending their days at green care farms and those who spend their days at other day care facilities. Positive indications such as more frequently available activities and more variation in activities at green care farms were found. ${ }^{25}$ In addition, research findings suggest higher involvement in activities of daily living $(A D L),{ }^{26}$ and more physical effort needed ${ }^{25}$ for people with dementia spending their daytime on green care farms. These findings are important because being engaged in activities allows people with dementia to connect with other people and to experience feelings of pleasure. ${ }^{27,28}$ Furthermore, $^{2}$ participation in activities is associated with a higher quality of life ${ }^{29}$ and is one of the priorities in nursing homes. ${ }^{30}$ Other aspects related to the daily lives of people with dementia such as social relations, interaction with the physical environment and mood can also influence quality of life. ${ }^{31-33}$

Recently, some green care farms that provide 24-hour nursing home care are being developed. These green care farms have many characteristics of small scale living, meaning that a small group of residents live together in a home-like and noninstitutional 'house' on the terrain of a farm. People living at green care farms have the opportunity to go outdoors and to take care of gardens or animals. Other daily activities include domestic activities (e.g., preparing dinner, dishwashing), work-related activities (e.g., cleaning the stables, feeding animals), social activities (e.g., coffee break, dinner) and leisure/recreational activities (e.g., playing a game, listening to music). This wide range of activities is incorporated into normal daily life activities. ${ }^{22}$

More insight is needed into the added value of green care farms as they relate to the spectrum of nursing home care environments. The current study investigates (1) the daily lives of residents, (2) the quality of care, and (3) the experiences of caregivers with the care environment. Green care farms are compared with traditional large scale nursing home wards and with other forms of small-scale, homelike care environments. 


\section{METHODS}

\section{Design}

This study uses an observational longitudinal design including a baseline measurement and a six-month follow-up measurement. The study takes place between April 2014 and December 2015.

\section{Setting}

Participants of this study are all admitted to or working in non-profit, collectively funded nursing homes in the southern part of the Netherlands. In order to be admitted to these facilities, the level of care people with dementia need is determined by a standardized procedure carried out by a governmental agency. Based on this procedure, determination regarding admission to a nursing home environment is made. Both largeand small-scale nursing home environments are compared. Figure 1 gives an overview of the different types of nursing home environments, the number of wards and the number of potential participants for this study.

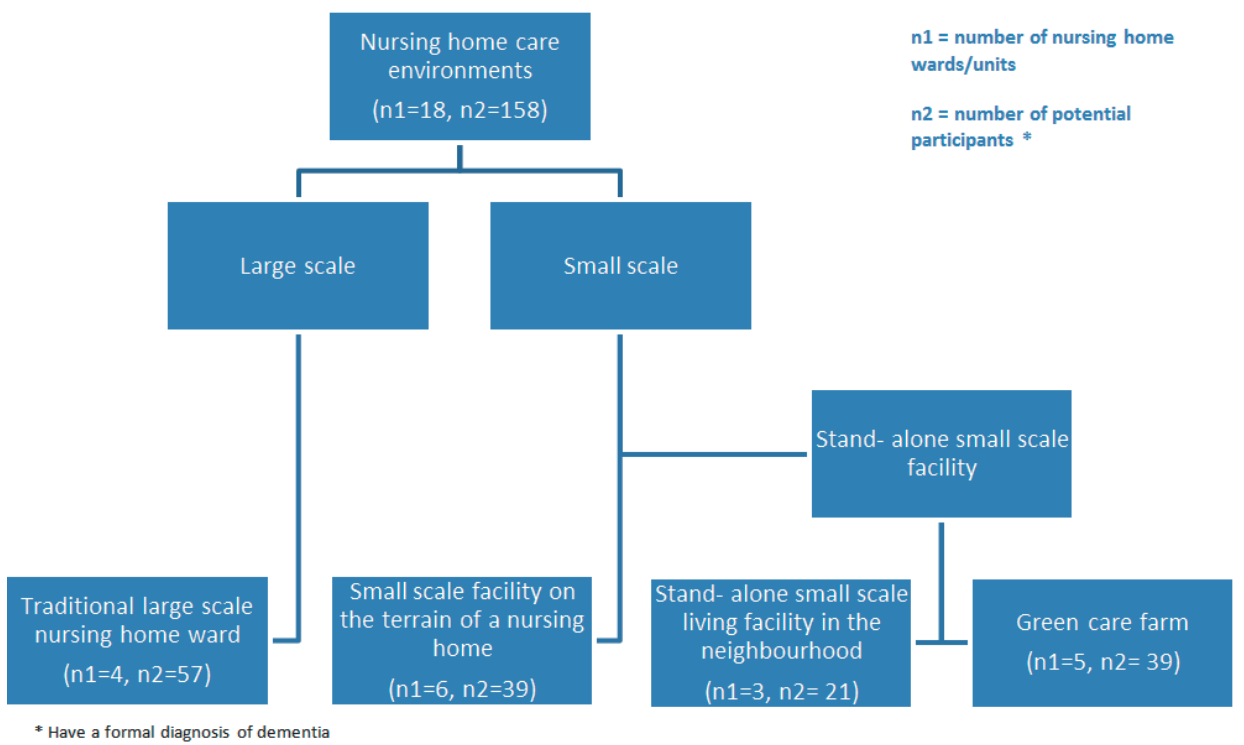

Figure 1. Overview of the different types of nursing home environments, the number of wards and the number of potential participants for this study 
Four types of nursing home environments are included:

Large-scale nursing home ward: has at least 20 residents on the ward; caregivers have differentiated tasks, aimed at nursing home care and daily life is determined by the routines and rules of the organization. ${ }^{12}$

Small-scale living facility on the terrain of a larger nursing home: has a maximum of 8 residents; has a joint household in which every day there is cooking in the home; caregivers have integrated tasks (they have multiple functions next to their care function); has a steady team of caregivers; daily living is mainly determined by the residents and informal caregivers; and the physical environment approaches a home like situation as much as possible. ${ }^{12}$ In addition, residents and staff have access to facilities provided by a large nursing home facility such as a restaurant and activity areas.

Stand-alone small scale living facility: has the same characteristics as a small scale living facility on the terrain of a larger nursing home, however, it is situated in a neighborhood and therefore does not have direct access to facilities provided at a larger nursing home. This facility is aimed at keeping contact with the community and opportunities to maintain a social network. ${ }^{12}$

Green care farm: A type of stand-alone small-scale nursing home facility where both care and agricultural activities are important ${ }^{18}$. Approximately 8 residents live together in a house on the area of the farm. Some of these green care farms are actual farms that have agricultural production while, for others, providing care is the main source of income and gaining agricultural production is a byproduct. ${ }^{24}$

\section{Participants}

\section{Residents}

All participants of this study receive a similar degree of nursing home care. Residents are eligible for participation in the study if they have a formal diagnosis of dementia according to their medical record.

Previous studies showed that residents living in small-scale facilities had a significantly better functional status and cognitive performance than residents living in large-scale facilities. ${ }^{9}, 34$ Following earlier research, ${ }^{8}$ to prevent large differences between participants at baseline on cognition and functional dependence, a matching procedure is carried out two weeks before the baseline measurement. This increases the comparability between the participants of the different nursing home environments. The Minimum Data Set (MDS) subscales for cognition (CPS) and ADL $(\mathrm{ADL}-\mathrm{H})$ are used to screen all residents. ${ }^{35-37}$ Residents of large-scale nursing home wards who have more or less similar scores as residents of the small scale facilities are invited to participate. 


\section{Caregivers}

In order to explore the experiences of caregivers, a convenient sample of formal and informal caregivers is interviewed up to the point of saturation. Caregivers of all four types of nursing home care environments are interviewed.

\section{Measures}

Table 1 summarizes the outcomes and outcome measures included in this study. Measurement instruments are selected based on their psychometric properties, the appropriateness for the target population and their availability in Dutch.

Table 1. Variables, operationalization and measures of the study.

\begin{tabular}{|c|c|c|}
\hline Variable type & Operationalization & Measure \\
\hline \multirow[t]{2}{*}{ Matching } & Cognition & Cognitive Performance Scale ${ }^{36}$ \\
\hline & Activities of daily living (ADL) & ADL-Hierarchy Scale ${ }^{37}$ \\
\hline \multirow[t]{3}{*}{$\begin{array}{l}\text { Quality of care } \\
\text { outcomes }\end{array}$} & $\begin{array}{l}\text { Structure indicators: number of residents and } \\
\text { caregivers; total amount of hours worked; } \\
\text { educational level of caregivers; competences of } \\
\text { caregivers }\end{array}$ & $\begin{array}{l}\text { Documentation care facility }+ \text { semi- } \\
\text { structured interviews formal caregiver }\end{array}$ \\
\hline & $\begin{array}{l}\text { Process indicators: presence of protocols patient } \\
\text { safety; accessibility of protocols; the way } \\
\text { protocols are followed }\end{array}$ & \\
\hline & $\begin{array}{l}\text { Outcome indicators: falling incidents; pressure } \\
\text { ulcers; malnutrition; use of psychotropic drugs; } \\
\text { use of restraints }\end{array}$ & $\begin{array}{l}\text { Questionnaire (quality framework } \\
\text { responsible care) }\end{array}$ \\
\hline $\begin{array}{l}\text { Primary } \\
\text { outcome } \\
\text { measure }\end{array}$ & Daily life & $\begin{array}{l}\text { Maastricht Electronic Daily Life Observation } \\
\text { tool (MEDLO-tool) })^{38}\end{array}$ \\
\hline \multirow{5}{*}{$\begin{array}{l}\text { Secondary } \\
\text { outcome } \\
\text { measures }\end{array}$} & Social engagement & $\begin{array}{l}\text { Revised Index for Social } \\
\text { Engagement(RISE) })^{40}\end{array}$ \\
\hline & Quality of life & $\begin{array}{l}\text { Quality of Life- Alzheimer's Disease (QoL- } \\
A D)^{41}\end{array}$ \\
\hline & & QUALIDEM $^{43}$ \\
\hline & Behavioral symptoms & $\begin{array}{l}\text { Neuropsychiatric Inventory - Nursing Home } \\
\text { Version(NPI-NH) }{ }^{45}\end{array}$ \\
\hline & Agitation & $\begin{array}{l}\text { Cohen Mansfield Agitation Inventory } \\
(\mathrm{CMAI})^{47}\end{array}$ \\
\hline \multirow{6}{*}{$\begin{array}{l}\text { Additional } \\
\text { variables }\end{array}$} & Demographics & Medical record \\
\hline & Comorbidity & Medical record \\
\hline & Cognitive impairment & $\begin{array}{l}\text { Standardized Mini Mental State } \\
\text { Examination(S-MMSE) })^{49,50}\end{array}$ \\
\hline & Activities of daily living (ADL) & Barthel index ${ }^{51,52}$ \\
\hline & Severity of dementia & Global Deterioration Scale (GDS) ${ }^{53}$ \\
\hline & Environmental characteristics & Checklist \\
\hline
\end{tabular}




\begin{tabular}{|c|c|c|}
\hline Variable type & Operationalization & Measure \\
\hline \multirow[t]{2}{*}{$\begin{array}{l}\text { Experiences } \\
\text { formal and } \\
\text { informal } \\
\text { caregivers }\end{array}$} & $\begin{array}{l}\text { Formal: a specific description of a 'typical' day, } \\
\text { necessary competences, required skills, attitude } \\
\text { and knowledge, training/schooling, pros and cons } \\
\text { of working within a particular care environment, } \\
\text { work-related pressure and the quality of care in } \\
\text { general. }\end{array}$ & Semi-structured interviews \\
\hline & $\begin{array}{l}\text { Informal: the process of choosing a particular care } \\
\text { setting, expectations regarding the quality of care, } \\
\text { the general perspective on quality of care, } \\
\text { positive and negative experiences with the care } \\
\text { facility and points of improvement. }\end{array}$ & \\
\hline
\end{tabular}

Daily lives of residents

The primary outcome measure of the study is the daily life of the residents. This is assessed by means of momentary assessments using the Maastricht Electronic Daily Life Observation tool (MEDLO-tool). ${ }^{38}$ The MEDLO- tool uses principles of ecological momentary assessment (EMA), ${ }^{39}$ meaning that observations are carried out in the moment, within the context they occur which enables researchers to study the interaction between several aspects of daily life and contextual factors. The MEDLOtool was specifically developed to provide a full and extensive description of the daily lives of people with dementia living in a nursing home care facility, including the following aspects:

\section{Activity}

The activity performed by or occurring in the immediate environment of the resident (scored on a list of 32 possible activities)

The engagement in this activity (e.g., no engagement, passively engaged or actively engaged)

The degree of physical effort during this activity (ranging from lying or sitting without movement to whole-body movement)

\section{Physical environment}

The location of the resident (e.g., in the communal area, own room or outside)

Whether the resident had interaction with the physical environment (yes or no)

\section{Social environment}

The level of social interaction (ranging from no social interaction to interaction with two or more people)

The type of social interaction (e.g., positive social or negative restrictive)

With whom this social interaction takes place (e.g., family, other resident or staff) 


\section{Psychological well-being}

Mood (e.g. small signs of negative mood or considerable signs of positive mood)

Agitation (ranging from no agitation to extreme agitation)

Each aspect of daily life is observed and scored using standardized scoring options. A pilot study demonstrated that agreement levels on the domains of the MEDLO-tool are high with an average absolute agreement of $86 \%$. More details regarding the MEDLOtool will be published elsewhere and are available upon request.

\section{Secondary outcome measures}

Social engagement. Social engagement is measured using the Revised Index for Social Engagement (RISE) for long-term care. ${ }^{40}$ The RISE consists of 6 dichotomous items that measure positive features of long-term care residents' social behavior leading to a score between 0 (lowest social engagement) and 6 (highest social engagement). The RISE has a Cronbach's alpha coefficient of .73, and an intra-class coefficient of .75. ${ }^{40}$

Quality of life. Quality of life is measured using two questionnaires often used in dementia care research. The Quality of Life- Alzheimer's Disease (QoL-AD) ${ }^{41}$ provides an overall quality of life (QoL) score by means of thirteen QoL domains rated on a fourpoint Likert scale, ranging from 1 (poor) to 4 (excellent). Total scores range from 13 to 52 , and higher scores indicate a better QoL. The QoL-AD has been found to have good content and construct validity and has a Cronbach's alpha ranging from .82 to $.90 .^{41-42}$ The QUALIDEM ${ }^{43}$ is a multi-dimensional scale consisting of 37 items across 9 subscales. The subscales are care relationship (7 items), positive affect (6), negative affect (3), restless tense behavior (3), positive self-image (3), social relations (6), social isolation (3), feeling at home (4) and having something to do (2). Items are rated using four response options: never, seldom, sometimes and often. The QUALIDEM was found to have good validity, ${ }^{43}$ the Cronbach's alpha of the subscales of the QUALIDEM are .59 for social isolation, .64 for positive self-image, .71 for negative affect, .73 for feeling at home, .74 for restless tense behavior, .80 for social relations, .83 for care relationship and .89 for positive affect. ${ }^{44}$

Behavioral symptoms. The Neuropsychiatric Inventory - Nursing Home version (NPI$\mathrm{NH}$ ) is used to measure behavioral symptoms. ${ }^{45,46}$ This instrument evaluates behavioral disturbances in people with dementia. It includes 12 neuropsychiatric symptoms (domains): 1) delusions; 2) hallucinations; 3) agitation; 4) depression/dysphoria; 5) anxiety; 6) euphoria/elation; 7) apathy/indifference; 8) disinhibition; 9) irritability/lability; 10)aberrant motor behavior; 11) nighttime disturbances; and 12) appetite/eating change. First, the presence of the symptoms is scored (yes/no). Second, the frequency of the symptoms is scored as rarely (1), sometimes (2), often (3), or very often (4). Third, the severity of the symptoms is scored as mild (1), moderate (2), or severe (3). The score for each domain is calculated by multiplying the frequency and 
severity. One study reports a Cronbach's alpha of 0.67 for the NPI-NH and convergent and discriminant validity were considered satisfactory. ${ }^{45}$

Agitation. The frequency of agitated behaviors is measured with the Cohen Mansfield Agitation Inventory (CMAI). ${ }^{47}$ The inventory consists of 29 items being scored on a 7-point scale of frequency (ranging from $1=$ never to $7=$ several times an hour). Total scores can be calculated ranging from 29 to 203 with higher scores indicating a higher frequency of agitated behaviors. Previous studies demonstrated that the CMAI was found to be a valid measure of agitation for nursing home residents; the Cronbach's alpha was $.86 .{ }^{48}$

Additional variables. The Standardized Mini-Mental State Examination (S-MMSE) ${ }^{49,50}$ is used to assess cognitive impairment. Scores on the S-MMSE range from 0 to 30, with higher scores indicating better cognition. The (in)dependence in activities of daily living (ADL) is assessed with the Barthel index. ${ }^{51,52}$ The Barthel index consists of 10 items and has a range of $0-20$, with higher scores indicating less ADL dependence. The Global Deterioration Scale (GDS) ${ }^{53}$ is used to measure the severity of the dementia on a range from 1 (normal) to 7 (highly severe dementia). Residents' medical records are used in order to retrieve background information regarding age, gender, admission date, type of dementia and comorbidities. Environmental characteristics of the different settings in the study are assessed using an observation checklist based on previous research. ${ }^{14,54,55}$ The checklist is specifically developed to measure long term care environments in a Dutch setting. It consists of 72 items which assess aspects of the environment on a 5point Likert scale, ranging from 1 'not at all' to 5 'completely'. The checklist is divided over 7 themes: 1) privacy and autonomy, 2) sensory stimulation, 3) view and nature, 4) facilities, 5) orientation and routing, 6) domesticity and 7) safety. Higher scores indicate a higher probability for the environment to have a positive effect on its' residents. An example item is: 'there is enough space for the resident to receive visitors in his/her own room'.

\section{Quality of care}

To examine quality of care the model of Donabedian is used. ${ }^{56}$ This is a widely recognized framework that divides quality of care in structure, process and outcome indicators. Structure indicators refer to all organizational aspects of providing care. ${ }^{56}$ In this study the following indicators are assessed: the number of residents and caregivers, the total amount of hours worked by nursing staff within a care facility, the staff/patient ratio, the educational level of the caregivers and the competences they need when providing care.

Process indicators refer to the way care is provided. ${ }^{56}$ The current study assesses the presence of protocols regarding patient safety, the accessibility of these protocols and the way these protocols are implemented. Information regarding the structure and process indicators are gathered through documents provided by the nursing homes and through semi-structured interviews with caregivers. 
Outcome indicators refer to consequences of care. ${ }^{56}$ In this study falling incidents, pressure ulcers, malnutrition and the use of psychotropic drugs or restraints are assessed. Outcome indicators are assessed with questionnaires based on the quality framework responsible care in the Netherlands. ${ }^{57}$

\section{Experiences caregivers}

Formal caregivers. Within the four types of nursing home care environments semistructured interviews with nursing staff are carried out. Topics discussed during these interviews include: a specific description of a 'typical' day at the care facility, competences necessary to provide care within a certain type of nursing home care facility, required skills, attitude and knowledge, training/schooling, differences between types of nursing home care environments in terms of pros and cons of working within a particular type, work-related pressure and the quality of care in general.

Informal caregivers. Semi-structured interviews are also carried out with informal caregivers. The goal is to interview the family member of the resident that is the most involved in the care of the resident. Topics discussed during these interviews include: the process of choosing a particular care setting, expectations regarding the quality of care, the general perspective on quality of care, positive and negative experiences with the care facility and points of improvement.

\section{Procedure}

Figure 2 shows the procedure of the study. After all participating nursing homes agreed to participate in the study; written consent is obtained through the legal representatives of the residents. Second, approximately two weeks before the baseline measurement, the cognitive performance scale and the ADL- hierarchy scale are filled out for all residents in order to match residents at baseline. Third, all measures using questionnaires and documents of the care facilities are collected through certified nursing assistants who provide hands-on care to the residents of the participating care facilities at both the baseline and the follow-up measurement. The S-MMSE and the QoL-AD are administered with the residents. Quality of care outcomes and the interviews with the formal and informal caregivers are only carried out at baseline. 
Figure 2. Procedure of the study

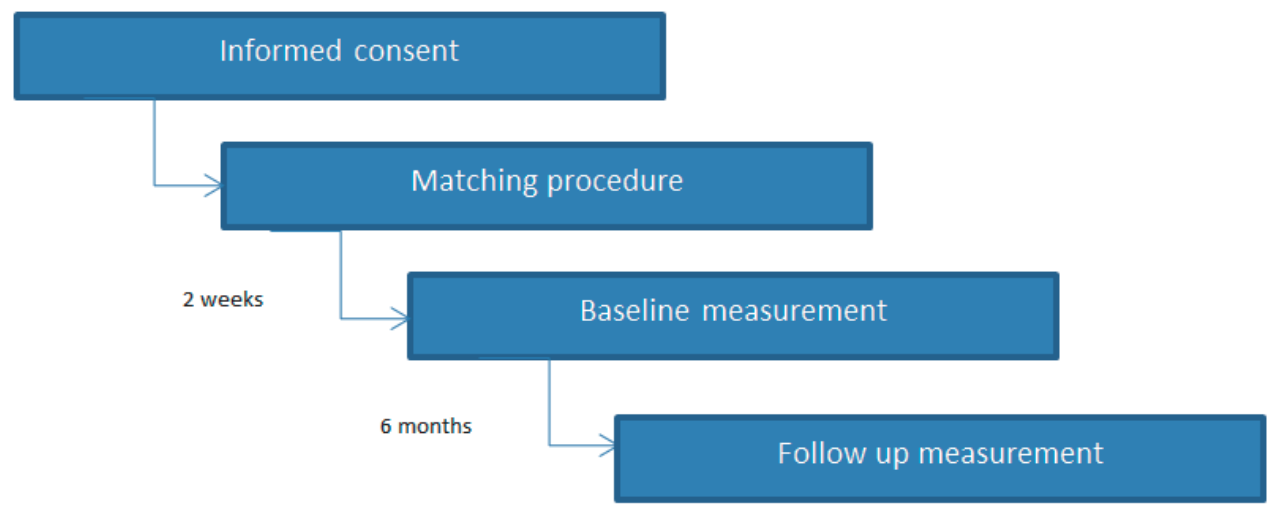

Data on the daily lives of the residents is collected through observations with the MEDLO-tool. Tablets are used to record momentary assessments of the different aspects of daily life. The observations take place on 2 mornings (7:00AM-11:30AM), 2 afternoons (11:30AM-16:00PM), and 2 evenings (16:00PM-20:30PM) at baseline and follow-up to reliably represent an ordinary day. In addition, one Saturday afternoon is included at baseline as the weekend may be different from the week-day. Thus, data was collected on 7 observation days. If it turns out there are no differences in the daily lives during the weekends, the Saturday will be excluded at the follow up measurement. Each observation day includes a half hour break for the observer, meaning that residents are observed for four hours each observation day. Every 20 minutes a maximum of eight residents are observed in a random order leading to 12 observations per resident each observation day. Eventually, this leads to a minimal of 156 observations per resident.

For each observation, the aspects of daily life are observed. In addition, the observer has the option to make field notes during the observations; this is done in case events occurred that could not be covered by the aspects of daily life from the MEDLO-tool. These field notes can be about the organizational, social, or physical environment.

Formal and informal caregivers receive an information letter about the study. After giving consent to participate in the study they are contacted via telephone or email for planning a date and location for an interview. The interviews are recorded with a recording device. After the interview, the recordings will be transcribed into a written transcript. The transcripts will be double checked and if necessary a member check will be carried out. 


\section{Ethics}

The medical ethics committee of the Maastricht University Medical Center reviewed the study; they declared that the study was non-invasive for people with dementia according to the Medical Research Involving Human Subjects Act. ${ }^{58}$ All participating nursing homes provided informed consent. Legal representatives of the residents are approached for written informed consent. In addition, the residents might not always have a full understanding of the study or may not be able to sign informed consent. Therefore, they are asked to assent, ${ }^{59}$ which is defined as willingness to participate even without full understanding of the complexity and the whole aims of the study. Formal and informal caregivers are always asked permission to record the interviews.

\section{Statistical analysis}

The data will be analyzed using IBM SPSS Statistics version $22 .^{60}$ For each variable, descriptive statistics at both baseline and follow-up measurement and the differences between them are computed for each type of nursing home care environment separately. Comparisons of residents' characteristics, and primary and secondary outcomes, are made between the four types of nursing home care environments. Regarding the observations of daily life; percentages will be calculated to investigate the proportion of time residents spend in each activity being scored. In addition, it is investigated whether or not residents are engaged in these activities, where residents spent their time, whether or not they have social interaction and with whom, how much physical effort they need during their days and their average mood and agitation levels are calculated. Furthermore, mixed-effects regression analyses are used to estimate differences between the types of nursing home care environments, taking into account that the momentary assessments (observations) on daily life are nested within participants.

Analyses of the interviews are done by several coding steps. ${ }^{61}$ Open coding is used to discover concepts discussed during the interviews, these are called 'main themes'. These main themes are subcategorized and by axial coding related to each other. The last step is selective coding; this is the process of integrating and refining categories. The whole coding process will be done by two researchers independently.

\section{DISCUSSION}

To our best knowledge, this is the first study that investigates green care farms that provide 24-hour nursing home care for people with dementia. The aim of this study is to explore the daily lives of residents at green care farms in comparison with other nursing home care environments. Furthermore, the quality of care, and the experiences of caregivers with the care environment are assessed. Green care farms are compared with other nursing home care environments (both large- and small-scale). The 
combination of momentary assessments and the use of questionnaires provide in-depth knowledge about important outcome measures for residents. The number of momentary assessments per resident gives a more precise estimate of the activities of residents, their quality of life, and physical and psychological well-being than a single measurement. It offers the possibility to investigate the added value of green care farms on the spectrum of nursing home care environments.

Due to ethical considerations, it is impossible to randomly allocate participants to a certain type of nursing home care environment. Therefore, it is possible that a certain nursing home care environment attracts a specific type of resident. For example, previous research has shown that residents in small-sale, homelike care environments have better cognitive and functional abilities compared with residents in traditional large-scale nursing home wards. ${ }^{9}$ In order to prevent these differences and to increase comparability of residents at baseline, participants in the current study are matched on cognition and ADL- capacity. 


\section{REFERENCES}

1. Ferri CP, Prince M, Brayne C, Brodaty H, Fratiglioni L, Ganguli M et al. Global prevalence of dementia: a Delphi consensus study. Lancet 2006;366(9503):2112-7. doi: 10.1016/s0140-6736(05)67889-0.

2. Nederland A. Cijfers en feiten over dementie. www.alzheimer-nederland.nl. 2015.

3. Association As. 2011 Alzheimer's disease facts and figures. Alzheimer's \& Dementia 2011;7(2):208.

4. Luppa M, Luck T, Weyerer S, König H-H, Brähler E, Riedel-Heller SG. Prediction of institutionalization in the elderly. A systematic review. Age \& Ageing 2009.

5. Flicker L. Dementia reconsidered: The person comes first. BMJ 1999;318(7187):880.

6. Taft LB, Fazio S, Seman D, Stansell J. A psychosocial model of dementia care: Theoretical and empirical support. Archives of Psychiatric Nursing 1997;11(1):13-20.

7. Buron B. Levels of personhood: A model for dementia care. Geriatric Nursing 2008;29(5):324-32.

8. Verbeek H, van Rossum E, Zwakhalen SM, Ambergen T, Kempen GI, Hamers JP. The effects of smallscale, homelike facilities for older people with dementia on residents, family caregivers and staff: design of a longitudinal, quasi-experimental study. BMC Geriatrics 2009;9(1):3.

9. Verbeek H, Zwakhalen SM, Van Rossum E, Ambergen T, Kempen GI, Hamers JP. Small-scale, homelike facilities versus regular psychogeriatric nursing home wards: a cross-sectional study into residents' characteristics. BMC Health Services Research 2010;10(1):30.

10. Finnema E, Dröes R-M, Ribbe M, Van Tilburg W. A review of psychosocial models in psychogeriatrics: implications for care and research. Alzheimer's Disease \& Associated Disorders 2000;14(2):68-80.

11. Rahman AN, Schnelle JF. The nursing home culture-change movement: Recent past, present, and future directions for research. Gerontologist 2008;48(2):142-8.

12. Verbeek H, van Rossum E, Zwakhalen SM, Kempen GI, Hamers JP. Small, homelike care environments for older people with dementia: a literature review. International Psychogeriatrics 2009;21(02):252-64.

13. Verbeek H, Zwakhalen SM, van Rossum E, Kempen GI, Hamers JP. Small-scale, homelike facilities in dementia care: a process evaluation into the experiences of family caregivers and nursing staff. International Journal of Nursing Studies 2012;49(1):21-9. doi:10.1016/j.ijnurstu.2011.07.008.

14. Verbeek H, Zwakhalen SM, van Rossum E, Ambergen T, Kempen GI, Hamers JP. Effects of small-scale, home-like facilities in dementia care on residents' behavior, and use of physical restraints and psychotropic drugs: a quasi-experimental study. International Psychogeriatrics 2014;26(04):657-68.

15. White-Chu EF, Graves WJ, Godfrey SM, Bonner A, Sloane P. Beyond the medical model: the culture change revolution in long-term care. Journal of the American Medical Directors Association 2009;10(6):370-8.

16. Willemse BM, Smit D, de Lange J, Pot AM. Nursing home care for people with dementia and residents' quality of life, quality of care and staff well-being: design of the Living Arrangements for people with Dementia (LAD)-study. BMC Geriatrics 2011;11:11. doi: 10.1186/1471-2318-11-11.

17. Hassink J, van Dijk M. Farming for Health across Europe: comparison between countries, and recommendations for a research and policy agenda. Farming for health 2006; Springer p. 345-57.

18. Haubenhofer DK, Elings M, Hassink J, Hine RE. The development of green care in western European countries. Explore 2010;6(2):106-11.

19. Hassink J, Van Dijk M. Farming for Health: Green-care farming across Europe and the United States of America. Springer; 2006.

20. Hassink J, Elings M, Zweekhorst M, van den Nieuwenhuizen N, Smit A. Care farms in the Netherlands: Attractive empowerment-oriented and strengths-based practices in the community. Health \& Place 2010;16(3):423-30.

21. De Bruin S. Sowing in the autumn season: exploring benefits of green care farms for dementia patients. Wageningen Universiteit (Wageningen University); 2009.

22. De Bruin S, Oosting S, van der Zijpp A, Enders-Slegers M-J, Schols J. The concept of green care farms for older people with dementia: an integrative framework. Dementia 2010;9(1):79-128. 
23. Hassink J, Hulsink W, Grin J. Care Farms in the Netherlands: An Underexplored Example of Multifunctional Agriculture-Toward an Empirically Grounded, Organization-Theory-Based Typology. Rural Socioly 2012;77(4):569-600.

24. Roest A. Kijk op multifunctionele landbouw; Omzet en impact 2007-2009. Wageningen, Den Haag: LEI; 2010.

25. Bruin SRD, Oosting SJ, Kuin Y, Hoefnagels EC, Blauw YH, Groot LCD et al. Green care farms promote activity among elderly people with dementia. Journal of Housing for the Elderly 2009;23(4):368-89.

26. Schols JM, van der Schriek-van Meel C. Day care for demented elderly in a dairy farm setting: positive first impressions. Journal of the American Medical Directors Association 2006;7(7):456-9. doi:10.1016/j.jamda.2006.05.011.

27. Phinney A, Chaudhury H, O'Connor DL. Doing as much as I can do: the meaning of activity for people with dementia. Aging \& Mental Health 2007;11(4):384-93. doi: 10.1080/13607860601086470.

28. Vernooij-Dassen M. Meaningful activities for people with dementia. Aging \& Mental Health: 2007: 11(4):359-60. doi: 10.1080/13607860701498443.

29. Edvardsson D, Petersson L, Sjogren K, Lindkvist M, Sandman PO. Everyday activities for people with dementia in residential aged care: associations with person-centredness and quality of life. International Journal of Older People Nursing 2014;4:269-276.

30. Morley JE, Caplan G, Cesari M, Dong B, Flaherty JH, Grossberg GT et al. International survey of nursing home research priorities. Journal of the American Medical Directors Association 2014;15(5):309-12.

31. Moyle W, Venturto L, Griffiths S, Grimbeek P, McAllister M, Oxlade D et al. Factors influencing quality of life for people with dementia: a qualitative perspective. Aging \& Mental Health 2011;15(8):970-7.

32. Day K, Carreon D, Stump C. The therapeutic design of environments for people with dementia a review of the empirical research. Gerontologist 2000;40(4):397-416.

33. Wood W. Toward Developing New Occupational Science Measures: An Example from Dementia Care Research. Journal of Occupational Sciences 2005;12(3):121-9. doi:10.1080/14427591.2005.9686555.

34. Dettbarn-Reggentin J. Study on the influence of environmental residential groups on demented old people in nursing home residents. Zeitschrift fur Gerontologie und Geriatrie 2005;38(2):95-100.

35. Gerritsen D, Ooms M, Steverink N, Frijters D, Bezemer D, Ribbe M. Drie nieuwe observatieschalen in het verpleeghuis: schalen uit het Resident Assessment Instrument voor Activiteiten van het Dagelijks Leven, cognitie en depressie. Tijdschrift voor Gerontologie en Geriatrie 2004;55-64.

36. Morris JN, Fries BE, Mehr DR, Hawes C, Phillips C, Mor V et al. MDS cognitive performance scale (C) Journal of Gerontology. Series A, Biological Science and Medical Sciences 1994;49(4):M174-M82.

37. Morris JN, Fries BE, Morris SA. Scaling ADLs within the MDS. Journal of Gerontoly. Series A, Biolological Science and Medical Sciences 1999;54(11):M546-M53.

38. de Boer B, Beerens HC, Hamers JPH, Verbeek H. Green care farms for people with dementia: an alternative to nursing home care? Irish Ageing Studies Review; Dublin: Irish Gerontological Society 2015.

39. Shiffman S, Stone AA, Hufford MR. Ecological momentary assessment. Annual Review of Clinical Psychology 2008;4:1-32.

40. Gerritsen DL, Steverink N, Frijters D, Hirdes JP, Ooms ME, Ribbe MW. A revised Index for Social Engagement for long-term care. Journal of Gerontological Nursing 2008;34(4):40-8.

41. Logsdon RG, Gibbons LE, McCurry SM, Teri L. Quality of life in Alzheimer's disease: patient and caregiver reports. Journal of Mental Health and Aging 1999;5:21-32.

42. Thorgrimsen L, Selwood A, Spector A, Royan L, de Madariaga Lopez M, Woods R et al. Whose quality of life is it anyway?: The validity and reliability of the Quality of Life-Alzheimer's Disease (QoL-AD) scale. Alzheimer's Disease \& Associated Disorders 2003;17(4):201-8.

43. Ettema TP, Dröes RM, de Lange J, Mellenbergh GJ, Ribbe MW. QUALIDEM: development and evaluation of a dementia specific quality of life instrument-validation. International Journal of Geriatric Psychiatry 2007;22(5):424-30.

44. Ettema TP, Dröes RM, de Lange J, Mellenbergh GJ, Ribbe MW. QUALIDEM: development and evaluation of a dementia specific quality of life instrument. Scalability, reliability and internal structure. International Journal of Geriatric Psychiatry 2007;22(6):549-56. 
45. Lange RT, Hopp GA, Kang N. Psychometric properties and factor structure of the Neuropsychiatric Inventory Nursing Home version in an elderly neuropsychiatric population. International Journal Geriatric Psychiatry 2004;19(5):440-8.

46. Wood S, Cummings JL, Hsu M-A, Barclay T, Wheatley MV, Yarema KT et al. The use of the neuropsychiatric inventory in nursing home residents: characterization and measurement. The American Journal of Geriatric Psychiatry 2001;8(1):75-83.

47. Cohen-Mansfield J. Instruction manual for the Cohen-Mansfield agitation inventory (CMAI). Research Institute of the Hebrew Home of Greater Washington. 1991.

48. Finkel SI, Lyons JS, Anderson RL. Reliability and validity of the Cohen-Mansfield agitation inventory in institutionalized elderly. International Journal of Geriatric Psychiatry 1992;7(7):487-90.

49. Molloy DW, Alemayehu E, Roberts R. Reliability of a standardized mini-mental state examination compared with the traditional mini-mental state examination. American Journal of Psychiatry 1991: 148(1);02-5.

50. Molloy DW, Standish TI. A guide to the standardized Mini-Mental State Examination. International Psychogeriatrics 1997;9(S1):87-94.

51. Collin C, Wade D, Davies S, Horne V. The Barthel ADL Index: a reliability study. Disability \& Rehabilitation 1988;10(2):61-3.

52. Wade D, Collin C. The Barthel ADL Index: a standard measure of physical disability? International Disability studies 1988;10(2):64-7.

53. Reisberg B, Ferris SH, De Leon M, Crook T. Global deterioration scale (GDS). Psychopharmacological Bulletin 1988;24(4):661-3.

54. CollegeBouwZorginstellingen. Kwaliteit Fysieke Zorgomgeving. Culemborg 2008.

55. Sloane PD, Mitchell CM, Weisman G, Zimmerman S, Foley KML, Lynn M et al. The Therapeutic Environment Screening Survey for Nursing Homes (TESS-NH) An Observational Instrument for Assessing the Physical Environment of Institutional Settings for Persons With Dementia. Journals of Gerontoly: Series B Psychological Sciences \& Social Sciences 2002;57(2):S69-S78.

56. Donabedian A. The quality of care: How can it be assessed? Journal of the American Medical Directors Association 1988;260(12):1743-8.

57. Du Moulin MF, van Haastregt JC, Hamers JP. Monitoring quality of care in nursing homes and making information available for the general public: state of the art. Patient Educaction and Counseling 2010;78(3):288-96. doi:10.1016/j.pec.2010.01.008.

58. Medical Research Involving Human Subjects Act, (26 February 1998).

59. Slaughter S, Cole D, Jennings E, Reimer MA. Consent and assent to participate in research from people with dementia. Nursing Ethics 2007;14(1):27-40.

60. Corp. I. IBM SPSS Statistics for Windows, Version 22.0. Armonk, NY: IBM Corp.; 2013.

61. Corbin J, Strauss A. Basics of qualitative research: Techniques and procedures for developing grounded theory. Sage publications; 2014. 



\section{CHAPTER}

\section{Daily lives of residents with dementia in nursing homes: development of the Maastricht Electronic Daily Life Observation}

Tool 


\section{ABSTRACT}

Background: Daily life is a dynamic and multidimensional concept, for which appropriate assessment tools are lacking. This study describes the development of the Maastricht Electronic Daily Life Observation tool (MEDLO-tool), a freely accessible, easy to use, electronic observation tool to assess relevant daily life aspects for nursing home residents with dementia.

Methods: 1) determining relevant aspects of daily life for nursing home residents with dementia based on a literature search and expert interviews; 2) pilot testing observation procedures and operationalizations of the aspects of daily life; and 3) exploring inter-rater reliability and feasibility of the tool in a nursing home facility with 16 residents (56\% female, mean age: 77 ).

Results: Four aspects of daily life are assessed with the MEDLO-tool: 1) activity (activity performed by resident, engagement in this activity and the degree of physical effort); 2) physical environment (location of the resident and interaction with the physical environment); 3) social interaction (the level and type of social interaction, and with whom this social interaction took place) and 4) emotional well-being (mood and agitation). Each aspect of daily life is observed and scored using standardized scoring options. Agreement on the aspects is high with an average absolute agreement of $86 \%$. Users of the MEDLO- tool indicated that it was feasible in practice and contained clear operationalizations of the aspects of daily life.

Conclusion: The MEDLO- tool is a promising tool to gain real time insights into the aspects of the daily lives of nursing home residents with dementia. 


\section{INTRODUCTION}

Studies report that nursing home residents with dementia spend the majority of their daily life doing little or nothing and remain in their rooms sitting alone most of the time. ${ }^{1,2}$ Having something to do, however, is important for residents of nursing homes because it allows them to connect with other people and to experience feelings of pleasure. ${ }^{3}$ Participation in activities is an important indicator of nursing home quality and one of the basic human needs. ${ }^{4}$ Furthermore, being engaged in activities allows people to express themselves, ${ }^{3}$ and is associated with a higher quality of life of nursing home residents with dementia. ${ }^{5}$

Daily life is a dynamic and multidimensional concept, and constitutes more than activities alone. The physical and social environments of nursing homes are also important for the daily lives of their residents because they can influence agency: a person's capacity to act in the world. For example, moderate levels of sound or the presence of a small group of people can act as facilitators for engagement in activities. ${ }^{6}$ Furthermore, the provision of outdoor areas can also accommodate activities and may decrease agitation and increase physical effort of residents. ${ }^{7}$

In both clinical practice and research, the concept of person-centered care is advocated as a way to provide high quality of care. ${ }^{8}$ A 'one size fits all' approach is not suitable for interventions targeted at nursing home residents with dementia due to differences in cognitive and functional dependency among residents. ${ }^{9}$ Therefore, insight is needed into the needs, possibilities, and environmental aspects that are important for individual nursing home residents. Gaining insights into the daily lives of residents allows nursing home staff and researchers to tailor interventions for individuals by targeting the relevant aspects of daily life.

\section{How can daily life situations of nursing home residents with dementia be measured?}

Observing nursing home residents with dementia in their daily lives allows researchers to consider several aspects of daily life simultaneously. In contrast to other measurement methods such as questionnaires, observation offers the opportunity to record the activities of residents with dementia in real time in relation to contextual factors. Furthermore, observing experiences or behaviors within the context that they naturally occur, provides a more representative assessment than a single static snapshot of time. ${ }^{10}$ Such an examination of sequences of events and experiences can be referred to as ecological momentary assessment (EMA). EMA enable investigators to describe and analyze interactions between events that shape behavior over periods of minutes, hours, or days. ${ }^{10}$ In addition, electronic devices such as handheld computers or tablets allow more observations within the same time period than pen and paper and process the observation data more efficiently. ${ }^{11}$ 
Few electronic observation tools have been reported that aim to study daily life in long-term care. A review conducted by Curyto et al. (2008) examined direct observation methods of behavior in people with dementia. They discuss over thirty-five observation tools, however, all these tools focus on one or two aspects of daily life only and do not incorporate multiple aspects to describe daily life completely. ${ }^{12}$ In addition, a freely accessible, easy to use, electronic observation tool to assess the daily lives of nursing home residents with dementia is lacking. The observation tools that have been reported show limitations in assessing aspects of daily life for nursing home residents with dementia. ${ }^{6,13,14}$ First, most existing tools do not cover the simultaneous observation of a variety of aspects of daily life (e.g. activities and social, psychological, and environmental aspects). As a result, they do not provide comprehensive insights into all the complex facets of daily life. Second, most tools are used only to observe residents within the communal living room or only during certain parts of the day and therefore miss important data. Third, existing tools require extensive training, separate licenses, and are designed to record observations using pen and paper. This makes data collection and analyses time consuming and expensive.

The aim of the current study was to develop a freely accessible, easy to use, electronic observation tool that provides a full and extensive description of the daily lives of nursing home resident with dementia. The goals were that the tool: a) allows researchers to assess multiple aspects of daily life simultaneously, b) can be used in multiple nursing home areas easily and c) provides an efficient way of data processing by using electronic devices to carry out the observations. The current paper describes the development process of the Maastricht Electronic Daily Life Observation tool (MEDLO-tool), including reliability and feasibility testing.

\section{METHODS}

To develop the MEDLO-tool, three steps were taken: 1) determining relevant aspects of daily life for nursing home residents with dementia; 2) determining observation procedure and operationalizations of the aspects of daily life; and 3) testing the final version of the MEDLO-tool. Steps were based on the development of other observation tools. ${ }^{11}$ The study protocol was reviewed by the medical ethics committee of the Maastricht University Medical Center. They declared that the study was non-invasive for nursing home residents with dementia according to the Medical Research Involving Human Subjects Act. The participating nursing homes provided informed consent for participation. All data were collected anonymously. 


\section{Determining relevant aspects of daily life for nursing home residents with dementia}

To take face- and content validity into account, the aspects of daily life which are important for nursing home residents with dementia were determined based on multiple sources. First, a literature search was conducted to determine relevant aspects of daily life. Pubmed, Web of Science, PsycINFO, and Google Scholar were searched. Search terms included 'daily life', 'meaningful activity', 'observation', 'nursing home care', 'dementia', and 'aspects of daily life'. To find additional relevant literature, snowballing techniques were used and grey literature was studied. The literature search revealed a list of important aspects of daily life. Next, experts were consulted individually and in groups to discuss relevant aspects of daily life, they were free to suggest as many aspects of daily life as they wanted. The participants included experts in the field of research ( $n=10$; background in psychology, architecture, nursing home care, nursing science, and occupational science) and professionals in dementia care ( $n=8$; nursing staff, managers of Dutch nursing home wards/ living facilities for people with dementia). All had at least a Bachelor's degree. When they had no further suggestions, they were told which aspects were found based on the literature and were then asked whether they agreed that these are indeed important and whether something was missing.

\section{Pilot testing observation procedures and operationalizations of the aspects of daily life}

To determine the observation procedure using the MEDLO-tool, the following factors were taken into account: the number of people that can be observed at the same time using the MEDLO-tool, the amount of time needed to do an observation, the areas in which the residents are going to be observed, observer fatigue, the sampling method (instantaneous or continuous), and the software and hardware needed for observations (e.g. whether observations could be carried out using standard tablets). Decisions regarding these factors were made based on the literature and by testing preliminary versions of the tool in practice. Completeness and feasibility of the tool were the main criteria guiding the decision process.

To determine the operationalizations of the relevant aspects of daily life, existing observation tools were reviewed. Several operationalization methods and procedures were tested and adapted in practice. Every adaptation was tested and re-adjusted if necessary. Following earlier observation research, ${ }^{15}$ several steps were taken to decide which operationalizations and procedures should be used. First, one researcher (BB) tested different observation procedures (e.g. ten, twenty or thirty minute observation periods, and instantaneous versus continuous sampling) and operationalizations (e.g. using a six- or a seven-point scale for mood) for approximately eight hours. Second, two 
researchers ( $\mathrm{BB}$ and $\mathrm{HB}$ ) tested preliminary versions of the tool in two different types of nursing homes (small-scale, homelike and large-scale traditional) for eight hours in total. This was done in order to check if there was agreement between observers and to see if the tool could be used in a variety of nursing home settings. If there was disagreement between the observers on how to score certain situations, discussions were held with a third researcher $(\mathrm{HV})$ until agreement was reached. After five alterations, the MEDLO-tool was finalized. Parallel to the alterations a manual was written with descriptions of the full observation procedure and the operationalizations of all aspects of daily life.

\section{Testing the final version of the MEDLO-tool}

The reliability of the MEDLO-tool was tested by carrying out anonymous observations in a convenience sample at a nursing home ward providing care for 16 residents. To assess inter-rater reliability, two researchers carried out observations simultaneously of a random selection of eight residents independently for 56 observations in total (7 observations per resident). Agreement was assessed by calculating absolute agreement percentages and (weighted) kappa values. For some aspects of daily life (activity, location, social interaction with whom and interaction with the physical environment) the 'standard' kappa was calculated, as these aspects do not have a hierarchical structure but are strictly categorical (the difference between activity 1 and 3 is the same as the difference between activity 1 and 22). However, for other aspects of daily life (engagement, degree of social interaction, type of social interaction, physical effort, mood and agitation) there is a hierarchical structure in the scoring options. For example, the difference between mood scores 1 and 5 is larger (4) than the difference between mood scores 1 and 2 (1). The relative distance between 2 successive scoring options for all these aspects was always equal to 1 . This means that for example scoring options ' 1 ' and ' 3 ' had a relative distance of 2 . Therefore, weighted kappa values were calculated to take the relative distances between scoring options into account. The minimum absolute agreement was determined to be $80 \%{ }^{16}$ The kappa values were assessed as slight (0.01-0.20), fair (0.21-0.40), moderate (0.41-0.60), substantial (0.61$0.80)$, or almost perfect $(0.81-0.99)$ agreement. $^{17}$ Resident characteristics and information on cognition and independence in activities of daily living (ADL) were collected at ward level via the nursing staff. This means that data were gathered anonymously and reported on an aggregated level instead of on an individual level. Cognition of the residents was assessed with the Cognitive Performance Scale (CPS). ${ }^{18}$ The total score of the CPS ranges from 0 to 6 , with lower scores indicating better cognition. ADL independency was measured with the Activities of Daily Living Hierarchy scale $(\mathrm{ADL}-\mathrm{H}) .{ }^{19}$ The total score of the $\mathrm{ADL}-\mathrm{H}$ ranges from 0 to 6 , with lower scores indicating more independence in activities of daily living.

The feasibility of the MEDLO-tool was assessed by a short questionnaire, filled out by three research assistants who were trained to use the MEDLO-tool. Training observers 
to use the MEDLO-tool went as follows: First, the research assistants studied the observation manual and the app for approximately two hours. Next, they joined the main researcher for three observation periods of four hours in which they practiced the observations. After each of these 3 observation periods the observations were evaluated for 2 hours each.

The questionnaire addressed several feasibility aspects such as 1) the use of the hardware and software; 2) the practical use of the MEDLO-tool (e.g. operationalization, observer fatigue); 3) the completeness of the tool; and 4) grading the overall feasibility of the MEDLO-tool with a possible score between one and ten, with ten being the highest (completely feasible). In addition, respondents had the opportunity to add other comments.

\section{RESULTS}

Table 1 gives an overview of the aspects of daily life that are included in the MEDLOtool, their operationalization and their theoretical / empirical base.

\section{Determining relevant aspects of daily life for nursing home residents with dementia}

Based on findings from the literature and consultations with the experts $(n=18)$, the following aspects of daily life were included in the MEDLO-tool:

Activity: the activity performed by or occurring in the immediate environment of the resident (e.g. eating, household chores, playing a game), the engagement in this activity (e.g. active engagement in activity, no engagement in activity), and the degree of physical effort (e.g. lying, sitting, standing, walking, etc.).

- Physical environment: the location of the resident (e.g. communal area, own room, outside, etc.), and whether he or she has interaction with the physical environment. $^{20}$

- Social interaction: the level of social interaction (e.g. talking with one, two or more persons), the type of social interaction, ${ }^{21}$ and with whom this social interaction takes place (e.g. other residents, family, etc.).

- Emotional well-being: mood - including both positive and negative mood - and agitation were considered most relevant aspects of emotional well-being in daily life. The mood scale is based on Kitwood's model of person-centered care, ${ }^{13}$ and Dementia Care Mapping. ${ }^{16}$ The agitation scale (e.g. no, small or extreme signs of agitation) is based on the Pittsburgh Agitation Scale. ${ }^{22}$

Based on the expert's advice, the possibility to make field notes was added in case events occurred that could not be covered by the aspects of daily life in the MEDLOtool. No other aspects were suggested by the experts. 
Table 1. MEDLO-tool aspects of daily life, operationalizations, and theoretical/empirical base

\begin{tabular}{|c|c|c|c|c|c|}
\hline $\begin{array}{l}\text { Aspects of } \\
\text { daily life }\end{array}$ & $\begin{array}{l}\text { Operationaliz } \\
\text { ation }\end{array}$ & \multicolumn{3}{|l|}{ Scoring options } & Based on... \\
\hline \multicolumn{6}{|l|}{ Activity } \\
\hline $\begin{array}{l}\text { Activity that is } \\
\text { being } \\
\text { performed by } \\
\text { resident or is } \\
\text { occurring in } \\
\text { vicinity }\end{array}$ & $\begin{array}{l}32 \text { category } \\
\text { options }\end{array}$ & $\begin{array}{l}\text { - Household chores } \\
\text { - Cooking } \\
\text { - Sports } \\
\text { - Dancing } \\
\text { - Spiritual activity } \\
\text { - Crafts/arts } \\
\text { - Music/singing } \\
\text { - Excursion or shopping } \\
\text { - Walking outside } \\
\text { - Playing cards/a } \\
\text { game/puzzles } \\
\text { - Reading/writing/ } \\
\text { crossword } \\
\text { - Talking groups } \\
\text { - Using the computer } \\
\text { - Sensory stimulation }\end{array}$ & $\begin{array}{l}\text { - } \text { Eating/drinking } \\
\text { - } \text { Beauty activity } \\
\text { - Speaking with } \\
\text { others/having a } \\
\text { chat } \\
\text { - } \text { Making a } \\
\text { telephone call } \\
\text { - Pets } \\
\text { - Helping others } \\
\text { - Watching } \\
\text { television/listeni } \\
\text { ng to radio } \\
\text { - Outing with } \\
\text { family or others } \\
\text { outside facility } \\
\text { - Farming activities }\end{array}$ & $\begin{array}{l}\text { - Gardening and } \\
\text { caring for plants } \\
\text { - Walking } \\
\text { - Sitting/lying } \\
\text { - } \text { Resting or } \\
\text { sleeping } \\
\text { - Visit } \\
\text { (para)medical } \\
\text { personnel } \\
\text { - (Self-)care } \\
\text { activities } \\
\text { - Purposeless } \\
\text { (repetitive) } \\
\text { behavior } \\
\text { - Not observable } \\
\text { - Other }\end{array}$ & $\begin{array}{l}\text { Literature, } \\
\text { 11,23-29 expert } \\
\text { opinion and } \\
\text { pilot testing }\end{array}$ \\
\hline $\begin{array}{l}\text { Engagement } \\
\text { in activity }\end{array}$ & $\begin{array}{l}5 \text { category } \\
\text { options }\end{array}$ & $\begin{array}{l}\text { - Active engagement (pa } \\
\text { - Passive engagement (fo } \\
\text { - Engagement with some } \\
\text { - Not engaged (gazing wi } \\
\text { - Not engaged (sleeping) }\end{array}$ & $\begin{array}{l}\text { octicipating in activity } \\
\text { ocus activity) } \\
\text { ething else } \\
\text { ithout focus) }\end{array}$ & & $\begin{array}{l}\text { Literature, } \\
30,31 \text { expert } \\
\text { opinion and } \\
\text { pilot testing }\end{array}$ \\
\hline Physical effort & $\begin{array}{l}7 \text { category } \\
\text { options }\end{array}$ & $\begin{array}{l}\text { - Lying or sitting without } \\
\text { sleeping) } \\
\text { - Sitting quietly (resident } \\
\text { - Light-to-moderate sittir } \\
\text { - Standing or light-standi } \\
\text { - Standing activity or wal } \\
\text { - Walking activity or cycl } \\
\text { - Whole-body movemen }\end{array}$ & $\begin{array}{l}\text { movements (resider } \\
\text { tis awake) } \\
\text { ng activity } \\
\text { ing activity } \\
\text { Iking around } \\
\text { ing } \\
\text { its }\end{array}$ & th is gazing or & $\begin{array}{l}\text { Literature, } \\
32 \text { expert } \\
\text { opinion and } \\
\text { pilot testing }\end{array}$ \\
\hline \multicolumn{6}{|c|}{ Physical environment } \\
\hline Location & $\begin{array}{l}5 \text { category } \\
\text { options }\end{array}$ & \multicolumn{3}{|c|}{$\begin{array}{l}\text { - Communal area on the ward } \\
\text { - Own room } \\
\text { - Communal area off the ward } \\
\text { - Bathroom/toilet } \\
\text { - Outside }\end{array}$} & $\begin{array}{l}\text { Literature, } \\
24 \\
\text { expert } \\
\text { opinion and } \\
\text { pilot testing }\end{array}$ \\
\hline $\begin{array}{l}\text { Interaction } \\
\text { with the } \\
\text { physical } \\
\text { environment }\end{array}$ & $\begin{array}{l}2 \text { category } \\
\text { options }\end{array}$ & \multicolumn{3}{|c|}{$\begin{array}{l}\text { - No interaction with the physical environment } \\
\text { - Yes, intentional handling, holding, manipulation, attention } \\
\text { towards or other use of freestanding physical objects or fixed } \\
\text { environmental features }\end{array}$} & $\begin{array}{l}\text { Literature, }^{20} \\
{ }^{33-36} \text { expert } \\
\text { opinion and } \\
\text { pilot testing }\end{array}$ \\
\hline
\end{tabular}




\begin{tabular}{|c|c|c|c|}
\hline $\begin{array}{l}\text { Aspects of } \\
\text { daily life }\end{array}$ & $\begin{array}{l}\text { Operationaliz } \\
\text { ation }\end{array}$ & Scoring options & Based on... \\
\hline \multicolumn{4}{|c|}{ Social environment } \\
\hline $\begin{array}{l}\text { Level of social } \\
\text { interaction }\end{array}$ & $\begin{array}{l}5 \text { category } \\
\text { options }\end{array}$ & $\begin{array}{l}\text { - No social interaction } \\
\text { - Resident attempts to interact, gets no response } \\
\text { - Environment attempts to interact, but resident does not } \\
\text { respond } \\
\text { - Interaction with someone else } \\
\text { - Interaction with two or more people }\end{array}$ & $\begin{array}{l}\text { Expert } \\
\text { opinion and } \\
\text { pilot testing }\end{array}$ \\
\hline $\begin{array}{l}\text { Type of social } \\
\text { interaction of } \\
\text { environment } \\
\text { towards } \\
\text { resident }\end{array}$ & $\begin{array}{l}5 \text { category } \\
\text { options }\end{array}$ & $\begin{array}{l}\text { - Negative restrictive (interactions that oppose or resist } \\
\text { resident's freedom of action without good reason, or ignore } \\
\text { resident as a person) } \\
\text { - Negative protective (providing care, keeping safe or removing } \\
\text { from danger in a restrictive manner without explanation or } \\
\text { reassurance) } \\
\text { - Neutral (brief, indifferent interactions) } \\
\text { - Positive care (interactions during the appropriate delivery of } \\
\text { care) } \\
\text { - Positive social (interactions principally involving 'good, } \\
\text { constructive, beneficial' conversation and companionship) }\end{array}$ & $\begin{array}{l}\text { Literature, } \\
21,37 \text { expert } \\
\text { opinion and } \\
\text { pilot testing }\end{array}$ \\
\hline $\begin{array}{l}\text { Social } \\
\text { interaction } \\
\text { with whom }\end{array}$ & $\begin{array}{l}5 \text { category } \\
\text { options }\end{array}$ & $\begin{array}{l}\text { - Personnel } \\
\text { - Other residents } \\
\text { - Family and/or friends } \\
\text { - Others } \\
\text { - Combination of the above }\end{array}$ & $\begin{array}{l}\text { Expert } \\
\text { opinion and } \\
\text { pilot testing }\end{array}$ \\
\hline \multicolumn{4}{|c|}{ Emotional well-being } \\
\hline Mood & $\begin{array}{l}7 \text { point Likert } \\
\text { scale }\end{array}$ & $\begin{array}{l}\text { 1. Great signs of negative mood } \\
\text { 2. Considerable signs of negative mood } \\
\text { 3. Small signs of negative mood, discomfort or boredom } \\
\text { 4. Neutral: no positive or negative mood observable, e.g. gazing or } \\
\text { sleeping } \\
\text { 5. Contentment and small signs of well being } \\
\text { 6. Considerable positive mood } \\
\text { 7. Very high positive mood }\end{array}$ & $\begin{array}{l}\text { Literature, }{ }^{11,} \\
\text { expert } \\
\text { opinion and } \\
\text { pilot testing }\end{array}$ \\
\hline Agitation & $\begin{array}{l}5 \text { point Likert } \\
\text { scale }\end{array}$ & $\begin{array}{l}\text { Definition of agitation: the presence of aberrant vocalization, } \\
\text { motor agitation, aggressiveness or resisting care } \\
\text { Levels: } \\
\text { 1. Not present } \\
\text { 2. Low volume, not disruptive in milieu / pacing or moving about } \\
\text { in chair at normal rate / verbal threats / procrastination or } \\
\text { avoidance } \\
\text { 3. Louder than conversational, mildly disruptive / increased rate of } \\
\text { movements / threatening gestures / verbal or gesture of refusal } \\
\text { 4. Loud and disruptive / rapid movements / physical towards } \\
\text { property / pushing away to avoid task } \\
\text { 5. Extremely loud, highly disruptive / intense movements / } \\
\text { physical towards self or others / striking out at caregiver }\end{array}$ & $\begin{array}{l}\text { Literature, }^{11,} \\
22 \text { expert } \\
\text { opinion and } \\
\text { pilot testing }\end{array}$ \\
\hline
\end{tabular}


2. Pilot testing observation procedures and operationalizations of the aspects of daily life

\section{Observation Procedure}

The MEDLO-tool is a tablet-based observation tool. It can be run using the app e-Droidcell Pro, which is able to run Microsoft Excel (.xls) files. The Excel files consist of observation schemes and include drop down boxes for each of the observed aspects of daily life. In addition, it is possible to make field notes in case events occurred that cannot be covered by the aspects of daily life from the MEDLO-tool. Furthermore, there is room for questions and remarks that need to be discussed with fellow colleagues.

Figure 1 shows the observation displayed on the tablet.

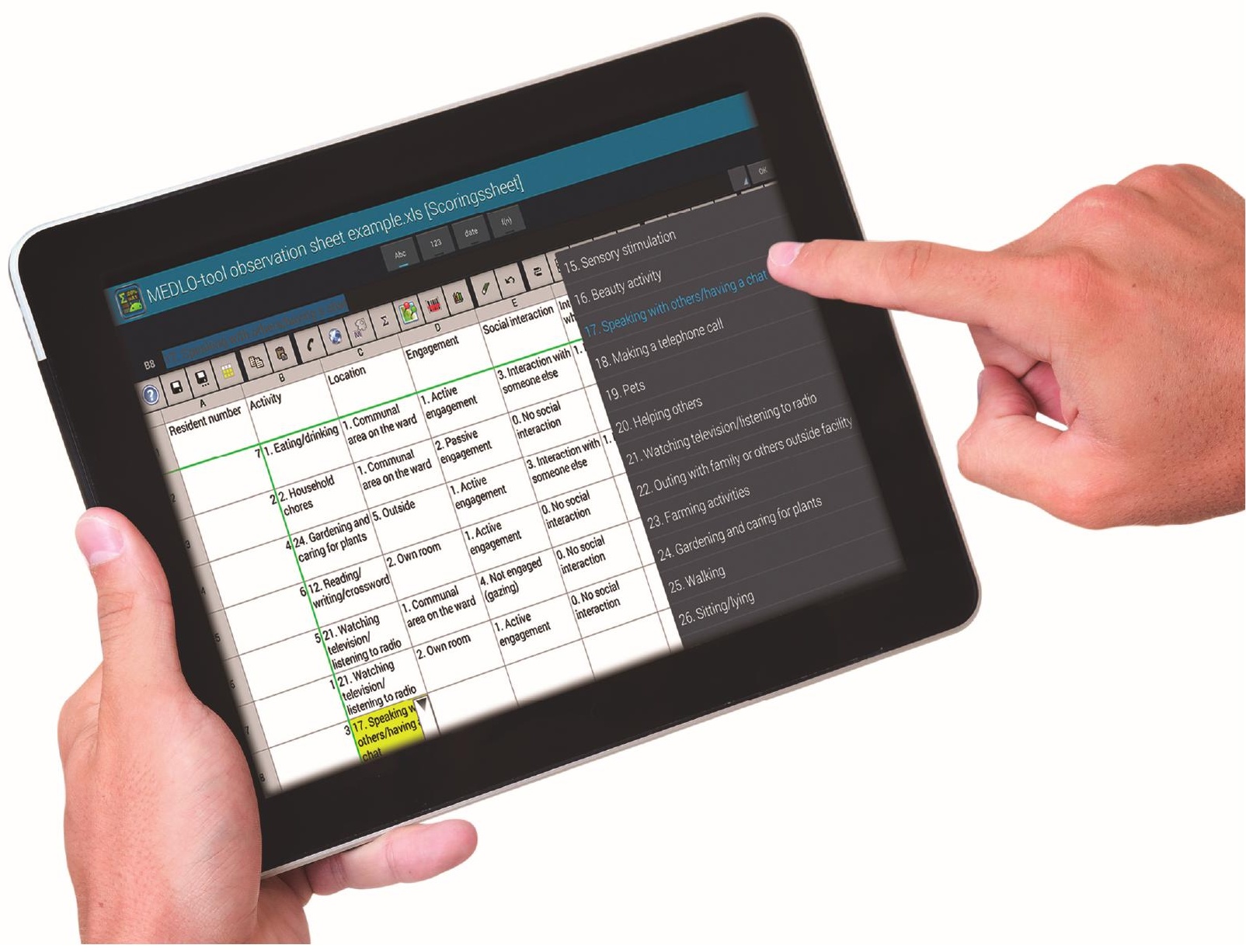


An instantaneous sampling procedure was chosen to obtain insights into the daily lives of nursing home residents. Observations are performed systematically at preselected moments, and each resident can be observed once during an observation period. Instantaneous sampling can give a good approximation of the proportion of time spent carrying out certain behaviors if an observation day consists of multiple observation periods. $^{39}$

Pilot testing showed that it often was not possible to observe eight residents (the number of residents living together in a small-scale facility) within a 10 minute observation period while 30 minutes too long. Based on this it was decided 20 minutes is an appropriate amount of time for an observation period to observe eight residents. During an observation period, the researcher observes a resident for one minute during which all aspects of daily life are noted in the observation scheme. The researcher then continues to the next resident. To prevent bias due to order- effect, the order of observations of residents within an observation period needs to be randomized in advance. Entering the scores on the tablet takes approximately one minute per resident. In addition, time is reserved for the observer to find the next resident. As the MEDLO-tool highly portable and can therefore be used to observe not only in communal areas, but to observe residents outside these areas as well. As a result, activities outside the communal area are captured. Privacy of residents is taken into account: when the door of their bedroom or bathroom is closed, they are not observed.

Figure 2 provides an overview of how the MEDLO-tool can be used on an observation day. To prevent observer fatigue, researchers should not observe longer than four hours per day. Observation days should also include breaks: after two hours, a half hour break is recommended. In order to increase the reliability of measurements, the observations and interpretations of situations should be discussed weekly with other observers.

\begin{tabular}{ll}
\hline OBSERVATION DAY (observations of eight residents in randomized order) \\
\hline Hour 1 & Observation period 1 (20 minutes): 1 observation per resident \\
& Observation period 2 (20 minutes): 1 observation per resident \\
& Observation period 3 (20 minutes): 1 observation per resident \\
Hour 2 & Observation period 4 (20 minutes): 1 observation per resident \\
& Observation period 5 (20 minutes): 1 observation per resident \\
BREAK (30 minutes) & Observation period 6 (20 minutes): 1 observation per resident \\
Hour 3 & Observation period 7 (20 minutes): 1 observation per resident \\
& Observation period 9 (20 minutes): 1 observation per resident \\
Hour 4 & Observation period 10 (20 minutes): 1 observation per resident \\
& Observation period 11 (20 minutes): 1 observation per resident \\
& Observation period 12 (20 minutes): 1 observation per resident \\
\hline
\end{tabular}

Figure 2. Overview of the observation procedure on one observation day 


\section{Operationalization of the aspects of daily life}

Based on pilot testing by two researchers adjustments in operationalizations were made to increase agreement. As can be seen in Table 1, the aspects of daily life are scored as categories (activity performed by resident, engagement, location, interaction with the physical environment, level and type of social interaction, interaction with whom) or according to Likert scales (physical effort, mood, agitation). The following operationalization was determined. First, the activity that the resident is performing or that occurs in the immediate environment of the resident is scored. There are 31 options to choose from (see Table 1). The option 'other' can be chosen if the activity that is observed is not covered by the pre-defined activity options. The observer always chooses one activity based on operational rules described below. The rules should be applied one at a time, beginning with the first rule and working through rule 2, 3, and 4 until a decision can be made.

1. The most meaningful activity is chosen (e.g. 'having a chat' is more meaningful than 'sitting/lying').

2. If two meaningful activities take place, the one with the longest duration is chosen.

3. If both have the same duration, the one which had the most influence on the residents' well-being is chosen.

4. If it is still unclear which activity to choose, field notes are made to describe the situation and a decision is made based on a discussion with the research team.

Second, engagement is scored by choosing one of five categories ranging from not engaged (sleeping) to active engagement. Third, the degree of physical effort of the residents is scores. The observer chooses between seven categories ranging from 'lying or sitting without movement' to 'whole body movements'. Fourth, the observer scores where the resident is located. The options are communal area on the ward, own room, communal area off the ward, bathroom/toilet, and outside. Fifth, the interaction with the physical environment was scores as yes or no. Interaction with the physical environment is defined as whether residents perform any form of intentional handling, holding, manipulation, attention towards or other use of freestanding physical objects or fixed environmental features. ${ }^{20}$ Sixth, the level of social interaction is scored by choosing from five categories ranging from no social interaction to interaction with two or more people. Seventh, with whom the interaction takes place is scored. Eighth, the type of social interaction is scored. The type of social interaction ranges from negative restrictive to positive social (based on the quality of interactions schedul ${ }^{21}$ ). Ninth, mood is assessed using a 7-point Likert scale ranging from 1 (great signs of negative mood) to 7 (very high positive mood). Initially, in line with Dementia Care Mapping, ${ }^{16}$ only 6 scoring options were used. However, a neutral scoring option had been missed and was therefore added to the scale. ${ }^{38}$ Tenth, the presence of agitation (aberrant vocalization, motor agitation, aggressiveness, or resisting care ${ }^{22}$ ) is scored on a 5-point scale ranging from 'not present' to 'extremely present'. Finally, the observer has the option to make field notes during the observations in case events occurred that could 
not be covered by the aspects of daily life in the MEDLO-tool. These field notes can be about organizational, social, or physical environmental factors as well as any prominent deviations from the 'normal' situation. Furthermore, there is room for questions and remarks that need to be discussed with fellow colleagues.

Figure 3 shows an example of a daily life situation and demonstrates how the observer scores all aspects of daily life using the MEDLO-tool. The manual of the MEDLO-tool is available upon request. 


\begin{tabular}{|c|c|c|c|c|}
\hline 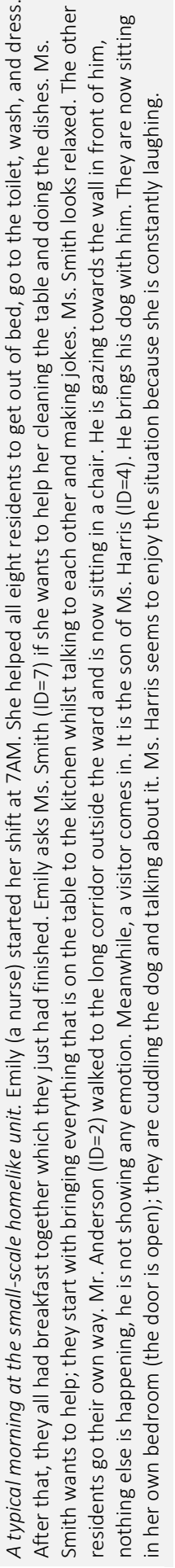 & 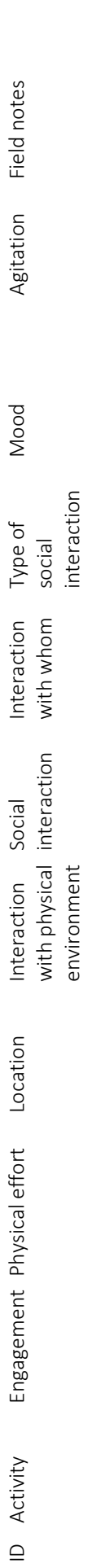 & 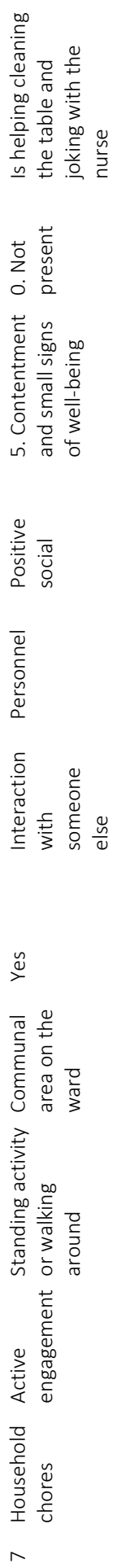 & 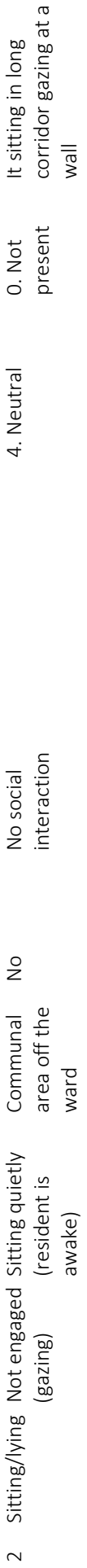 & 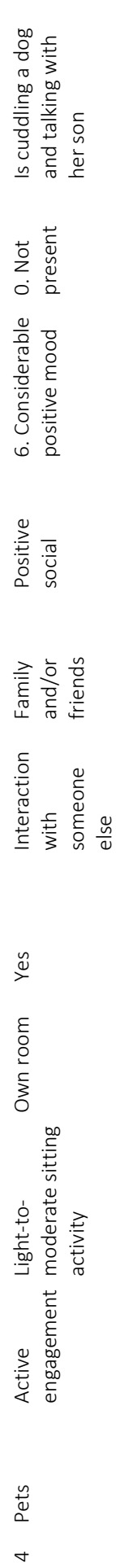 \\
\hline
\end{tabular}




\section{Testing the final version of the MEDLO-tool}

The final version of the MEDLO-tool was tested in a nursing home ward in the Netherlands. The residents $(n=16)$ had a mean age of 77 and $56 \%$ were women. They had a mean ADL-H score of 3.8 (range 0-6) and a mean CPS score of 3.5 (range 0-6), indicating extensive functional dependence and moderate to severe cognitive impairment. Table 2 provides information regarding the inter-rater reliability of the MEDLO-tool. Agreement levels on the aspects of the MEDLO-tool are positive with an average absolute agreement of $86 \%$. Kappa values were low for 'type of social interaction' and 'mood' had low kappa values. Regarding 'type of social interaction', the low kappa values may have arisen because there were very few data for this aspect of daily life. Often no social interaction at all was scored (63\%) and consequently also no type of social interaction. For 'mood', one option (contentment and small signs of wellbeing) was scored in most instances (70\%). Disagreement in only a few cases caused a large decline in the kappa value. Further investigation showed that a difference of two or more points on the mood scale occurred in only $5.5 \%$ of the cases.

Table 2. Inter-rater reliability of the MEDLO-tool

\begin{tabular}{lllll}
\hline Aspect of daily life & $\begin{array}{l}\text { Absolute } \\
\text { agreement (\%) }\end{array}$ & Kappa & Standard error & $\begin{array}{l}\text { 95\% confidence } \\
\text { interval }\end{array}$ \\
\hline Activity & 90.7 & 0.9 & 0.05 & $0.79-0.99$ \\
Location & 100 & 1 & 0.00 & - \\
Engagement & 82.1 & 0.8 (weighted kappa) & 0.07 & $0.68-0.96$ \\
Degree of social interaction & 88.4 & 0.8 (weighted kappa) & 0.07 & $0.69-0.99$ \\
Social interaction with whom & 92.9 & 0.9 & 0.10 & $0.68-1$ \\
Type of social interaction & 55.6 & 0.5 (weighted kappa) & 0.21 & $0.10-0.90$ \\
Interaction with physical & 92.1 & 0.8 & 0.12 & $0.53-1$ \\
environment & & 0.9 (weighted kappa) & 0.04 & $0.89-1$ \\
Physical effort & 97.4 & 0.5 (weighted kappa) & 0.12 & $0.23-0.70$ \\
Mood & 69.4 & 0.8 (weighted kappa) & 0.08 & $0.62-0.94$ \\
Agitation & 93.2 & & & \\
\hline
\end{tabular}

Feasibility

The respondents completing the questionnaire $(n=3)$ all had at least a Master's degree. They were trained by the main researcher $(B d B)$ to conduct observations using the MEDLO tool. No difficulties in using the hardware and software were experienced. In addition, the practical use of the tool and its operationalization were clear. One user indicated that the observations and weekly discussions were quite time consuming. The users suggested that observer fatigue might result when the tool was intensively used for several mornings, afternoons and evenings for a long period of time. With respect to the completeness of the tool, the respondents indicated that the activity 'smoking' was missing as an activity option. In addition, the presence of visitors (family, friends) could 
be added to the MEDLO-tool. Two users graded the overall feasibility of the MEDLO-tool with an eight, one with a seven.

Overall, the observers were positive about the feasibility of the MEDLO-tool as an instrument to assess the daily lives of nursing home residents with dementia. One user answered: "I think the observation method is a thorough method to collect detailed information about the daily lives of people with dementia. It seems very reliable because it -in contradiction to questionnaires-does not rely on retrospective assessments but on real time occurrences'. Another user considered the MEDLO-tool to be 'a good instrument which I would recommend other researchers to use'.

\section{DISCUSSION}

The current study described the development and pilot testing of the Maastricht Electronic Daily Life Observation (MEDLO) tool). The MEDLO-tool is an electronic, freely accessible tool that can be used to provide a full and extensive description of the daily life context of nursing home residents with dementia. First results indicate that the MEDLO-tool is a reliable and feasible tool to assess multiple aspects of daily life related to activity, physical environment, social interaction and emotional well-being simultaneously. By using tablets, observers are flexible to assess nursing home residents in the entire nursing home environment easily. This gives a more complete view of the daily lives than only observing them in the communal living room. Furthermore, the MEDLO-tool has an efficient data processing system by using apps and tablets, which are compatible with statistical software. This prevents the time-consuming process of transferring the observation data for statistical analyses.

Some study limitations have to be acknowledged. First, this study focused on the development of the tool and first testing of reliability and validity. Therefore, some important aspects of the validity remain unknown, for example the construct validity. This requires further investigation. Second, the feasibility questionnaire was filled out by three assistants working in the same research team as the main researcher. Although they were able to freely answer in detail and clarify their responses, social desirability of their answers cannot be ruled out. Therefore, and for the further development of the tool we advise other (independent) researchers to use the tool and investigate feasibility as well.

Evidence indicates that nursing home residents with dementia perceive activities as meaningful if they experience feelings of pleasure during the activities, and if they are connected to other people. ${ }^{3,40,41}$ Research suggests that these aspects are also related to quality of life. ${ }^{5}$ The MEDLO-tool can be used to investigate whether activities are accompanied by active engagement, a positive mood, and social interaction, as it assesses all these aspects simultaneously in the context of everyday life. For example, the activity 'watching television' can be meaningful for nursing home residents with 
dementia when it matches their personal identity or when it is accompanied by feelings of pleasure and social interaction. ${ }^{40,41}$ However, it can also be accompanied by sleeping. The MEDLO addresses all these various aspects of daily life (i.e. activities, engagement, emotional well-being) simultaneously. This provides insight in possible associations between aspects of resident's daily life and their quality of life. ${ }^{42}$

A range of innovative nursing home initiatives has been developed, focusing on providing person-centered care in a small-scale and homelike environment. ${ }^{43}$ They aim to provide more meaningful activities for residents in comparison with traditional nursing homes. ${ }^{29}$ The MEDLO-tool could be a valuable tool to evaluate the nursing home environment and compare the daily lives of residents with dementia cross different settings. The MEDLO-tool considers contextual factors (both physical and social) and can therefore be used to investigate which aspects of daily life are affected by innovative nursing home care facilities. In order to gain such a detailed insight into the daily lives of nursing home residents with dementia it is important to use multiple observation periods preferably divided over weekdays/ weekends and over mornings, afternoons and evenings over a longer period of time.

\section{CONCLUSION}

This study suggests that the MEDLO-tool is a reliable and feasible method to achieve detailed, in-depth insights into the daily lives of nursing home residents with dementia. It is a tool that provides researchers with repeated, real time and simultaneous measures of multiple aspects of daily life. 


\section{REFERENCES}

1. Harper Ice G. Daily life in a nursing home: Has it changed in 25 years? Journal of Aging Studies 2002;16:345-359.

2. den Ouden M, Bleijlevens MH, Meijers JM, et al. Daily (In) Activities of Nursing Home Residents in Their Wards: An Observation Study. Journal of the American Medical Directors Association 2015;16:963-968.

3. Vernooij-Dassen M. Meaningful activities for people with dementia. Aging \& Mental Health 2007;11:359-360.

4. Hancock GA, Woods B, Challis D and Orrell M. The needs of older people with dementia in residential care. International Journal of Geriatric Psychiatry 2006;21:43-49.

5. Edvardsson D, Petersson L, Sjogren K, et al. Everyday activities for people with dementia in residential aged care: associations with person-centredness and quality of life. International Journal of Older People Nursing 2014;9:269-276.

6. Cohen-Mansfield J, Thein K, Dakheel-Ali M and Marx MS. Engaging nursing home residents with dementia in activities: the effects of modeling, presentation order, time of day, and setting characteristics. Aging \& Mental Health 2010;14:471-480.

7. Whear R, Coon JT, Bethel A, et al. What is the impact of using outdoor spaces such as gardens on the physical and mental well-being of those with dementia? A systematic review of quantitative and qualitative evidence. Journal of the American Medical Directors Association 2014;15:697-705.

8. Edvardsson D, Winblad B and Sandman P.O. Person-centred care of people with severe Alzheimer's disease: current status and ways forward. The Lancet Neurology 2008;7:362-367.

9. Zarit $\mathrm{S}$ and Femia E. A future for family care and dementia intervention research? Challenges and strategies. Aging \& Mental Health 2008;12:5-13.

10. Shiffman S, Stone AA and Hufford MR. Ecological momentary assessment. Annual Review of Clinical Psychology 2008;4:1-32.

11. Casey AN, Low LF, Goodenough B, et al. Computer-Assisted Direct Observation of Behavioral Agitation, Engagement, and Affect in Long-Term Care Residents. Journal of the American Medical Directors Association 2014;15:514-520.

12. Curyto KJ, Van Haitsma K and Vriesman DK. Direct observation of behavior: a review of current measures for use with older adults with dementia. Research in Gerontological Nursing 2008;1:52-76.

13. Kitwood T and Bredin K. A new approach to the evaluation of dementia care. Journal of Advances in Health and Nursing Care 1992;1:41-60.

14. Brooker D. Dementia care mapping: a review of the research literature. The Gerontologist 2005;45:1118.

15. Doherty-King B, Yoon JY, Pecanac K, et al. Frequency and duration of nursing care related to older patient mobility. Journal of Nursing Scholarship 2014;46:20-27.

16. Bradford Dementia Group. DCM 8 User's Manual. Bradford: University of Bradford, 2005.

17. Viera AJ and Garrett JM. Understanding interobserver agreement: the kappa statistic. Family Medicine 2005;37:360-363.

18. Morris JN, Fries BE, Mehr DR, et al. MDS cognitive performance scale (C. Journal of Gerontology 1994;49:M174-M182.

19. Morris JN, Fries BE and Morris SA. Scaling ADLs within the MDS. The Journals of Gerontology Series A: Biological Sciences and Medical Sciences 1999;54:M546-M553.

20. Wood W. Toward Developing New Occupational Science Measures: An Example from Dementia Care Research. Journal of Occupational Science 2005;12:121-129.

21. Dean R, Proudfoot R and Lindesay J. The quality of interactions schedule (QUIS): development, reliability and use in the evaluation of two domus units. International Journal of Geriatric Psychiatry 1993;8:819826.

22. Rosen J, Burgio L, Kollar M, et al. The Pittsburgh Agitation Scale: A User-Friendly Instrument for Rating Agitation in Dementia Patients. The American Journal of Geriatric Psychiatry 1995;2:52-59. 
23. Phinney A, Chaudhury $\mathrm{H}$ and O'Connor DL. Doing as much as I can do: the meaning of activity for people with dementia. Aging \& Mental Health 2007;11:384-393.

24. Bruin SRD, Oosting SJ, Kuin Y, et al. Green care farms promote activity among elderly people with dementia. Journal of Housing for the Elderly 2009;23:368-389.

25. Harmer BJ and Orrell M. What is meaningful activity for people with dementia living in care homes? A comparison of the views of older people with dementia, staff and family carers. Aging \& Mental Health 2008;12:548-558.

26. Morley JE, Philpot CD, Gill D and Berg-Weger M. Meaningful activities in the nursing home. Journal of the American Medical Directors Association 2014;15.

27. Tak SH, Kedia S, Tongumpun TM and Hong SH. Activity Engagement: Perspectives from Nursing Home Residents with Dementia. Educational Gerontology 2015;41:182-192.

28. Edvardsson D, Petersson L, Sjogren K, et al. Everyday activities for people with dementia in residential aged care: associations with person-centredness and quality of life. International Journal of Older People Nursing 2013;9:269-276.

29. Smit D, de Lange J, Willemse B and Pot AM. The relationship between small-scale care and activity involvement of residents with dementia. International Psychogeriatrics 2012;24:722-732.

30. Kovach CR and Magliocco JS. Late-stage dementia and participation in therapeutic activities. Applied Nursing Research 1998;11:167-173.

31. Kolanowski A. Factors that relate to activity engagement in nursing home residents. American Journal of Alzheimer's Disease and Other Dementias 2006;21:15-22.

32. Van Raaij J, Schonk CM, Vermaat-Miedema SH, et al. Energy cost of physical activity throughout pregnancy and the first year postpartum in Dutch women with sedentary lifestyles. The American Journal of Clinical Nutrition 1990;52:234-239.

33. Wood W. Activity situations on an Alzheimer's disease special care unit and resident environmental interaction, time use, and affect. American Journal of Alzheimer's Disease and Other Dementias 2005;20:105-118.

34. Wood W, Womack J and Hooper B. Dying of boredom: An exploratory case study of time use, apparent affect, and routine activity situations on two Alzheimer's special care units. American Journal of Occupational Therapy 2009;63:337-350.

35. Cohen-Mansfield J, Thein K, Dakheel-Ali M and Marx MS. The underlying meaning of stimuli: Impact on engagement of persons with dementia. Psychiatry Research 2010;177:216-222.

36. Day K, Carreon D and Stump C. The therapeutic design of environments for people with dementia a review of the empirical research. The Gerontologist 2000;40:397-416.

37. Knight $\mathrm{T}$ and Mellor $\mathrm{D}$. Social inclusion of older adults in care: Is it just a question of providing activities? International Journal of Qualitative Studies on Health and Well-being 2007;2:76-85.

38. Sloane PD, Brooker D, Cohen L, et al. Dementia care mapping as a research tool. International Journal of Geriatric Psychiatry 2007;22:580-589.

39. Martin P and Bateson P. Measuring behaviour: an introductory guide. Cambridge: Cambridge University Press, 2007.

40. Harmer BJ and Orrell M. What is meaningful activity for people with dementia living in care homes? A comparison of the views of older people with dementia, staff and family carers. Aging \& Mental Health 2008;12:548-558.

41. Phinney A, Chaudhury H and O'Connor DL. Doing as much as I can do: The meaning of activity for people with dementia. Aging \& Mental Health 2007;11:384-393.

42. Beerens HC, de Boer B, Zwakhalen SMG, et al. The association between aspects of daily life and quality of life of people with dementia living in long-term care facilities: repeated real-time observations. International Psychogeriatrics 2016.

43. Verbeek H, Zwakhalen SM, van Rossum E, et al. Small-scale, homelike facilities in dementia care: a process evaluation into the experiences of family caregivers and nursing staff. International Journal of Nursing Studies 2012;49:21-29. 



\section{CHAPTER}

\section{Green care farms as innovative nursing homes, promoting activities and social interaction for people with dementia}

This chapter was published as: de Boer B, Hamers J, Zwakhalen S, Tan F, Beerens, H, Verbeek $\mathrm{H}$. Green care farms as innovative nursing homes, promoting activities and social interaction for people with dementia. Journal of the American Medical Directors Association International psychogeriatrics, 


\begin{abstract}
Objectives: Innovative care environments are developed for people with dementia to encourage person-centred care. This study aims to investigate whether residents of green care farms that provide 24-hour nursing care participate more in (physical) activities and social interaction compared to residents of other nursing homes.
\end{abstract}

Design: Longitudinal observation study

Setting: Nursing homes in the Netherlands (green care farms, traditional nursing homes, and regular small-scale living facilities).

Participants: 115 nursing home residents at baseline, 100 at follow-up.

Measurements: Ecological momentary assessments $(N=16 \cdot 860)$ were conducted using the Maastricht Electronic Daily Life Observation Tool. Residents living at green care farms were compared with residents living in traditional nursing homes and regular small-scale living facilities. The following aspects were collected for this study: the activity performed by the participant or occurring in his/her vicinity, the engagement in the activity, the level of physical activity during the activity, the physical environment (location where the activity occurred), and the level of social interaction during the activity.

Results: In total, 9660 baseline observations and 7200 follow-up observations were conducted. Analyses showed that residents of green care farms significantly more often participated in domestic activities ( $p=.004, E S=1.6)$ and outdoor/nature-related activities ( $p=\cdot 003, E S=0.9)$, and significantly less often engaged in passive/purposeless activities $(p<.001, E S=1.7)$ compared to residents of traditional nursing homes. Furthermore, residents of green care farms had significantly more active engagement ( $p$ $=.014, E S=0.9)$, more social interaction $(p=.006, E S=1 \cdot 1)$, and came outside significantly more $(p=.010, E S=1 \cdot 1)$ than residents of traditional nursing homes. Residents of green care farms were significantly more physically active $(p=\cdot 013, E S=$ $0 \cdot 8$ ) than were residents of regular small-scale living facilities. No other significant differences were found.

Conclusion: Green care farms can be a valuable alternative to traditional nursing homes. They provide an attractive, homelike environment and activities, which positively influences engagement and social interaction. Research is needed to study how successful elements of green care farms can be implemented in existing nursing homes. 


\section{INTRODUCTION}

Green care farms that provide 24-hour nursing care for people with dementia are a new phenomenon within the geriatric landscape in the Netherlands. The development is part of a larger worldwide movement towards small-scale, homelike care environments that aim to provide person-centred care. ${ }^{1,2}$

This radical redesign is believed to be necessary to solve the ongoing struggle in nursing homes against passivity and related negative outcomes, such as boredom, loneliness, isolation and social exclusion., ${ }^{3,4}$ Residents in traditional nursing homes spend a substantial part of their days doing little or nothing while remaining in a lying or sitting position, without social interaction, and they are rarely engaged in meaningful activities. $^{5-7}$

In order to tackle these problems, various alternative facilities are developing across the world. ${ }^{8}$ Examples are small-scale living facilities on the terrain of larger nursing homes, stand-alone units in the neighbourhood, and recently, green care farms that provide 24-hour nursing care for people with dementia. ${ }^{9}$ Traditional institutional care settings are being redesigned into smaller group homes that provide a more homelike and familiar atmosphere for people with dementia. ${ }^{10}$ These new facilities are aimed at allowing people to continue the life they had before admission for as long as possible and reaching or maintaining a good quality of life. ${ }^{11}$ They try to achieve this by focusing on engaging residents in activities, giving them feelings of meaning in life and allowing them to express themselves and interact with other people. A recent review on the impact of homelike residential care models showed that the current evidence on the effectiveness of these models is limited and that more comparative research is needed to provide a stronger evidence base to justify the uptake of more homelike residential care models such as green care farms. ${ }^{12}$

Green care farms combine agricultural with care activities and are a new type of smallscale living facility (Figure 1 and https://www.academischewerkplaatsouderenzorg.nl/ node/10802). ${ }^{13}$ Within day care, green care farms are a widely adopted way of providing care for different client groups. Norway, the Netherlands and France are the leading countries with each approximately 1000 green care farms providing day care. ${ }^{14}$ It is suggested that nursing staff require explicit competencies for working in these new smallscale facilities because of the integrated tasks they have. ${ }^{15-16}$ The rationale of green care farms is that people should be able to participate in daily activities as much as possible. Furthermore, the physical environment offers many opportunities to incorporate these activities into normal daily care practices and offers residents to move more freely than in existing nursing homes. The environment involves the presence of animals, plants and other natural aspects. Residents have the opportunity to participate in outdoor, domestic, work-related, and other types of activities incorporated into normal daily life. Some of these green care farms are actual farms that have agricultural production while, for others, care is the main source of income. Green care farms that provide 24-hour nursing 
care are expected to have benefits regarding the way residents spend their days when compared with regular nursing homes, which can influence well-being. However, available research on the effects of green care farms only focusses on day care practices. Here, findings indicate a positive effect of day care at green care farms, such as more involvement in activities and more physical effort needed during the day compared to regular day care services. ${ }^{17-18}$

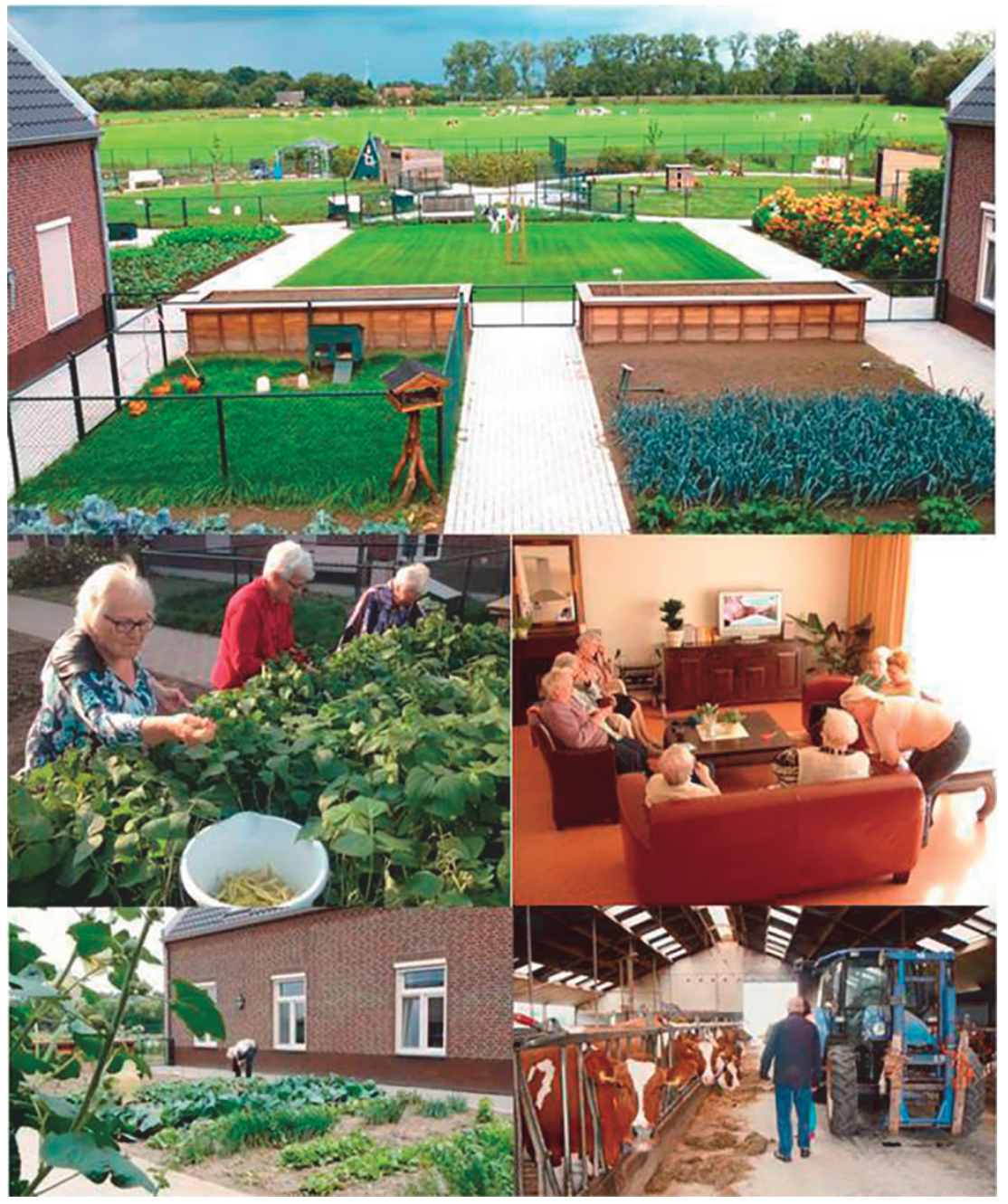

Figure 1. Impression of green care farms.

Evidence is lacking on the effects of green care farms on the daily lives of residents in comparison with other existing nursing homes for people with dementia. Therefore, this study investigates whether residents of green care farms are more engaged in 
(physical) activities and social interaction than are residents of other nursing homes. This will be examined by comparing green care farms with traditional nursing homes and with regular small-scale living facilities. The largest differences are expected between green care farms and traditional nursing homes.

\section{METHODS}

\section{Design}

A longitudinal observational design was used, including a baseline measurement and six-month follow-up. ${ }^{9}$ Ecological momentary assessments (EMA) ${ }^{19}$ of residents' living in different types of nursing home facilities were conducted. These repeated assessments allow researchers to assess affect, behaviour and environmental factors (both socially and physically) close in time to the actual experience. ${ }^{19,20}$ Residents were observed at a baseline measurement and a six-month follow-up.

\section{Setting/sample}

The experimental group consisted of five homes on green care farms; these are a type of stand-alone small-scale facility providing nursing care for people with dementia; both care and agricultural activities are important and approximately eight residents live together in a house on the farm. The control groups consisted of traditional nursing homes and regular small-scale living facilities. The traditional nursing homes had at least 20 residents on the ward; caregivers here have differentiated tasks and daily life is mainly determined by routines and rules of the organisation. ${ }^{1}$ Regular small-scale living facilities had a maximum of eight residents, making it a joint household with cooking in the home; the steady stream of caregivers here have integrated tasks. In the small-scale living facilities, daily living is mainly determined by the residents and informal caregivers and the physical environment approaches a home-like situation as much as possible. ${ }^{1}$ In order to increase comparability between residents in terms of cognitive and functional status, a matching procedure was conducted two weeks before the baseline measurement. ${ }^{9}$ Residents of all participating locations were screened and residents of the traditional nursing homes were selected based on their screening scores in order to match with residents of green care farms and small-scale living facilities.

In total, 158 residents living in 18 nursing homes were eligible for inclusion in the study. Residents were eligible if they had a formal diagnosis of dementia according to their medical record. Residents included in the study were all admitted to non-profit, collectively funded nursing homes in the southern part of the Netherlands. 


\section{Measures}

Daily lives

Table 1 clarifies the operationalisation of the outcomes related to the daily lives of the residents. The Maastricht Electronic Daily Life Observation tool (MEDLO-tool) was used assess the primary outcomes of this study. ${ }^{21}$ The MEDLO-tool is a tablet-based observational tool that assesses the residents' activity, their physical environment and their social interactions. It was demonstrated to be valid, feasible and reliable with, on average, 86\% absolute agreement between observers and Kappa values between 0.5-1 (depending on the aspect of daily life measured). ${ }^{18}$ The following aspects were collected for this study: $1 \mathrm{~A})$ the activity performed by the participant or occurring in his/her vicinity (e.g. eating/drinking, playing a game, having a chat, walking, music, dancing, sitting/lying down, etc.), 1B) the engagement in the activity, 1C) the level of physical activity during the activity, 2) the physical environment (location where the activity occurred), and 3 ) the level of social interaction during the activity.

\section{Background characteristics}

Cognitive functioning was assessed using the Standardized Mini-Mental State Examination (S-MMSE) ${ }^{22}$. The scores on this assessment range from 0 to 30 , with higher scores indicating better cognition. Dependence in activities of daily living (ADL) was assessed using the Barthel index ${ }^{23}$. The total scores of the Barthel index range from 0 to 20, with higher scores indicating less ADL dependence. The Global Deterioration Scale (GDS) ${ }^{24}$ was used to measure the severity of the dementia, ranging from 1 (normal) to 7 (highly severe dementia). Demographic information was collected through the medical records of the residents.

\section{Procedure}

At baseline and follow-up, residents were observed spread over a period of two weeks, including two mornings (07:00-11:30), two afternoons (11:30-16:00), two evenings (16:00-20:30) and one Saturday afternoon (11:30-16:00; only at baseline), with a halfhour break each day.

Every 20 minutes, a maximum of eight residents were observed for one minute in a random sequence. This led to 12 observations per resident each observation day and 156 observations per resident in total. Residents were observed for one minute, after which the observer scored: 1) the activity that the resident was performing or that occurred in the immediate environment, 2) the place of the activity, 3) residents' engagement in the activity, 4) degree of physical activity that was needed during the activity, and 5) the level of social interaction. 
Table 1. Operationalization of activity, engagement, physical activity, physical environment and social interaction.

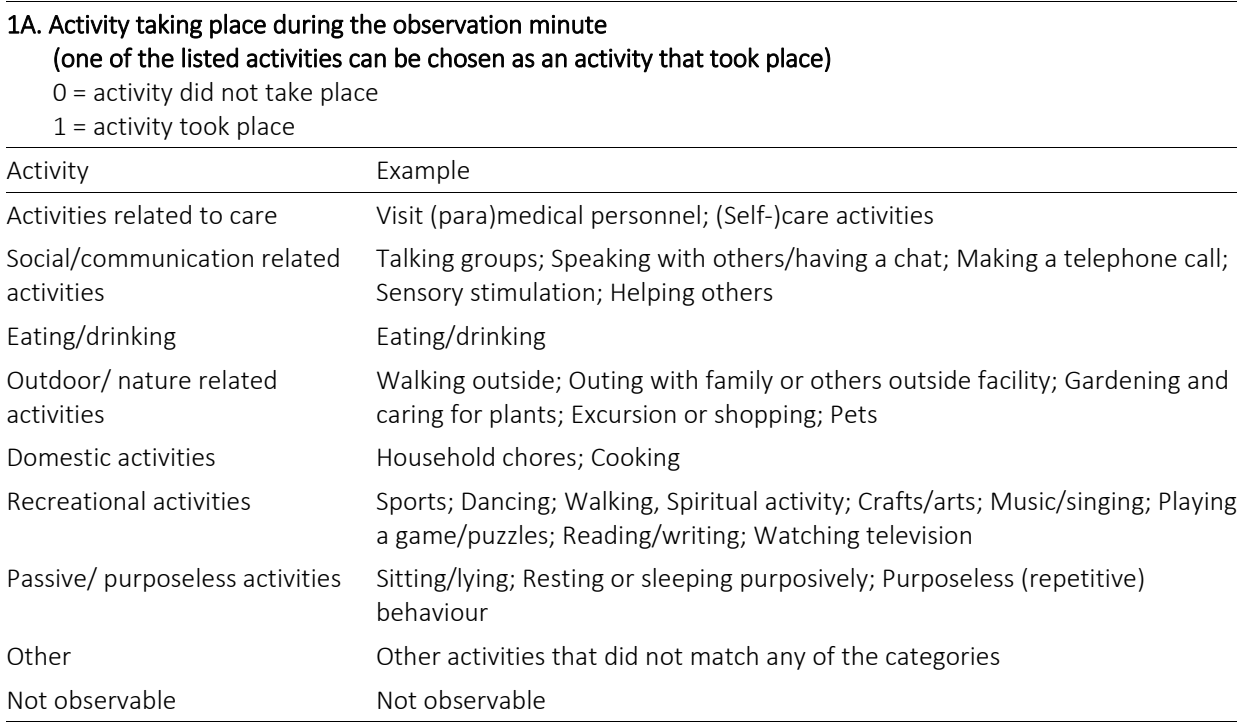

1B. Engagement in main activity that was chosen in step 1a

$0=$ no, not engaged: sleeping, staring, not engaged in main activity

1 = yes, engaged: active participation in activity or a focus on activity

1C. Physical activity

$0=$ none/minimal physical activity: lying or sitting quietly

1 = yes, physically active: light-to-moderate sitting activity, standing activity, walking around, cycling,

whole-body movements

2. Physical environment - location where the activity is occurring

$0=$ inside

1 = outside

3. Social interaction during activity

$0=$ no social interaction, attempted interaction without response

1 = yes, social interaction with one or more persons

\section{Analyses}

First, differences at baseline between the three types of nursing homes (green care farm, traditional nursing home, and regular small-scale living) on socio-demographic characteristics were assessed with a one-way ANOVA (Table 2). Second, descriptive analyses on the aspects of daily life were conducted. For each aspect, the percentage of 'yes' (1) responses was calculated per resident for the baseline and follow-up. A 'yes' response indicated whether a resident was participating in a certain type of activity, and whether he/she was activity engaged, was physically active, was outside and had social interaction. An overall score per resident (average of baseline and follow-up) was calculated, providing the most reliable and valid estimate of the daily lives, as it takes into account seasonal influences (e.g. weather conditions). In case of drop-out before 
follow-up, only the baseline scores were used. Third, differences between the types of nursing homes on the dependent variables 'activity', 'the engagement in the activity', 'physical activity during the activity', 'the location of the activity' and 'social interaction during the activity' were tested. To test the effect of nursing home type, a multilevel regression analysis on the overall scores was conducted, controlling for age, gender, cognition (S-MMSE), and independence in activities of daily living (Barthel index. The residents (level one) were nested in nursing homes (level two). All variables were entered into the model simultaneously (forced entry method). The Holm method ${ }^{25}$ for correcting for multiple testing was used. Effect sizes were calculated, indicating a small $(d>0 \cdot 2)$, medium $(d>0 \cdot 5)$, or large $(d>0 \cdot 8)$ effect size. ${ }^{26}$

\section{Ethics}

The medical ethics committee of the Maastricht University Medical Centre declared that the study was non-invasive for people with dementia. Legal representatives of the residents provided written informed consent. Furthermore, verbal consent was given by the residents.

\section{RESULTS}

Consent was obtained from 115 of 158 eligible residents (73\%). At follow-up, 100 residents still participated in the study. This resulted in 9660 baseline observations and 7200 follow-up observations.

\section{Sample characteristics}

Table 2 provides the characteristics of the residents at baseline. Except for gender, $F(2$, $112)=3 \cdot 75, p<0 \cdot 05$, the one-way ANOVA did not reveal any significant group differences in baseline characteristics. Pairwise comparisons revealed significantly more female residents at regular small-scale living facilities compared with traditional nursing homes.

\section{Daily life at green care farms}

Overall, residents at green care farms participated almost half the time (50\%) in social/communication-related activities, eating/drinking or recreational activities (see Table 3). Domestic activities, outdoor/nature-related activities and care-related activities occurred less often (almost 20\%). Residents of green care farms spent $27 \%$ of their time in passive/purposeless activities or doing other activities. When residents were doing an activity, they were mostly showing signs of engagement (74\%). Residents were physically active during $12 \%$ of the observations and came outside during $8 \%$ of the observations. 
Promoting Activities and social interaction

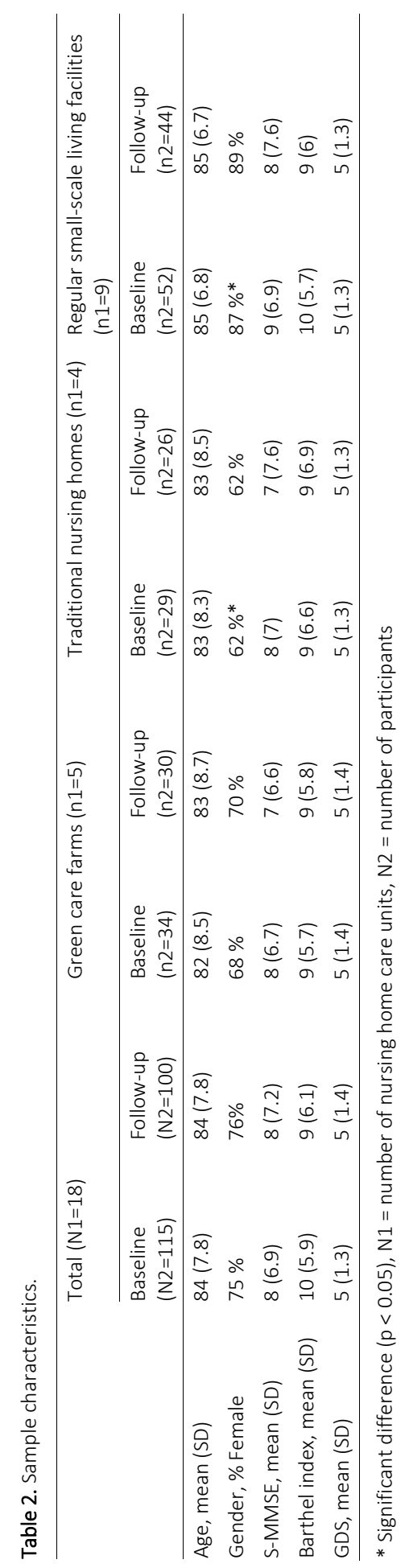


Chapter 4

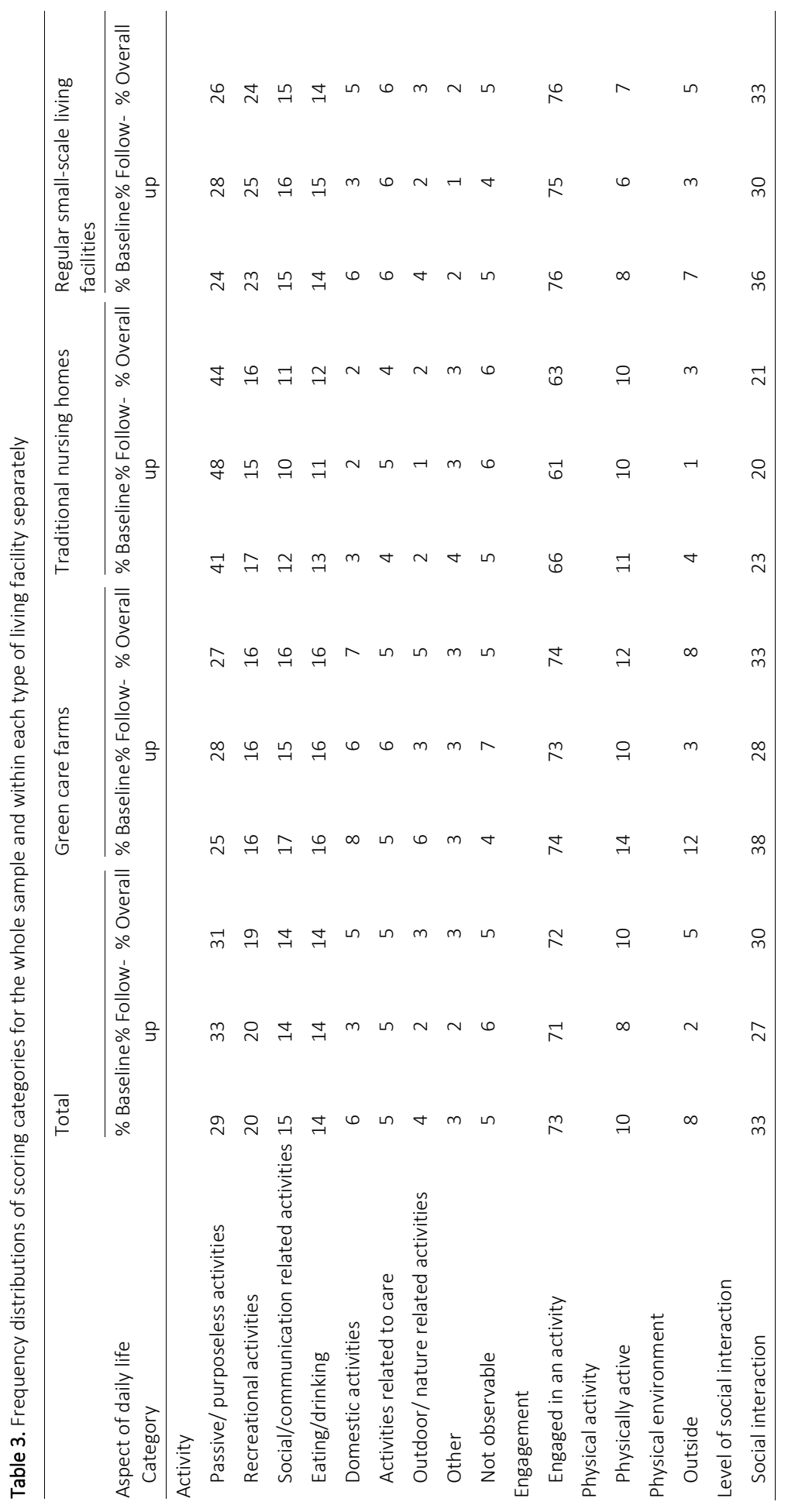




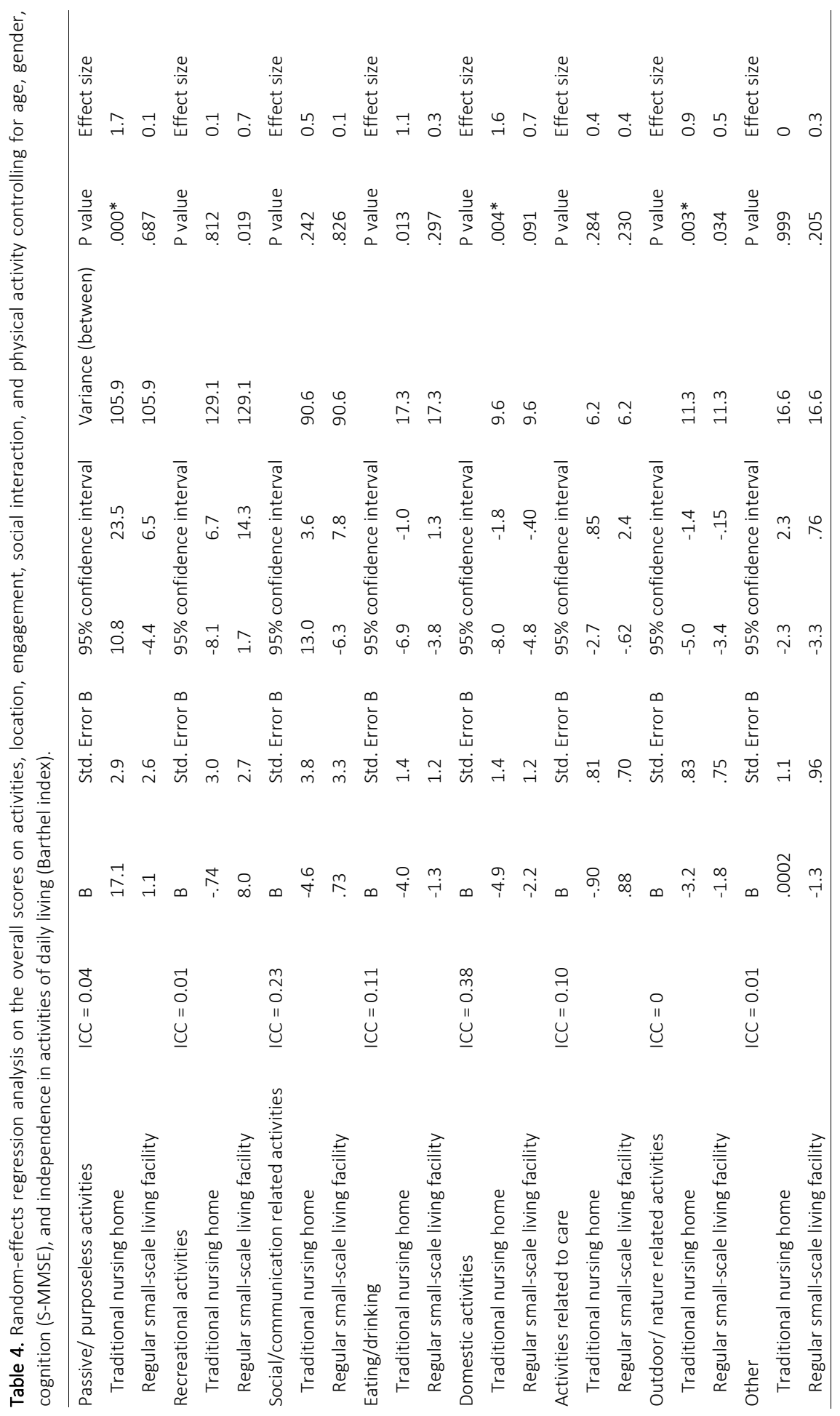


Chapter 4

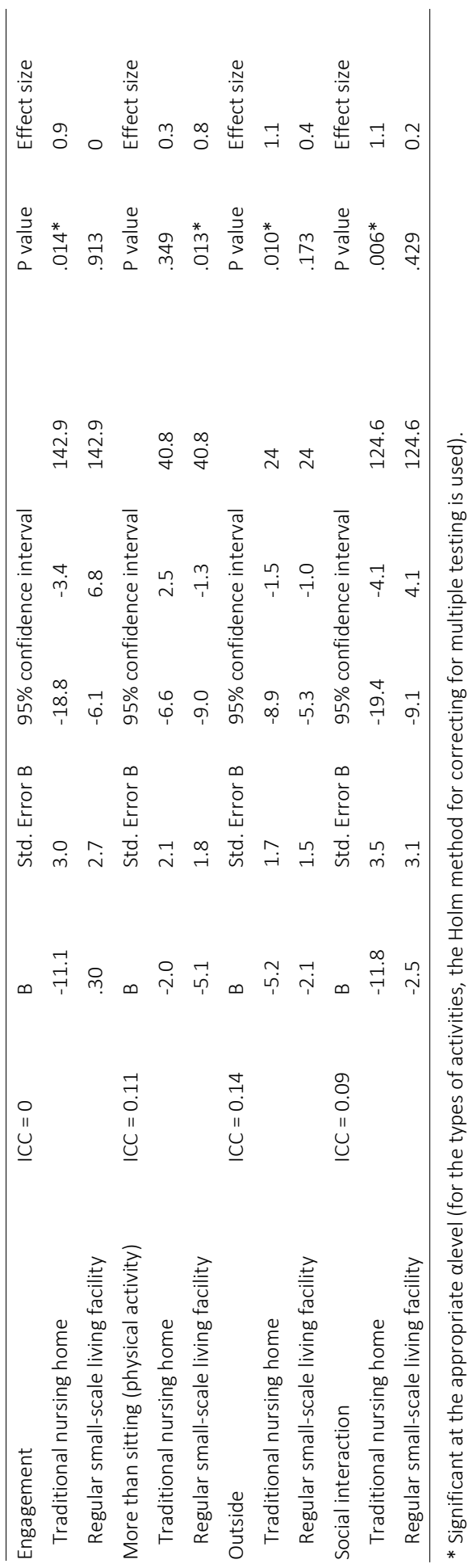




\section{Green care farms compared with traditional nursing homes wards}

The results of the multilevel regression analyses are shown in Table 4. Residents of green care farms were significantly less involved in passive activities compared with residents in traditional nursing homes (27\% vs. 44\%, $p<\cdot 001, E S=1 \cdot 7)$. Furthermore, residents of green care farms were significantly more often participating in domestic activities $(p=.004, E S=1.6)$ and in outdoor/nature-related activities $(p=.003, E S=0.9)$ than were residents of traditional nursing homes. In addition, residents of green care farms had significantly more active engagement in activities $(p=\cdot 014$, ES $=0.9)$, more social interaction $(p=\cdot 006, E S=1 \cdot 1)$, and came outside significantly more often $(p=010$, $\mathrm{ES}=1 \cdot 1$ ) compared to residents of traditional nursing homes.

\section{Green care farms compared with regular small-scale living facilities}

Residents of green care farms were significantly more physically active during the observations ( $p=\cdot 013, E S=0.3$ ) than were residents of regular small-scale living facilities (see Table 4). No statistically significant differences were found between residents of green care farms and regular small-scale living facilities regarding the different types of activities.

\section{DISCUSSION}

The current study shows that green care farms are a valuable addition to the nursing home spectrum. Residents living at green care farms are more active than are residents of traditional nursing homes. Furthermore, when activities are carried out, residents are more often engaged, have more social interaction, and come outside more often at green care farms. Compared with residents of regular small-scale living facilities, residents of green care farms were more physically active during their days. In this study, residents' cognitive and functional performances were equal across settings.

Possible factors explaining the more active and engaged daily life of residents living at green care farms lie the physical environment and the focus on providing (meaningful) activities incorporated into normal daily care practises. ${ }^{27}$ Unique features of green care farms include the presence of animals, stables, gardens, and other outdoor areas. Green care farms provide residents with an environment that allows them to initiate activities and go outside whenever they want.

Being engaged in (physical) activities and having social interaction is important for nursing home residents, as these can influence their quality of life. Engagement in active, expressive and social activities has been associated with a higher quality of life compared with passive activities. ${ }^{28} \mathrm{~A}$ lack of engagement can lead to more behavioural problems $^{29}$ and a lower quality of life ${ }^{30}$. This emphasises the importance of a nursing 
care environment that facilitates the engagement of residents in activities and social interaction.

Another finding was that residents of green care farms come outside more often than did residents of the existing traditional nursing homes. Several reviews indicate that nature, outdoor access, and/or spending time outside are of great importance to nursing home residents. ${ }^{31-32}$ They showed that factors such as sunlight and provision of outdoor areas can influence residents' perceived stress, physical effort, and agitation in a positive manner. This indicates the importance for nursing homes to expedite the possibilities for residents to go outside.

We found that residents of green care farms were more physically active during their days than were residents of regular small-scale living facilities. Physical inactivity in nursing homes has been reported by previous studies and is associated with negative outcomes for residents, such as a higher care dependency and decreased physical fitness. ${ }^{5,6,33}$ It is worth mentioning that the difference found in physical activity was largest with stand-alone small-scale living facilities. This is a type of small-scale living within the neighbourhood, meaning that there are no facilities present that might invite residents to be physically active (restaurant, activity rooms, long interactive corridors, etc.). The largest differences were expected between green care farms and traditional nursing homes. Nevertheless, although regular small-scale facilities provide nursing home care according to a similar care vision as green care farms (integrating daily activities into care practices, forming a household, etc.) it could be argued that green care farms add some unique characteristics to this in the form of the physical environment and the opportunities this provides. However, only adding a certain physical environment to a nursing home is not enough. Nursing staff is important in implementing this physical environment and using it to its full potential. More research is needed on effective strategies enabling nursing staff of green care farms to do this.

Some methodological considerations should be taken into account. First, a strength of the current study is the method of data collection, including a matching procedure to increase comparability of residents regarding cognitive and functional status. However, although the matching procedure increased the comparability between groups in the study, it limits the generalisability of the findings as the residents of traditional nursing homes included in this study might not represent a 'normal' population of traditional nursing home. Second, using the repeated ecological momentary assessments with the MEDLO-tool allows researchers to report on symptoms, affect, behaviour and environmental factors (both socially and physically) close in time to the experience giving a more precise estimate compared to commonly used methods, such as single measurements or proxy-reports. However, although the MEDLO-tool was found to have sufficient inter-rater reliability, validity of the tool should be investigated further. Third, only a few green care farms could be included in the study as green care farms providing 24-hour nursing care for people with dementia are still rare. 


\section{Conclusion}

In conclusion, green care farms have demonstrated that they are a valuable alternative to traditional nursing homes as they provide residents with engagement in activities, social interaction, physical activity and increased opportunities to go outside. These findings can be valuable for existing nursing home facilities, given the current focus on person-centred care for people with dementia in nursing homes, which emphasises factors such as social interaction and participation in (meaningful) activities. Education should pay attention to the wide range in types of nursing homes that exist and different care visions that underlie them. Nursing staff can learn from these facilities and apply this knowledge into daily practice. It is important that nursing staff knows what the successful factors of different types of nursing home care are since they are the ones providing the care. More research is needed to investigate which lessons can be learned from successful innovative nursing home facilities and on how to transfer successful elements of these facilities into existing nursing homes. Furthermore, more knowledge on the quality and costs of care and the experiences of (in)formal caregivers at green care farms is needed. 


\section{REFERENCES}

1. Verbeek H, van Rossum E, Zwakhalen SM, Kempen GI, Hamers JP. Small, homelike care environments for older people with dementia: a literature review. International Psychogeriatrics 2009;21(02): 252-64.

2. White-Chu EF, Graves WJ, Godfrey SM, Bonner A, Sloane P. Beyond the medical model: the culture change revolution in long-term care. Journal of the American Medical Directors Association 2009;10(6): 370-8.

3. Knight T, Mellor D. Social inclusion of older adults in care: Is it just a question of providing activities? International Journal of Qualitative Studies on Health and Well-being 2007;2(2): 76-85.

4. Cahill S, Diaz-Ponce AM. 'I hate having nobody here. I'd like to know where they all are': Can qualitative research detect differences in quality of life among nursing home residents with different levels of cognitive impairment? Aging \& Mental Health 2011;15(5): 562-72.

5. Ice GH. Daily life in a nursing home: Has it changed in 25 years? Journal of Aging Studies 2002;16(4): 345-59.

6. den Ouden M, Bleijlevens MH, Meijers JM, et al. Daily (in) activities of nursing home residents in their wards: An observation study. Journal of the American Medical Directors Association 2015;16(11): 963-8.

7. Winblad B, Amouyel P, Andrieu S, et al. Defeating Alzheimer's disease and other dementias: a priority for European science and society. Lancet Neurology 2016;15(5): 455-532.

8. WHO. World Report on Ageing and Health, 2015.

9. de Boer B, Hamers J, Beerens H, Zwakhalen S, Tan F, Verbeek H. Living at the farm, innovative nursing home care for people with dementia - study protocol of an observational longitudinal study. BMC Geriatrics 2015;15(1): 144

10. Pot AM. Improving nursing home care for dementia: is the environment the answer? Aging \& Mental Health 2013;17(7): 785-7.

11. Smit D, de Lange J, Willemse B, Twisk J, Pot AM. Activity involvement and quality of life of people at different stages of dementia in long term care facilities. Aging \& Mental Health 2015;1-10.

12. Ausserhofer D, Deschodt M, De Geest $S$, et al. 'There's no place like home': A scoping review on the impact of homelike residential care models on resident-, family-, and staff-related outcomes. Journal of the American Medical Directors Association 2016.

13. Hassink J, Grin J, Hulsink W. Multifunctional agriculture meets health care: Applying the multi-level transition sciences perspective to care farming in the Netherlands. Journal of the European Society of Rural Sociology 2013;53(2): 223-45.

14. Haubenhofer DK, Elings M, Hassink J, Hine RE. The development of green care in western European countries. Explore 2010;6(2): 106-11.

15. Backhaus R, Verbeek H, Van Rossum E, Capezuti E, Hamers JPH. Future distinguishing competencies of baccalaureate-educated nurses in nursing homes. Geriatric Nursing 2015;36(6): 438-444.

16. Verbeek H, Van Rossum E, Zwakhalen SMG, Ambergen T, Kempen GIJM, Hamers JPH. The effects of small-scale, homelike facilities for older people with dementia on residents, family caregivers and staff: design of a longitudinal, quasi-experimental study. BMC Geriatrics 2009;9(3).

17. Schols JMGA, Van der Schriek-van Meel C. Day Care for Demented Elderly in a Dairy Farm Setting: Positive First Impressions. Journal of the American Medical Directors Association 2006; 7: 456-459.

18. Bruin SRD, Oosting SJ, Kuin Y, et al. Green care farms promote activity among elderly people with dementia. Journal of Housing for the Elderly 2009;23(4): 368-89.

19. Shiffman S, Stone AA, Hufford MR. Ecological momentary assessment. Annual Review of Clinical Psychology 2008;4: 1-32.

20. Moskowitz DS, Young SN. Ecological momentary assessment: what it is and why it is a method of the future in clinical psychopharmacology. Journal of Psychiatry \& Neuroscience 2006;31(1): 13.

21. de Boer B, Beerens HC, Zwakhalen SMG, Tan FES, Hamers JPH, Verbeek H. Daily lives of residents with dementia in nursing homes: development of the Maastricht electronic daily life observation tool. International Psychogeriatrics 2016;28(8): 1333-43. 
22. Molloy DW, Alemayehu E, Roberts R. Reliability of a standardized mini-mental state examination compared with the traditional mini-mental state examination. American Journal of Psychiatry 1991;148(1): 102-5.

23. Collin C, Wade D, Davies S, Horne V. The Barthel ADL Index: a reliability study. Disability \& Rehabilitation 1988;10(2): 61-3.

24. Reisberg B, Ferris SH, De Leon M, Crook T. Global Deterioration Scale (GDS). Psychopharmacological Bulletin 1988;24(4): 661-3.

25. Holm S. A simple sequentially rejective multiple test procedure. Scandinavian Journal of Statistics 1979;65-70.

26. Hedges LV. Effect sizes in cluster-randomized designs. Journal of Education and Behavioral Statistics 2007;32(4): 341-70.

27. De Bruin S, Oosting S, van der Zijpp A, Enders-Slegers M-J, Schols J. The concept of green care farms for older people with dementia. An integrative framework. Dementia 2010;9(1): 79-128.

28. Beerens HC, de Boer B, Zwakhalen SMG, et al. The association between aspects of daily life and quality of life of people with dementia living in long-term care facilities: a momentary assessment study. International Psychogeriatrics 2016;28(8): 1323-31.

29. Cohen-Mansfield J, Dakheel-Ali M, Marx MS, Thein K, Regier NG. Which unmet needs contribute to behavior problems in persons with advanced dementia? Psychiatry Research 2015;228(1): 59-64.

30. Wood W, Womack J, Hooper B. Dying of boredom: An exploratory case study of time use, apparent affect, and routine activity situations on two Alzheimer's special care units. American Journal of Occupational Therapy 2009;63(3): 337-50.

31. Day K, Carreon D, Stump C. The therapeutic design of environments for people with dementia a review of the empirical research. Gerontologist 2000;40(4): 397-416.

32. Dijkstra K, Pieterse M, Pruyn A. Physical environmental stimuli that turn healthcare facilities into healing environments through psychologically mediated effects: systematic review. Journal of Advanced Nursing 2006;56(2): 166-81.

33. Ikezoe T, Asakawa Y, Shima H, Kishibuchi K, Ichihashi N. Daytime physical activity patterns and physical fitness in institutionalized elderly women: an exploratory study. Archives of Gerontology and Geriatrics 2013;57(2): 221-5. 



\section{CHAPTER}

The association between aspects of daily life and quality of life of people with dementia living in long-term care facilities: a momentary assessment study 


\section{ABSTRACT}

Background: To improve the quality of life of people with dementia living in long-term care facilities, insight into the association between quality of life and how people spend their daily lives is urgently needed. This study investigated which aspects of daily life are related to quality of life in dementia.

Methods: An observational study was conducted. Daily life was assessed with the tabletbased Maastricht Electronic Daily Life Observation-tool (MEDLO-tool). Aspects included activity, engagement in the activity, social interaction, physical effort, mood and agitation. Quality of life was assessed by formal nursing caregivers using the Quality of Life-Alzheimer's Disease scale (QoL-AD). A total of 9,660 momentary assessments were conducted.

Results: The mean age of the 115 participants was 84 and most (75\%) were women. Bivariate analyses showed that residents with a higher quality of life carried out less passive/purposeless activities ( $25 \%$ vs. $38 \%$ ), were more engaged in active, expressive, and social activities, ( $40 \%$ vs. $27 \%$ ), had more social interaction (34\% vs. $22 \%$ ), and had better mood scores (scale 1-7, 5.0 vs. 4.8), compared with residents with a lower quality of life (all p-values < 0.001). Multivariate analyses showed that having more social interaction and a positive mood are related to a higher quality of life.

A higher quality of life was related to having more social interaction and positive mood.

Conclusion: The results underline the importance of social interaction and a positive mood for a higher quality of life. Future research should investigate the importance of engagement in activities in more detail. 


\section{INTRODUCTION}

Quality of life (QoL) of people with dementia (PwD) living in long-term care facilities remains a priority in dementia research. ${ }^{1,2} \mathrm{QoL}$ is a complex, multidimensional construct and both objective components (e.g. behavioral competence and environment) and subjective components (perceived QoL and psychological well-being) are generally considered to be important for QoL of PwD. ${ }^{3}$ Several studies showed that clinical conditions such as depressive and behavioral symptoms have a negative impact on QoL. ${ }^{4,5}$

There is less knowledge about which aspects of daily life are important for QoL and how these aspects contribute to a good QoL. As proposed by a study including expert interviews and a literature study, daily life entails: 1 ) activities performed by PwD; 2 ) the physical environment PWD live in; 3) social interactions of PwD with others; and 4) emotional well-being. ${ }^{6}$ Prior research suggests that PWD who engage in a variety of activities have a higher QoL than those who are inactive. ${ }^{7}$ Especially activities related to personal hobbies, ${ }^{8}$ reminiscence, leisure, expression, and vocational occupation ${ }^{9}$ have a large potential for QoL enhancement. In contrast, a low QoL is associated with passive activities such as daytime sleep and sitting/standing without doing any activities. 70 Qualitative literature indicates that activity engagement is important because it may give PWD pleasure and enjoyment, contributes to a sense of connection and belonging, and helps them to retain a sense of autonomy and personal identity. ${ }^{11}$ Besides activities, PwD and their caregivers also consider aspects such as social relationships, physical movement, attachment and affect, control over life and contributing to the community as important for PwD's QoL. ${ }^{12,13}$

However, to date, it is unknown how the daily lives of PwD with a higher QoL differ from those with a lower QoL. More insight is essential because it will direct QoL improvement. It will inform caregivers on how to set priorities during daily caregiving, as daily life aspects such as social interaction and activity level can be improved without complex interventions. ${ }^{14}$ Factors of daily life that contribute to a good QoL of PwD living in long-term care facilities are currently unknown. Prior research has not considered multiple aspects of daily life simultaneously. Furthermore, many studies used proxy questionnaires to investigate daily life and calculated sum scores. Such measures are prone to recall bias and do not consider the broad context in which daily life takes place. Caregivers may for example easily overestimate the time that PWD engage in activities. ${ }^{15}$

Therefore, the current study investigates the direct context in which activity, engagement, social interaction, and other aspects of daily life naturally occur. It uses an ecological momentary assessment approach, ${ }^{16}$ taking snapshots of everyday life to picture PWD's life repeatedly. First, this study aimed to gain more insight into the daily lives of PwD of PwD living in long-term care facilities. Second, this study addressed two research questions specifically focusing on the relationship between QoL and everyday 
life: 1) How does the daily life of PWD living in long-term care facilities with a high QoL differ from those with a lower QoL?; and 2) Which aspects of daily life of PWD living in long-term care facilities are associated with QoL?

\section{METHODS}

Design

This study has an observational study design and includes ecological momentary assessments of the daily lives of PWD. ${ }^{16}$

\section{Participants and setting}

This study was part of a larger study looking at differences between long-term care facilities for PwD living in the Netherlands. ${ }^{17}$ Eighteen wards in eight locations accommodating 158 potential participants - in the southern provinces of the Netherlands participated. PwD of all types of long-term care facilities (e.g. large- and small scaled) were eligible. All participants with a formal diagnosis of dementia were included. In total, the legal representatives of 115 of the 158 potential participants (73\%) agreed to participation in the study.

\section{Instruments}

Dependent variable: quality of life

QoL was assessed by formal caregivers using the Quality of Life-Alzheimer's Disease scale (QoL-AD). This scale allows thirteen QoL domains to be rated on a four-point Likert scale, ranging from 1 (poor) to 4 (excellent). Total scores range from 13 to 52, and higher scores indicate a better QoL. ${ }^{18}$

Independent variables: aspects of daily life

The Maastricht Electronic Daily Life Observation-tool (MEDLO-tool), ${ }^{6}$ a tablet-based observational tool, was used to conduct momentary assessments ${ }^{16}$ to gain insight in aspects of daily life. The MEDLO-tool demonstrated to be valid, reliable and feasible for research purposes with on average $86 \%$ absolute agreement between observers. ${ }^{6}$ The following daily life aspects of the MEDLO-tool were collected for this study: 1a) the activity performed by the participant or occurring in his/her vicinity; $1 \mathrm{~b}$ ) the extent to which the participant was engaged in this activity; 2) whether the participant had social interaction; 3) participant's level of physical effort; 4) the mood of the participant; and 5) participant's agitation level. Box 1 provides a full explanation of these aspects of daily 
life and accompanying operationalizations. A manual of the MEDLO-tool is available upon request.

Box 1. Aspects of daily life and their operationalizations

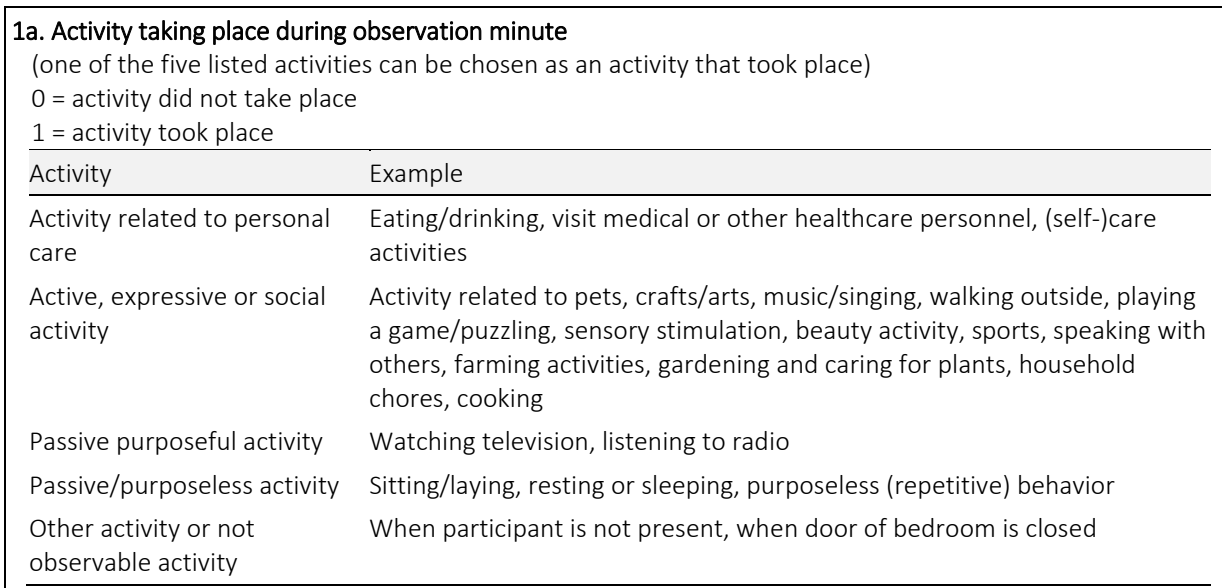

\section{1b. Engagement in main activity that was chosen in step 1a}

$0=$ no, not engaged: sleeping, staring, engagement in something else

1 = yes, engaged: active participation in activity or a focus on activity

\section{Social interaction during observation minute}

$0=$ no social interaction, attempted interaction without response

$1=$ yes, social interaction with one or more persons

\section{Physical effort during observation minute}

$0=$ none/minimal physical effort: lying or sitting quietly

1 = yes, physical effort: light-to-moderate sitting activity, standing activity, walking around, cycling, wholebody movements
4. Mood during observation minute
Seven-point Likert scale.
1. Great signs of negative mood
2. Considerable signs of negative mood
3. Small signs of negative mood
4. Neutral
5. Contentment and small signs of well-being
6. Considerable positive mood
7. Very high positive mood

\section{Agitation during observation minute}

Defined as aberrant vocalization, motor agitation, aggressiveness, or resisting care

Five-point Likert scale:

0. No agitation

1. E.g. vocalization is not disruptive, seeking comfort, verbal threats, procrastination or avoidance

2. E.g. vocalization is louder than usual, mildly intrusive movements, threatening gestures, rejection

3. E.g. loud vocalization, quick movements, physical toward material goods, pushing away

4. E.g. extremely loud vocalization, extreme movements, physical towards people, threshing 
Activity and engagement were considered to be two distinct aspects of daily life. An activity occurring in the participant's vicinity does not imply that they are actually engaged in this activity. Therefore, we recorded 1a) the activity and 1b) participant's level of engagement in this activity. Engagement in active, expressive, and social activities was of particular interest and therefore, a combination variable connecting the activity cluster 'active, expressive, and social activities' (step 1a) and 'yes, engagement' (step 1b) was created.

For the dichotomous variables (activity, engagement, social interaction, physical effort), percentages of how frequently they occurred on a total of 84 observations were calculated. For the dichotomous variables (activity, engagement, social interaction, physical effort), percentages of how frequently they occurred were calculated per participant. For the continuous variables (mood and agitation), mean scores were calculated per participant.

\section{Background characteristics}

Cognitive functioning was assessed using the Standardized Mini-Mental State Examination (S-MMSE). Total scores on this scale range from 0 to 30, with higher scores indicating better cognition. ${ }^{19}$ Dependence in activities of daily living (ADL) was assessed using the Barthel Index. Total scores on this scale range from 0 to 20, with higher scores indicating more independency in ADL. ${ }^{20}$ Information on age, gender (male/female), and marital status (widowed/not widowed) was also collected.

\section{Procedure}

All data were collected by two researchers (the first and second authors) and a research assistant who spent a maximum of three weeks in every location. Within this period, all data were collected using two methods. First, standardized interviews were held with certified nursing assistants who provided hands-on care to participants (PwD's QoL and background characteristics) and PWD (cognition). Second, momentary assessments of the daily lives of PwD were carried out. PwD were not only observed in communal areas, but were followed wherever they went. If observers had the impression that they were too intrusive in the daily lives of PWD, they stepped back and recorded an observation as missing. To take privacy into account, PwD were not observed in private spaces such as the bathroom or the bedroom with a closed door.

Observations took place at one ward per observation day. The order of observations was randomized in advance. A randomized observation schedule ensured that every participant (with a maximum of eight per ward) was observed for one minute during every 20-minute period. After the end of each one-minute observation period, the observer recorded the scores of all aspects of daily life that are shown in Box 1 . Observations took place on seven days: two weekday mornings (07:00-11:30), two weekday afternoons (11:30-16:00), two weekday evenings (16:00-20:30) and one 
Saturday afternoon (11:30-16:00). There was a half-hour break within each 4.5 hour observation block. In total, data of (12 one-minute observation periods per day * 7 observation days =) 84 momentary assessments were recorded per participant.

\section{Analyses}

First, the sample characteristics were described. Participants were assigned to one of two QoL groups according to whether their QoL-AD score was above or below the median of the sample (32.0). Differences in sample characteristics between PwD in the 'higher QoL' group and PwD in the 'lower QoL' group were assessed using chi-square tests in the case of marital status and gender and independent samples t-tests for other variables.

Second, differences between the aspects of the daily lives of PWD with 'higher QoL' and PwD with 'lower QoL' were evaluated. Therefore, differences between the two QoL groups regarding activities, engagement, social interaction, physical effort, mood, and agitation were assessed using chi-square tests.

Third, to assess which aspects of daily life contribute to QoL, a multiple linear regression analysis with the QoL-AD score as the dependent variable was conducted. The selection of independent variables went as follows: First, aspects of daily life that were not significantly different between the two QoL groups (see Table 2) were excluded (three activity categories, physical effort, and agitation). Second, whether or not a participant was actually engaged in activities such as musical activities, craft activities, or sports was considered most important. Therefore, we included the combination variable 'engagement in active, expressive and social activities'. As a result, two closely related variables ('active, expressive, or social activities' and 'engagement in all activities together') were removed. The final set of independent variables related to aspects of daily life included: 'passive/purposeless activity'; 'engagement in active, expressive or social activity'; 'social interaction' and 'mood'. We controlled for the potential effects of age, gender, cognitive status and location as these variables might influence the range of activities in which participants are involved, their level of engagement or social interaction. All independent variables were entered in the model simultaneously.

All analyses used a significance level of $\alpha=.05$ (two-tailed) and were conducted using SPSS version 22.0 (IBM SPSS Statistics, IBM Corporation, Chicago, IL).

\section{Ethics}

The study protocol was reviewed by the medical ethics committee of the Maastricht University Medical Center. They declared that the study was non-invasive for people with dementia according to the Medical Research Involving Human Subjects Act. Legal representatives of PWD received a letter with information about the study and an 
informed consent form. They were asked to return the form in which they filled out whether they provided informed consent or not. Next to this informed consent procedure, PwD were asked to assent to participation. This was defined as a verbal agreement to participate or a non-verbal indication of willingness to cooperate with the study.

\section{RESULTS}

\section{Sample characteristics}

The legal representatives of 115 of 158 potential participants (73\%) agreed to participation in the study. The mean age of participants was 84 years and most were female (75\%) and widowed (66\%). The mean S-MMSE score was 8.5, which indicates severe cognitive impairment. The mean Barthel Index score was 9.7, which indicates a limited ability to perform ADL activities independently.

The median QoL-AD score was 32.0 and the mean QoL-AD score was 31.7 (SD=5.0). To gain insight in the difference between PwD with a higher and lower QoL, the sample was divided into two QoL groups using the median QoL-AD score as the boundary. The mean QoL-AD score was 35.9 (SD=2.6) for the 'higher QoL' group ( $n=59)$ and 27.3 $(S D=2.6)$ for the 'lower QoL' group $(n=56)$. Table 1 shows the sample characteristics for the sample as a whole and for the two QoL groups. PwD with higher QoL had significantly better cognition than those with lower QoL ( $p=.006)$.

Table 1. Sample characteristics (groups defined relative to the median QoL-AD score)

\begin{tabular}{lllll}
\hline & $\begin{array}{l}\text { Total } \\
\mathrm{n}=115\end{array}$ & $\begin{array}{l}\text { Higher QoL } \\
\mathrm{n}=59\end{array}$ & $\begin{array}{l}\text { Lower QoL } \\
\mathrm{n}=56\end{array}$ & $\mathrm{p}$ value* \\
\hline Age, mean (SD) & $83.8(7.8)$ & $83.9(7.7)$ & $83.6(8.0)$ & 0.802 \\
Gender (female), \% & 75 & 78 & 71 & 0.420 \\
Marital status (widowed), \% & 66 & 70 & 63 & 0.429 \\
S-MMSE, mean (SD) & $8.5(6.9)$ & $10.1(6.6)$ & $6.5(6.7)$ & 0.006 \\
\hline
\end{tabular}

QoL-AD = Quality of Life in Alzheimer's Disease scale; QoL = quality of life; SD = standard deviation

* Independent samples t-test or chi square test of difference between the QoL groups

Description of the daily lives of PwD

In total, (115 participants * 84 observations per participant =) 9,660 observations were completed. Table 2 provides an overview of the percentage of times spent on activities, engagement, social interaction, physical effort, and the average mood and agitation scores of participating PWD during the observations. Most of the time, active, expressive, or social activities such as household activities or musical activities or 
passive/purposeless activities such as sleeping took place in the vicinity of the PwD during $34 \%$ and $31 \%$, respectively. Less time was spent on activities related to personal care $(20 \%)$, television or radio activities (8\%), and other activities (7\%). PWD were engaged in one of all these activities during $69 \%$ of the observations. However, engagement in active, expressive, or social activities occurred less frequently (31\%). PwD had any form of social interaction such as talking or eye contact during $32 \%$ of the observations. Furthermore, PwD were lying or sitting passively during $91 \%$ of their time, and were physically active (e.g. sitting with arm movements, standing, walking) during $9 \%$ of their time. Overall, PwD were content and displayed small signs of happiness (mean mood score $=4.7$ ) and agitation was rarely observed.

Table 2. Aspects of daily life for the sample as a whole and grouped according to QoL-AD score

\begin{tabular}{|c|c|c|c|c|c|}
\hline \multicolumn{2}{|c|}{ Aspect of daily life } & \multirow{2}{*}{$\begin{array}{l}\text { Total } \\
n=115\end{array}$} & \multirow{2}{*}{$\begin{array}{l}\text { Higher QoL } \\
n=59\end{array}$} & \multirow{2}{*}{$\begin{array}{l}\begin{array}{l}\text { Lower QoL } \\
n=56\end{array} \\
19\end{array}$} & \multirow{2}{*}{$\begin{array}{l}p \text { value* } \\
0.301\end{array}$} \\
\hline 1a. Activity & Personal care, \% & & & & \\
\hline & Active, expressive or social, \% & 34 & 40 & 27 & 0.000 \\
\hline & Television/radio, \% & 8 & 8 & 8 & 0.970 \\
\hline & Passive/purposeless, \% & 31 & 25 & 38 & 0.000 \\
\hline & Other, \% & 7 & 7 & 8 & 0.615 \\
\hline \multirow[t]{2}{*}{ 1b. Engagement } & Engagement in all activities together, \% & 69 & 75 & 63 & 0.000 \\
\hline & $\begin{array}{l}\text { Engagement in active, expressive, or social } \\
\text { activity, \% }\end{array}$ & 31 & 37 & 24 & 0.000 \\
\hline \multicolumn{2}{|c|}{ 2. Social interaction, $\%$} & 32 & 38 & 26 & 0.000 \\
\hline \multicolumn{2}{|c|}{ 3. Mild to intense physical effort, \% } & 9 & 10 & 8 & 0.195 \\
\hline \multicolumn{2}{|c|}{ 4. Mood: mean score (SD), range $1-\underline{7}^{+}$} & $4.7(0.2)$ & $4.8(0.1)$ & $4.7(0.2)$ & 0.000 \\
\hline \multicolumn{2}{|c|}{ 5. Agitation: mean score (SD), range $\underline{0}-4^{\dagger}$} & $0.0(0.1)$ & $0.0(0.0)$ & $0.0(0.1)$ & 0.225 \\
\hline
\end{tabular}

QoL-AD = Quality of Life in Alzheimer's Disease scale; QoL = quality of life; SD = standard deviation

* Independent samples t-tests on difference between QoL groups

${ }^{+}$Underlined score is most favorable score

The daily lives of PwD with higher and lower quality of life

\section{Bivariate analyses}

Table 2 presents an overview of the aspects of daily life of PwD with higher QoL in comparison to those with lower QoL. Active, expressive, or social activities such as household activities, musical activities or conversations with others occurred most frequently in the daily lives of PWD with high QoL (40\%). In contrast, PwD with lower QoL spent more time on passive/purposeless activities such as sleeping, sitting without doing anything, or purposeless repetitive behavior (38\%). The difference between the QoL groups was statistically significant for both activity categories $(p<.001)$. Furthermore, PwD with a higher QoL were also more frequently engaged (active participation or clear focus) in active, expressive, or social activities (37\% vs. $24 \%$, 
$\mathrm{p}<.001)$, had more social interaction such as talking or eye contact with other people ( $38 \%$ vs. $26 \%, p<.001$ ), and had higher mood scores (4.8 vs. $4.7, p<.001$ ) than those with lower QoL.

\section{Multivariate analyses}

The result of the regression analysis that focused on the association between aspects of daily life and QoL is presented in Table 3. A higher QoL was associated with having frequent social interaction $(p=.007)$, and higher mood scores $(p=.017)$. In other words, PwD who had frequent social interaction or a good mood during their day were more likely to have a good QoL than PWD who had less social interaction or lower mood scores. In addition, PwD with higher QoL scores had better cognitive abilities than PwD with lower QoL ( $p=.003)$.

Table 3. Association between aspects of daily life and QoL-AD score: regression analyses

\begin{tabular}{|c|c|c|c|c|c|c|}
\hline & \multirow[t]{2}{*}{ Estimate } & \multirow[t]{2}{*}{ Std. Error } & \multirow[t]{2}{*}{$\mathrm{t}$} & \multicolumn{2}{|c|}{ 95\% confidence interval } & \multirow[t]{2}{*}{$p$ value } \\
\hline & & & & Lower & Upper & \\
\hline Age & .025 & .054 & .460 & -.082 & .131 & .647 \\
\hline Gender & .251 & 0.973 & .258 & -1.678 & 2.181 & .797 \\
\hline Cognition (S-MMSE) & .192 & .063 & 3.026 & .066 & .317 & .003 \\
\hline Passive/purposeless activity & -.035 & .041 & -.841 & -.116 & .047 & .402 \\
\hline $\begin{array}{l}\text { Engagement in active, expressive, or } \\
\text { social activity }\end{array}$ & -.047 & .048 & -.979 & -.141 & .048 & .330 \\
\hline Social interaction & .115 & .042 & 2.763 & .032 & .197 & .007 \\
\hline Mood & 6.361 & 2.612 & 2.436 & 1.183 & 11.540 & .017 \\
\hline
\end{tabular}

QoL-AD = Quality of Life in Alzheimer's Disease scale; S-MMSE = Standardized Mini-Mental State Examination

\section{DISCUSSION}

This study showed that residents with a higher quality of life carried out less passive/purposeless activities, were more engaged in active, expressive, and social activities, had more social interaction, and had better mood scores, than residents with a lower quality of life. Corrected for age and cognition, a higher quality of life was related to having more social interaction and positive mood.

The finding that frequent social interaction is associated with higher QoL is in line with studies showing that social contact is essential for PWD and improves their QoL. ${ }^{12}$, ${ }^{13}$ However, evidence suggests that the need PwD have for social contact is often not met. ${ }^{21}$ This concern is reflected by the observations of the daily lives of PwD in the current study, which shows that PWD spend most of their time without social contact. The lack of social contact may be a result of the difficulties nursing staff experience in communicating with PwD. Evidence suggests that nurses have few interactions with 
PwD with little conversational capacity, ${ }^{22}$ and find it difficult to cope with aggressive, hostile, stubborn, resistant, and unpredictable behavior. ${ }^{23}$

The current study demonstrates an association between higher QoL and a better mood as observed in daily life. This result is in line with the majority of research that focused on concepts closely related to mood, for example depressive symptoms, affect, and happiness. ${ }^{4,} 24$ One could argue that the relationship between QoL and mood is also expected because mood is a part of the QoL construct as operationalized in the QoL-AD. The issue about whether factors such as mood should be considered correlates or a part of the QoL construct remains unresolved in the literature. ${ }^{25}$ However, it is plausible that a positive mood has a positive influence on a variety of QoL domains, e.g. social relationships and the overall judgement of QoL. Similarly, a negative mood is likely to negatively influence a variety of QoL domains such as functional abilities and social support.

It is widely recognized that it is important for PwD to be engaged in what they are doing. ${ }^{26}$ Our finding that PWD with higher QoL were more engaged in active, expressive, and social activities and did less passive/purposeless activities than PWD with lower QoL underlines the importance of activity engagement. Unexpectedly, this finding was not detected in multivariate analyses correcting for age, gender, and cognition. Other studies focusing on activity involvement suggested an association between QoL and activity engagement. ${ }^{7,9,11}$ A possible reason for the discrepancy between the current study and other studies is that most were unable to perform multivariate analyses enabling correction for potential confounders such as cognitive ability. It might be true that PwD with better cognitive abilities do more daily activities than those with less cognitive capabilities and this could have influenced the relationship between QoL and activity engagement.

Behavioral symptoms, particularly agitation, are generally thought to have a negative impact on QoL of PWD. ${ }^{5}$ In the current study, agitation was rarely observed, which made it difficult to assess how agitation was related to QoL. This result is in line with another observational study which found that nursing home residents exhibited agitation sporadically. ${ }^{27}$ A Dutch prevalence study using standardized questionnaires suggested that $85 \%$ of the PWD living in nursing homes display at least one symptom of agitation within one week. ${ }^{28}$ Although this percentage appears relatively high, having one symptom within one week might be comparable to the low average agitation level in the current study.

A major strength of the current study was that the momentary assessments enabled us to build an extensive, rich picture of the daily lives of PwD. A variety of aspects of daily life that were considered potentially relevant to QoL could be observed simultaneously using one instrument. Recall bias, that can for example occur when asking nursing staff about how frequently PwD are engaged in activities, ${ }^{15}$ was avoided. This study does, however, have some limitations. QoL evaluation may be influenced by personal values which can lead to caregivers rating PwD's QoL different and often lower 
than PwD themselves. ${ }^{29}$ It should be noted, however, that caregiver reports enabled the inclusion of all PwD living in long-term care facilities, whereas self-reports of QoL can only be obtained from PwD who are able to express themselves. In addition, the QoL$A D$ has been extensively investigated and validated ${ }^{18,30}$ and has been identified as the method of choice for evaluating QoL in PwD. ${ }^{1}$ Another limitation is related to the nature of observational research as PWD's facial expressions were sometimes difficult to interpret. As a result, the observers may have influenced the recordings of subjective constructs such as mood. To overcome this observer bias as much as possible, care staff informed the observers about PWD's background and behaviors prior to the data collection. In addition, difficulties were discussed during weekly meetings with the research team. Finally, the influence of factors such as physical health on QoL was not assessed in this study. Doing this could have led to a richer insight into associations with QoL. On the other hand, a strength of the independent variables chosen for this study was that they were assessed using momentary assessments, which are less prone to proxy bias than caregiver questionnaires.

\section{Conclusion and future directions}

The results underline the importance of social activities and a positive mood for QoL of PwD living in long-term care facilities. Social interventions to achieve and maintain frequent meaningful interactions with PwD are recommended. To gain more insight into the association between social contact and QoL, future studies could incorporate information about the quality of the interaction or the identity of the interaction partner. Psychological interventions that address mood disturbances are also important. Low mood can be explained by individual factors such as unmet needs or environmental factors, so tailored guidance is preferred over a 'one size fits all' approach. It is recommended to investigate activity categories more into detail. For example, information relating the purposefulness of specific activities to specific personal characteristics (e.g. gender) would contribute to our understanding of the relationship between QoL and activities.

Fully exploiting momentary assessments by conducting hierarchical analyses would enable the assessment of the quality of the daily lives of PwD more into depth. In addition, analysis of associations between aspects of daily life and self-reported QoL is recommended. 


\section{REFERENCES}

1. Moniz-Cook E, Vernooij-Dassen M, Woods R, et al. A European consensus on outcome measures for psychosocial intervention research in dementia care. Aging \& Mental Health 2008;12:14-29.

2. Morley JE, et al. International survey of nursing home research priorities. Journal of the American Medical Directors Association 2014a;15:309-312.

3. Lawton MP. Quality of Life in Alzheimer Disease. Alzheimer Disease and Associated Disorders 1994;8:138-150.

4. Banerjee S, Samsi K, Petrie CD, et al. What do we know about quality of life in dementia? A review of the emerging evidence on the predictive and explanatory value of disease specific measures of health related quality of life in people with dementia. International Journal of Geriatric Psychiatry 2009;24:1524.

5. Beerens HC, Zwakhalen SM, Verbeek H, et al. Factors associated with quality of life of people with dementia in long-term care facilities: A systematic review. International Journal of Nursing Studies 2013;50:1259-1270.

6. de Boer B, Beerens HC, Zwakhalen SMG, et al. Daily lives of people with dementia: development of the Maastricht Electronic Daily Life Observation-tool. International Psychogeriatrics 2016.

7. Edvardsson D, Petersson L, Sjogren K, et al. Everyday activities for people with dementia in residential aged care: associations with person-centredness and quality of life. International Journal of Older People Nursing 2014;9:269-276.

8. Giebel CM, Challis DJ and Montaldi D. A revised interview for deterioration in daily living activities in dementia reveals the relationship between social activities and well-being. Dementia 2014;0:1-14.

9. Smit D, Willemse B, de Lange J and Pot AM. Wellbeing-enhancing occupation and organizational and environmental contributors in long-term dementia care facilities: an explorative study. International Psychogeriatrics 2014;26:69-80.

10. Kuhn D, Edelman P and Fulton BR. Daytime sleep and the threat to well-being of persons with dementia. Dementia 2005;4:233-247.

11. Phinney A, Chaudhury $\mathrm{H}$ and $\mathrm{O}^{\prime}$ Connor DL. Doing as much as I can do: The meaning of activity for people with dementia. Aging \& Mental Health 2007;11:384-393.

12. Cahill S and Diaz-Ponce AM. 'I hate having nobody here. I'd like to know where they all are': Can qualitative research detect differences in quality of life among nursing home residents with different levels of cognitive impairment? Aging \& Mental Health 2011;15:562-572.

13. Moyle W, Venturto L, Griffiths S, et al. Factors influencing quality of life for people with dementia: a qualitative perspective. Aging \& Mental Health 2011;15:970-977.

14. van der Ploeg ES, Eppingstall B, Camp CJ, et al. A randomized crossover trial to study the effect of personalized, one-to-one interaction using Montessori-based activities on agitation, affect, and engagement in nursing home residents with dementia. International Psychogeriatrics 2013;25:565-575.

15. Smit D, de Lange J, Willemse B, et al. Activity involvement and quality of life of people at different stages of dementia in long term care facilities. Aging \& Mental Health 2015:1-10.

16. Shiffman S, Stone AA and Hufford MR. Ecological momentary assessment. Annual Review of Clinical Psychology 2008;4:1-32.

17. de Boer B, Hamers JPH, Beerens HC, Zwakhalen SMG, and Verbeek H. Living at the farm, innovative nursing home care for people with dementia - study protocol of an observational longitudinal study. BMC Geriatrics 2015;14:144.

18. Logsdon RG, Gibbons LE, McCurry SM and Teri L. Assessing quality of life in older adults with cognitive impairment. Psychosomatic Medicine 2002;64:510-519.

19. Molloy DW, Alemayehu E and Roberts R. Reliability of a Standardized Mini-Mental State Examination compared with the traditional Mini-Mental State Examination. American Journal of Psychiatry 1991;148:102-105. 


\section{Chapter 5}

20. de Haan R, Limburg M, Schuling J, et al. Klinimetrische evaluatie van de Barthel-Index, een maat voor beperkingen in het dagelijks leven. Nederlands Tijdschrift voor Geneeskunde 1993;137:917-921.

21. Ward R, Vass AA, Aggarwal N, et al. A different story: exploring patterns of communication in residential dementia care. Ageing and Society 2008;28:629-651.

22. Perkins $G$ and Nolan M. Purposeful activity as an indicator of quality in the care of elderly patients. British Journal of Nursing 1992;2:197-201.

23. Brodaty H, Draper B and Low LF. Nursing home staff attitudes towards residents with dementia: strain and satisfaction with work. Journal of Advanced Nursing 2003;44:583-590.

24. Dröes R-M, Boelens-Van Der Knoop EC, Bos J, et al. Quality of life in dementia in perspective An explorative study of variations in opinions among people with dementia and their professional caregivers, and in literature. Dementia 2006;5:533-558.

25. Ettema TP, Dröes RM, de Lange J, et al. A review of quality of life instruments used in dementia. Quality of Life Research 2005;14:675-686.

26. Morley JE, Philpot CD, Gill D and Berg-Weger M. Meaningful activities in the nursing home. Journal of the American Medical Directors Association 2014b;15:79-81.

27. Kolanowski A and Litaker M. Social interaction, premorbid personality, and agitation in nursing home residents with dementia. Archives of Psychiatric Nursing 2006;20:12-20.

28. Zuidema SU, Derksen E, Verhey FRJ and Koopmans RTCM. Prevalence of neuropsychiatric symptoms in a large sample of Dutch nursing home patients with dementia. International Journal of Geriatric Psychiatry 2007;22:632-638.

29. Gräske J, Fischer T, Kuhlmey A and Wolf-Ostermann K. Quality of life in dementia care-differences in quality of life measurements performed by residents with dementia and by nursing staff. Aging \& Mental Health 2012;16:819-827.

30. Thorgrimsen L, Selwood A, Spector A, et al. Whose quality of life is it anyway? The validity and reliability of the Quality of Life-Alzheimer's Disease (QoL-AD) scale. Alzheimer Disease and Associated Disorders 2003;17:201-208. 
CHAPTER

\section{Quality of Care and Quality of Life of People with Dementia Living at Green Care Farms: a cross-sectional study}

This chapter was published as: De Boer B, Hamers JPH, Zwakhalen SMG, Tan FES \& Verbeek H. Quality of Care and Quality of Life of People with Dementia Living at Green Care Farms: a Cross-Sectional Study. BMC Geriatrics, 2017:17(1):155 doi:10.1186/s12877-017-0550-0 


\section{ABSTRACT}

Background: Many countries are introducing smaller, more home-like care facilities that represent a radically new approach to nursing home care for people with dementia. The green care farm is a new type of nursing home developed in the Netherlands. The goal of this study was to compare quality of care, quality of life and related outcomes in green care farms, regular small-scale living facilities and traditional nursing homes for people with dementia.

Methods: A cross-sectional design was used. Three types of nursing homes were included: (1) green care farms; (2) regular small-scale living facilities; (3) traditional nursing homes. All participating nursing homes were non-profit, collectively funded nursing homes in the south of the Netherlands. One hundred and fifteen residents with a formal diagnosis of dementia were included in the study. Data on quality of care was gathered and consisted of outcome indicators (e.g. falling incidents, pressure ulcers), structure indicators (e.g. hours per resident per day), and process indicators (e.g. presence, accessibility and content of protocols on care delivery). Furthermore, questionnaires on cognition, dependence in activities of daily living, quality of life, social engagement, neuropsychiatric symptoms, agitation, and depression were used.

Results: Data showed that quality of care was comparable across settings. No large differences were found on clinical outcome measures, hours per resident per day, or process indicators. Higher quality of life scores were reported for residents of green care farms in comparison with residents of traditional nursing homes. They scored significantly higher on the Quality of Life - Alzheimer's disease Scale $(p<0.05, E S=0.8)$ indicating a better quality of life. In addition, residents of green care farms scored higher on three quality of life domains of the Qualidem: positive affect, social relations and having something to do $(p<0.05, E S>0.7)$. No differences with regular small-scale living facilities were found.

Conclusions: Green care farms seem to be a valuable alternative to existing nursing homes. This is important as people with dementia are a heterogeneous group with varying needs. In order to provide tailored care there also is a need for a variety of living environments.

Keywords: Dementia, Long-term care, Nursing homes, Quality of care, Quality of life, Small-scale living facilities. 


\section{BACKGROUND}

The number of people with dementia is expected to double every 20 years reaching almost 75 million by 2030 worldwide. ${ }^{1}$ A substantial proportion of people with dementia live in nursing homes because they require complex care that cannot be provided in the home situation. There is considerable debate about the quality of nursing home care for people with dementia. The care at traditional nursing homes often focusses on physical care, keeping residents safe, and preventing health care problems (e.g. ${ }^{2}$ ). However, in recent years there has been more emphasis on a psychosocial and more homelike care concept with an increased interest in values such as quality of life, autonomy and striving to allow residents of nursing homes to continue the life they had before admission as much as possible. ${ }^{3,4}$ This change in care concept can also be seen in policies, strategies or frameworks launched in many countries aimed at improving the quality of care and quality of life for people with dementia living in nursing homes.

In many countries existing nursing homes are changing, and new initiatives are developing that redesign nursing home care with the aim to better meet the needs of people with dementia and to improve the quality of care and quality of life of nursing home residents, focusing on small-scale, homelike care facilities. ${ }^{3}$ These facilities follow a psychosocial approach of care that emphasizes, normalization, quality of life and person centred care. Provision of care is organized around small groups (approximately 8 residents); residents and staff form a household together, so daily activities (cooking, cleaning, etc.) are integrated with daily care. Some studies have found that there are benefits to such small-scale, household-like facilities, such as better nutritional status, more engagement in activities and a better quality of life. ${ }^{5,6}$ However, others have reported no differences in the quality of life of residents of small, home-like facilities and residents of traditional nursing homes. ${ }^{7,8}$ Some studies suggest negative effects such as more behavioral problems [e.g. ${ }^{9}$ ]. Although there have been some studies (e.g. $\left.{ }^{10}{ }^{11}\right)$, the need for more comparative research on the effects of small-scale facilities was highlighted in a recent literature review. ${ }^{12}$

The green care farm is a new type of small-scale, homelike long-term care facility that has been developed in the Netherlands over the last few years. Green care farms combine agricultural with care activities and are aimed at involving residents in activities such as gardening, taking care of animals, household chores, and other types of activities that are incorporated into normal daily life. ${ }^{13}$ In the Netherlands, there are over 1000 green care farms for a variety of client groups (e.g. people with psychological problems, learning disabilities, or addiction problems). Approximately 200 provide care for people with dementia. There are a few green care farms that provide 24-hour nursing home care for people with dementia. Green care farms stem from developments within the agricultural sector and provide unique physical and organizational environments for dementia care. Residents of green care farms have free 
access to outdoor areas and are often exposed to outdoor stimuli (daylight, animals). The physical environment offers many possibilities for both indoor and outdoor activities such as preparing dinner, playing games, picking eggs, gardening, and feeding the animals. Activities can be performed at different areas on the farm, which invites residents to be physically active. Furthermore, because these activities fit within normal daily life, this is considerably different with more traditional nursing homes, where activities often have an institutional character (memory training, bingo). ${ }^{14}$ In addition, compared with other facilities (both large- and small-scale) the way a certain care philosophy is implemented differs considerably. At green care farms, farmers are personally involved and motivated to transfer their vision regarding person centeredness, creativity and radically redesigning dementia care to their staff. They thus often have a different leadership role than managers in existing nursing homes. ${ }^{14}$

Research on the effects of green care farms is scarce, especially research on 24-hour nursing home care. ${ }^{14,15}$ The first study of 24-hour care in green care farms indicated that there are differences between the daily lives of residents at green care farms and traditional nursing homes. Residents of green care farms took part in more activities, enjoyed more social interaction and more time spend outdoors than residents of traditional nursing homes. ${ }^{16}$

More research is needed into the differences between green care farms and existing nursing homes with respect to quality of care, quality of life and related outcomes for people with dementia. Therefore the current study investigates two research questions: How does quality of care for people with dementia differ between green care farms, regular small-scale living facilities, and traditional nursing homes?

How do quality of life and related outcomes for people with dementia differ between green care farms, regular small-scale living facilities, and traditional nursing homes?

\section{METHODS}

\section{Design}

The current study is part of a larger research project of which the protocol is published elsewhere. ${ }^{15}$ This was a cross-sectional study, comparing quality of care, quality of life and related outcomes in residents living in green care farms, regular small-scale living facilities and traditional nursing homes. Data were collected between April and October 2014.

\section{Setting}

The data for this study were collected in non-profit, collectively funded nursing homes in the south of the Netherlands. At green care farms both care and agricultural activities are important and the exterior physical environment is different from that of other 
types of nursing homes. It includes animals, stables, vegetable gardens and other features of a farm environment. Indoor and outdoor activities are incorporated into normal daily life to make it easier for residents to participate. Green care farms and regular small-scale living facilities have approximately six to eight residents and staff forms a household with the residents. There is a steady team of caregivers which have integrated tasks. Daily living is mainly determined by the residents and their informal caregivers and the physical environment is designed to be like an ordinary home environment as much as possible. Regular small-scale living facilities may be situated at the terrain of a larger nursing home or exist as stand-alone facilities in a neighbourhood. 3,15 Traditional nursing homes have at least 20 residents per ward; caregivers have differentiated tasks and daily life is mainly determined by routines and rules of the organisation.

\section{Participants}

Residents were eligible to participate in the study if their medical record included a formal diagnosis of dementia. Legal representatives were asked to provide written informed consent for participation in the study. Residents were asked to assent, which is defined as a verbal agreement to participate or a non-verbal indication of willingness to cooperate with the study. In order to increase comparability between residents in terms of cognitive and functional status, a matching procedure was conducted two weeks before the measurement. Residents of all participating locations were screened and residents of the traditional nursing homes were selected based on their screening scores in order to match with residents of green care farms and small-scale living facilities. ${ }^{15}$

\section{Measures}

All data was collected by a small trained team of researchers and research assistants under supervision of the whole research team. Standardized operating procedures that described how the data had to be collected were used.

\section{Quality of care}

Quality of care was assessed by means of outcome, structure, and process indicators. ${ }^{17}$ The outcome indicators were collected in line with the international prevalence measurement of care problems. ${ }^{18}$ Indicators that were collected were falling incidents during the last 30 days; pressure ulcers; malnutrition during the last year; use of psychotropic drugs; and use of physical restraints during the last 30 days. Structure indicators included information regarding the hours worked per resident per day (HPRD); and the educational level of caregivers. The process indicators were the 
presence, accessibility, and content of protocols about care delivery. More specific, corresponding to themes investigated by the Health Care Inspectorate (IGZ) protocols regarding 5 topics were explored: quality improvement, staff deployment, client records, physical restraints, and medication safety. These protocols were gathered by logging into electronic portals where the up to date protocols could be accessed. Outcome indicators were gathered on resident level, structure and process outcomes were gathered on ward level.

\section{Quality of life and related outcomes}

Quality of life was measured using two widely used dementia-specific questionnaires: the Quality of Life-Alzheimer's Disease scale (QoL-AD) ${ }^{19}$ and the QUALIDEM. $^{20}$ The QoL-AD uses thirteen items rated on a four-point Likert scale to assess current quality of life. The QoL-AD consists of thirteen items that are rated on a four-point Likert scale; total scores range from 13 to 52 and higher scores indicate better quality of life. Differences of three or more points in total QoL-AD score are considered meaningful. ${ }^{21}$ We used both proxy and self-report QoL-AD scores. The Qualidem consists of 37 items about the last seven days rated on a four-point Likert scale. Items are divided into nine subscales (care relationship, positive affect, negative affect, restless tense behavior, positive self-image, social relations, social isolation, feeling at home and having something to do). Both questionnaires have acceptable psychometric properties. ${ }^{20,22}$

The Revised Index for Social Engagement (RISE) was used to measure social engagement. The RISE consists of 6 dichotomous items that measure positive features of long-term care residents' social behavior in the last seven days. Scores range from 0 (minimal social engagement) to 6 (maximal social engagement). The RISE has a Cronbach's alpha coefficient of .73, and an intra-class coefficient of .75. ${ }^{23}$

The Neuropsychiatric Inventory - Nursing Home version (NPI-NH) ${ }^{24}$ was used to measure behavioral symptoms during the last month. It includes 12 neuropsychiatric symptoms (delusions, hallucinations, agitation, depression/dysphoria, anxiety, euphoria/elation, apathy/indifference, disinhibition, irritability/lability, aberrant motor behavior, nighttime disturbances, and appetite/eating change). First, the presence of the symptoms is scored (yes/no). Second, the frequency of the symptom is scored using a four-point scale: rarely (1), sometimes (2), often (3) or very often (4). Third, the severity of the symptom is scored as mild (1), moderate (2), or severe (3). Domain scores are calculated by multiplying the frequency and severity scores ${ }^{24}$. The NPI-NH was reported to have a Cronbach's alpha of .67 and convergent and discriminant validity. ${ }^{24}$

Agitation was measured using the Cohen Mansfield Agitation Inventory (CMAI), which captures the frequency of 29 agitated behaviors during the last 2 weeks using a seven-point Likert scale ranging from $1=$ never to $7=$ several times an hour. CMAI scores range from 29 to 203, with higher scores indicating more agitated behavior ${ }^{25}$. Acceptable psychometric properties were reported for the CMAI. ${ }^{26}$ 
The Cornell Scale for Depression (CSDD) ${ }^{27}$ was used to assess signs and symptoms of depression during the last seven days. It consists of 19 items on five domains: mood related signs, behavioral disturbance, physical signs, cyclic functions and ideational disturbance. All items are rated for severity using a three-point scale ( $0=$ absent; $1=$ mild or intermittent; $2=$ severe) and items scores are summed. CSDD scores range from 0 to 38 and higher scores indicate more depressive symptoms. The CSDD was found to be valid and reliable. ${ }^{28}$

\section{Background characteristics}

Information on residents' age, gender, cognition and independence in activities of daily living was collected. Age and gender data were retrieved from medical records. Cognitive impairment at the time of the study was assessed with the Standardized MiniMental State Examination (S-MMSE). ${ }^{29}$ S-MMSE scores range from 0 to 30, with higher scores indicating better cognition. The Barthel index was used to measure the current independence in activities of daily life. ${ }^{30}$ Barthel index scores range from 0 to 20 and higher scores indicate greater independence in ADL.

\section{Analyses}

First, descriptive statistics were used to explore potential differences between green care farms, traditional nursing homes, and regular small-scale living facilities with respect to background characteristics, quality of care outcomes, quality of life and related outcomes. Differences in background characteristics were then assessed using an ANOVA.

Different analysis strategies were used to analyse the quality of care outcomes. First, Fisher's exact tests were used to test for differences in outcome indicators between green care farms and the other types of nursing homes. The outcome indicators were the dependent variable, and the type of nursing home was the independent variable. Due to the low prevalence or absence of the outcome indicators in some of the nursing home types, or the sampling distribution not being Chi-square distributed, it was not possible to use a logistic regression or chi-square test. Missing values were random, and treated as such. Second, regarding the structure indicators of quality of care, a descriptive approach was used. For each participating nursing homes the average hours per resident per day (HPRD) was calculated, this was also done per educational level, the nightshift was not included in the comparison. Third, the process indicators of quality of care were subjected to a document analysis; the procedure entailed finding, selecting, appraising and synthesizing the data contained in the documents through skim-reading (superficial examination), reading (thorough examination) and interpretation. This iterative process combined elements of content analysis and thematic analyses. Protocols were explored on the following topics: presence, accessibility, and content. The document analysis was not aimed at adjudicating the 
protocols; rather it had explorative purposes to indicate whether differences between green care farms, traditional nursing homes and regular small-scale living facilities could be found. The document analysis was performed by the first author (BdB) and independently checked by the last author (HV). Differences were discussed in order to reach agreement. Furthermore, findings were discussed within the whole research team. Regarding the outcomes on quality of life and related outcomes, a two-level multilevel regression analysis was carried out, with the QoL-AD, Qualidem, RISE, NPI$\mathrm{NH}, \mathrm{CMAl}$ or Cornell as dependent variables, and the type of nursing home as the main independent variable. There was controlled for age, gender, cognition (S-MMSE), and independence in activities of daily living (Barthel index). The residents (level 1) were nested in nursing homes (level 2).

\section{RESULTS}

\section{Background characteristics}

Legal representatives of 115 of 158 eligible residents (73\%) provided informed consent for participation in the study. In total, 18 nursing home locations participated in the study, five green care farms, nine regular small-scale living facilities, and four traditional nursing homes. Table 1 provides information on the characteristics of the residents. The ANOVA did not reveal any significant group differences on background characteristics except for gender, $F(2,112)=3.75, p<0.05$. Descriptive data show that there are more female residents at regular small-scale living facilities compared with green care farms and traditional nursing homes ( $87 \%$ vs. $68 \%$ and $62 \%$ respectively). Pairwise comparisons revealed significantly more female residents at regular small-scale living facilities compared with traditional nursing homes $(p<0.05)$.

\section{Quality of care}

\section{Outcome indicators}

Table 1 shows the scores on each of the measured outcome indicators. Descriptive statistics showed that overall; residents scored similar on all outcome indicators, regardless of nursing home type. Fisher's exact test revealed no significant differences between green care farms, traditional nursing homes and regular small-scale living facilities.

\section{Structure indicators}

Table 1 shows the hours per resident per day (HPRD) for each type of nursing home. The figures were similar for green care farms, traditional nursing homes and regular small-scale living facilities. Data suggested that there were some minor differences 
between the educational levels of the staff in the different types of nursing homes. In descriptive terms there were more nurse assistants/nurse aids (less than 2 year education) and vocationally trained registered nurses (RNs) (at least 4 year education) at green care farms and traditional nursing homes than in regular small-scale residential facilities, where there were more certified nurse assistants (2-3 year education).

Table 1. Background characteristics, outcome indicators, and structure indicators

\begin{tabular}{|c|c|c|c|c|c|c|c|c|c|}
\hline \multirow[t]{2}{*}{$\begin{array}{l}\text { Background characteristics } \\
\text { (range) }\end{array}$} & \multicolumn{2}{|c|}{ Total $(\mathrm{N}=115)$} & \multicolumn{2}{|c|}{$\begin{array}{l}\text { Green care farm } \\
(\mathrm{N}=34)\end{array}$} & \multicolumn{2}{|c|}{$\begin{array}{l}\text { Traditional nursing } \\
\text { home }(N=29)\end{array}$} & \multicolumn{2}{|c|}{$\begin{array}{l}\text { Regular small- scale } \\
\text { living facility }(\mathrm{N}=52)\end{array}$} & \multirow[t]{2}{*}{ p-value } \\
\hline & M & SD & M & SD & $\mathrm{M}$ & SD & M & SD & \\
\hline Age (59-97) & 83.8 & 7.8 & 82.1 & 8.5 & 82.6 & 8.3 & 85.5 & 6.8 & 0.1 \\
\hline Gender (\% female) & 75 & & 68 & & 62 & & 87 & & 0.03 \\
\hline Barthel index (0-20) & 9.7 & 5.9 & 9.1 & 5.7 & 9.4 & 6.6 & 10.3 & 5.7 & 0.6 \\
\hline S-MMSE (0-30) & 8.4 & 6.8 & 8.1 & 6.7 & 7.5 & 7 & 9.1 & 6.9 & 0.6 \\
\hline \multirow[t]{2}{*}{ Outcome indicators } & \multicolumn{2}{|l|}{ Total } & \multicolumn{2}{|c|}{ Green care farm } & \multicolumn{2}{|c|}{$\begin{array}{l}\text { Traditional nursing } \\
\text { home }\end{array}$} & \multicolumn{2}{|c|}{$\begin{array}{l}\text { Regular small- scale } \\
\text { living facility }\end{array}$} & p-value \\
\hline & $\mathrm{N}$ & $\%$ & $\mathrm{~N}$ & $\%$ & $\mathrm{~N}$ & $\%$ & $\mathrm{~N}$ & $\%$ & \\
\hline Malnutrition & 12 & 10 & 5 & 15 & 5 & 17 & 2 & 4 & 0.1 \\
\hline Missing & 7 & 6 & 1 & 3 & 2 & 7 & 4 & 7 & \\
\hline Physical restraints & 13 & 11 & 1 & 3 & 5 & 17 & 7 & 13 & 0.1 \\
\hline Missing & 6 & 5 & 1 & 3 & 1 & 3 & 4 & 8 & \\
\hline Pressure ulcers & 7 & 6 & 4 & 12 & 0 & 0 & 3 & 6 & 0.2 \\
\hline Missing & 5 & 4 & 0 & 0 & 0 & 0 & 5 & 9 & \\
\hline Falling incidents & 16 & 14 & 6 & 18 & 3 & 10 & 7 & 13 & 0.7 \\
\hline Missing & 1 & 1 & 0 & 0 & 0 & 0 & 1 & 2 & \\
\hline Medication incidents & 4 & 4 & 0 & 0 & 1 & 3 & 3 & 6 & 0.4 \\
\hline Missing & 7 & 6 & 1 & 3 & 0 & 0 & 6 & 12 & \\
\hline Antipsychotic use & 22 & 19 & 8 & 23 & 6 & 21 & 8 & 15 & 0.6 \\
\hline Missing & 0 & 0 & 0 & 0 & 0 & 0 & 0 & 0 & \\
\hline Structure indicators & \multicolumn{2}{|l|}{ Total } & \multicolumn{2}{|c|}{ Green care farm } & \multicolumn{2}{|c|}{$\begin{array}{l}\text { Traditional nursing } \\
\text { home }\end{array}$} & \multicolumn{2}{|c|}{$\begin{array}{l}\text { Regular small- scale } \\
\text { living facility }\end{array}$} & \\
\hline $\begin{array}{l}\text { Total hours per resident per } \\
\text { day (HPRD)* }\end{array}$ & \multicolumn{2}{|l|}{3.1} & \multicolumn{2}{|l|}{3.1} & \multicolumn{2}{|l|}{3.1} & \multicolumn{2}{|l|}{3.2} & \\
\hline $\begin{array}{l}\text { HPRD nurse assistant } \\
\text { staffing/nurse aid staffing* }\end{array}$ & \multicolumn{2}{|l|}{1} & \multicolumn{2}{|l|}{1.3} & \multicolumn{2}{|l|}{1.1} & \multicolumn{2}{|l|}{0.7} & \\
\hline $\begin{array}{l}\text { HPRD Certified nurse } \\
\text { assistant staffing* }\end{array}$ & \multicolumn{2}{|l|}{1.8} & \multicolumn{2}{|l|}{1.5} & \multicolumn{2}{|l|}{1.5} & \multicolumn{2}{|l|}{2.4} & \\
\hline $\begin{array}{l}\text { HPRD Vocationally trained } \\
\text { RN staffing* }\end{array}$ & \multicolumn{2}{|l|}{0.3} & \multicolumn{2}{|l|}{0.4} & \multicolumn{2}{|l|}{0.4} & \multicolumn{2}{|l|}{0.1} & \\
\hline $\begin{array}{l}\text { HPRD baccalaureate- } \\
\text { educated RN staffing* }\end{array}$ & 0 & & 0 & & 0 & & 0 & & \\
\hline
\end{tabular}




\section{Process indicators}

Table 2 provides information regarding the content of protocols. All nursing homes had protocols covering quality improvement, staff deployment, client records, physical restraints, and medication safety. All protocols were periodically evaluated and updated if necessary. All nursing home facilities were part of, or cooperated with three larger care organizations based in the Netherlands. This means that some of the participating facilities were influenced by the same organizational rules and board of directors. The care organizations had an electronic portal through which all staff had access to the protocols. All staff was notified when protocols were added or revised via a communication folder or an organizational newsletter. The content of the protocols was similar across settings. Quality improvement protocols included provisions for client satisfaction surveys, complaint commissions, client boards, incident registration and quality labels. All nursing homes had guidelines covering supervision of residents. Client records consisted of a paper record and an electronic record containing a care plan, daily reports and client-related agreements. All the physical restraints protocols were designed to minimize physical restraints. Medication safety protocols were also similar across settings.

Table 2. Content of protocols regarding care delivery

\begin{tabular}{|c|c|}
\hline \multicolumn{2}{|c|}{ Content of protocols } \\
\hline $\begin{array}{l}\text { Quality } \\
\text { improvement }\end{array}$ & $\begin{array}{l}\text { Several activities aimed at quality improvement are described. First, all nursing homes work } \\
\text { with a client satisfaction survey which is spread out periodically to all first responsible informal } \\
\text { caregivers of the residents. Second, mechanisms for handling complaints are installed by means } \\
\text { of a 'complaint commission' and a client board. Third, all incidents are registered in a national } \\
\text { reporting system which is checked by the Health Care Inspectorate. Fourth, participating } \\
\text { nursing homes had a nationally recognized quality label which was granted after inspection. }\end{array}$ \\
\hline $\begin{array}{l}\text { Staff } \\
\text { employment }\end{array}$ & $\begin{array}{l}\text { All nursing homes had specified in their protocols that nursing home care does not mean } \\
\text { residents need to be supervised or watched } 24 \text { hours every day. Instead, nursing homes use } \\
\text { the term 'attentive supervision', which means that each resident is supervised at the level that } \\
\text { he or she needs. A general guideline is that residents are left 'unsupervised' for a maximum of } \\
\text { ten minutes. Furthermore, all participating nursing homes could use technological aids if this is } \\
\text { deemed necessary. }\end{array}$ \\
\hline Clien & $\begin{array}{l}\text { Each client has its' own personal record consisting of a paper record and an electronic one. In } \\
\text { the paper record a care agreement and the indication for a care package are included. The } \\
\text { electronic record contains a care plan, daily reports, and client-related agreements. The client } \\
\text { records need to be complete six weeks after admission (meaning it should also be evaluated } \\
\text { by family members of the resident). Each half year the client records are discussed within a } \\
\text { multidisciplinary team and if needed adjusted. }\end{array}$ \\
\hline $\begin{array}{l}\text { Physical } \\
\text { restraints }\end{array}$ & $\begin{array}{l}\text { All participating nursing homes try to reduce the physical restraints to a minimum. The goal is } \\
\text { to look for alternatives for physical restraints. However, the guidelines for these alternatives } \\
\text { differ across settings. At green care farms, there were no defined guidelines on which } \\
\text { alternatives to use when. At the other types of nursing homes it was clearly stated when to } \\
\text { use a particular alternative for physical restraints. In addition, it was determined which staff } \\
\text { was allowed to apply certain measures. At green care farms, this was left unspecified. }\end{array}$ \\
\hline $\begin{array}{l}\text { Medication } \\
\text { safety }\end{array}$ & $\begin{array}{l}\text { For medication safety, no differences were found between green care farms and other types } \\
\text { of nursing homes. All nursing homes use individual and up to date medication lists. Medication } \\
\text { is wrapped in individual doses which are kept in a medication cabinet. Only the responsible } \\
\text { physicians are allowed to alter medication prescriptions. }\end{array}$ \\
\hline
\end{tabular}




\section{Quality of life}

Table 3 shows the descriptive results of the scores related to quality of life. The results of the multilevel regression analyses are shown in Table 4. Self-reports of the QoL-AD did not differ significantly between green care farms and the other types of nursing homes, however, they did indicate a meaningful difference (3 or more points) between residents of green care farms and residents of traditional nursing homes. Results of the proxy-reports were in the same direction and did reach significance $(p<0.05, E S=0.8)$, suggesting that residents of green care farms had a better quality of life compared with residents of traditional nursing homes. In line with these findings, residents of green care farms scored higher than residents of traditional nursing homes on three Qualidem domains: positive affect, social relations and having something to do $(p<0.05, E S>0.7)$. Table 4 shows that overall, residents of green care farms and regular small-scale living facilities had similar scores on quality of life and related outcomes. No differences were found between green care farms and regular small-scale living facilities.

Table 3. Quality of life and related outcomes

\begin{tabular}{|c|c|c|c|c|c|c|c|c|}
\hline \multirow[t]{2}{*}{$\begin{array}{l}\text { Quality of life and related outcomes } \\
\text { (range) }\end{array}$} & \multicolumn{2}{|c|}{ Total $(\mathrm{N}=115)$} & \multicolumn{2}{|c|}{$\begin{array}{l}\text { Green care farm } \\
(\mathrm{N}=34)\end{array}$} & \multicolumn{2}{|c|}{$\begin{array}{l}\text { Traditional NH } \\
(\mathrm{N}=29)\end{array}$} & \multicolumn{2}{|c|}{$\begin{array}{l}\text { Regular SSL } \\
(\mathrm{N}=52)\end{array}$} \\
\hline & M & SD & M & SD & M & SD & M & SD \\
\hline QoL-AD proxy report (13- $\underline{52})$ & 31.7 & 5 & $32.9 *$ & 4.5 & $29.1^{*}$ & 4.9 & 32.5 & 4.9 \\
\hline QoL-AD self-report (13- $\underline{52})$ & $\begin{array}{l}37.3 \\
(n=66)\end{array}$ & 4.7 & $\begin{array}{l}37.6 \\
(n=21)\end{array}$ & 4.1 & $\begin{array}{l}35.2 \\
(n=15)\end{array}$ & 6 & $\begin{array}{l}38.2 \\
(n=30)\end{array}$ & 4.2 \\
\hline \multicolumn{9}{|l|}{ Qualidem } \\
\hline Care relationship $(0-\underline{21})$ & 15.1 & 4.6 & 16 & 4.9 & 14.9 & 4.2 & 14.6 & 4.6 \\
\hline Positive affect (0-18) & 14.1 & 3.7 & $15.8^{*}$ & 3.6 & $12.9 *$ & 3.5 & 13.8 & 3.6 \\
\hline Negative affect (0- $\underline{9})$ & 6 & 2.2 & 6 & 2.6 & 6.7 & 2.1 & 5.6 & 2.1 \\
\hline restless tense behavior (0-9 $)$ & 5.4 & 2.9 & 5.2 & 2.7 & 5.5 & 2.8 & 5.5 & 3 \\
\hline positive self-image (0-9 $)$ & 7.1 & 1.9 & 7.3 & 2.1 & 7.8 & 1.6 & 6.6 & 2 \\
\hline social relations $(0-\underline{18})$ & 12 & 3.7 & $13^{*}$ & 3.5 & $10.4^{*}$ & 3.8 & 12.3 & 3.6 \\
\hline Social isolation (0-9 ) & 6.5 & 2.2 & 6.9 & 2.4 & 6.7 & 1.8 & 6 & 2.3 \\
\hline feeling at home (0-12) & 9.6 & 2.5 & 9.5 & 2.9 & 9.9 & 2.2 & 9.4 & 2.3 \\
\hline having something to do $(0-\underline{6})$ & 2.7 & 2 & $3 *$ & 2.2 & $1.6^{*}$ & 1.8 & 3 & 1.9 \\
\hline RISE (0- $\underline{6})$ & 4.1 & 2 & 4.4 & 1.9 & 3.4 & 1.8 & 4.4 & 2 \\
\hline NPI-NH (ㅁ-144) & 15.9 & 15.7 & 17.3 & 17.5 & 18.6 & 14 & 13.6 & 15.3 \\
\hline CMAI (29-203) & 41.9 & 12.5 & 41.5 & 12.2 & 42.4 & 11.3 & 41.8 & 13.5 \\
\hline CSDD (ㅁ-38) & 5.4 & 4.9 & 5 & 4.4 & 6.4 & 5.4 & 5 & 4.9 \\
\hline
\end{tabular}

* Significant difference at $\alpha=.05$ 
Table 4. Random-effects regression analysis on quality of life and related outcomes controlling for age, gender, cognition (S-MMSE), and independence in activities of daily living (Barthel index).

\begin{tabular}{|c|c|c|c|c|c|c|c|c|}
\hline QoL-AD proxy report & $\begin{array}{l}\mathrm{ICC}= \\
0.21\end{array}$ & B & Std. Error B & \multicolumn{2}{|c|}{$\begin{array}{l}95 \% \text { confidence } \\
\text { interval }\end{array}$} & Variance & $P$ value & $\begin{array}{l}\text { Effect } \\
\text { size }\end{array}$ \\
\hline Traditional nursing home & & -3.7 & 1.7 & -7.2 & -.07 & 19 & $0.046^{*}$ & 0.8 \\
\hline $\begin{array}{l}\text { Regular small-scale living } \\
\text { facility }\end{array}$ & & -1.2 & 1.4 & -4.2 & 1.9 & 19 & 0.4 & 0.3 \\
\hline QoL-AD self-report & $\begin{array}{l}\mathrm{ICC}= \\
0.14\end{array}$ & B & Std. Error B & $\begin{array}{l}95 \% \\
\text { inter }\end{array}$ & fidence & Variance & $P$ value & $\begin{array}{l}\text { Effect } \\
\text { size }\end{array}$ \\
\hline Traditional nursing home & & -2.3 & 1.9 & -6.5 & 1.9 & 21 & 0.3 & 0.5 \\
\hline $\begin{array}{l}\text { Regular small-scale living } \\
\text { facility }\end{array}$ & & .09 & 1.6 & -3.4 & 3.6 & 21 & 0.9 & 0.02 \\
\hline Qualidem Care relationship & $\begin{array}{l}I C C= \\
0.07\end{array}$ & B & Std. Error B & $\begin{array}{l}95 \% \\
\text { inter }\end{array}$ & fidence & & $P$ value & $\begin{array}{l}\text { Effect } \\
\text { size }\end{array}$ \\
\hline Traditional nursing home & & -.9 & 1.4 & -3.9 & 2.1 & 20 & 0.5 & 0.2 \\
\hline $\begin{array}{l}\text { Regular small-scale living } \\
\text { facility }\end{array}$ & & -1 & 1.2 & -3.5 & 1.6 & 20 & 0.4 & 0.2 \\
\hline Qualidem Positive affect & $\begin{array}{l}\mathrm{ICC}= \\
0.12\end{array}$ & B & Std. Error B & $\begin{array}{l}95 \% \\
\text { inter }\end{array}$ & idence & & $P$ value & $\begin{array}{l}\text { Effect } \\
\text { size }\end{array}$ \\
\hline Traditional nursing home & & -2.8 & 1.2 & -5.4 & -.2 & 13 & $0.037^{*}$ & 0.7 \\
\hline $\begin{array}{l}\text { Regular small-scale living } \\
\text { facility }\end{array}$ & & -1.9 & 1 & 4.1 & .4 & 13 & 0.1 & 0.5 \\
\hline Qualidem Negative affect & $\begin{array}{l}\mathrm{ICC}= \\
0.09\end{array}$ & B & Std. Error B & $\begin{array}{l}95 \% \\
\text { inter }\end{array}$ & idence & & P value & $\begin{array}{l}\text { Effect } \\
\text { size }\end{array}$ \\
\hline Traditional nursing home & & .7 & .7 & -.7 & 2.1 & 4 & 0.3 & 0.4 \\
\hline $\begin{array}{l}\text { Regular small-scale living } \\
\text { facility }\end{array}$ & & -.05 & .6 & -1.3 & 1.2 & 4 & 0.9 & 0.3 \\
\hline $\begin{array}{l}\text { Qualidem restless tense } \\
\text { behavior }\end{array}$ & $\begin{array}{l}\mathrm{ICC}= \\
0.15\end{array}$ & B & Std. Error B & $\begin{array}{l}95 \% \\
\text { inter }\end{array}$ & fidence & & $P$ value & $\begin{array}{l}\text { Effect } \\
\text { size }\end{array}$ \\
\hline Traditional nursing home & & .3 & 1 & -1.7 & 2.4 & 7 & 0.7 & 0.1 \\
\hline $\begin{array}{l}\text { Regular small-scale living } \\
\text { facility }\end{array}$ & & .1 & .8 & -1.6 & 1.9 & 7 & 0.9 & 0.03 \\
\hline Qualidem positive self-image & $\begin{array}{l}\mathrm{ICC}= \\
0.15\end{array}$ & B & Std. Error B & $\begin{array}{l}95 \% \\
\text { inter }\end{array}$ & idence & & $P$ value & $\begin{array}{l}\text { Effect } \\
\text { size }\end{array}$ \\
\hline Traditional nursing home & & .5 & .6 & -.9 & 1.9 & 3 & 0.4 & 0.3 \\
\hline $\begin{array}{l}\text { Regular small-scale living } \\
\text { facility }\end{array}$ & & -.3 & .5 & -1.4 & .9 & 3 & 0.6 & 0.2 \\
\hline Qualidem social relations & $\begin{array}{l}\mathrm{ICC}= \\
0.13\end{array}$ & B & Std. Error B & $\begin{array}{l}95 \% \\
\text { inter }\end{array}$ & idence & & $P$ value & $\begin{array}{l}\text { Effect } \\
\text { size }\end{array}$ \\
\hline Traditional nursing home & & -2.5 & 1.1 & -4.8 & -.1 & 10 & $0.042 *$ & 0.8 \\
\hline $\begin{array}{l}\text { Regular small-scale living } \\
\text { facility }\end{array}$ & & -1.3 & .9 & -3.3 & .7 & 10 & 0.2 & 0.4 \\
\hline Qualidem Social isolation & $\begin{array}{l}\mathrm{ICC}= \\
0.19\end{array}$ & B & Std. Error B & $\begin{array}{l}95 \% \\
\text { inter }\end{array}$ & fidence & & $P$ value & $\begin{array}{l}\text { Effect } \\
\text { size }\end{array}$ \\
\hline Traditional nursing home & & -.1 & .8 & -1.9 & 1.6 & 4 & 0.9 & 0.1 \\
\hline $\begin{array}{l}\text { Regular small-scale living } \\
\text { facility }\end{array}$ & & -.8 & .7 & -2.3 & .7 & 4 & 0.3 & 0.4 \\
\hline
\end{tabular}




\begin{tabular}{|c|c|c|c|c|c|c|c|c|}
\hline Qualidem feeling at home & $\begin{array}{l}\mathrm{ICC}= \\
0.13\end{array}$ & B & Std. Error B & \multicolumn{3}{|c|}{$\begin{array}{l}\text { 95\% confidence } \\
\text { interval }\end{array}$} & $P$ value & $\begin{array}{l}\text { Effect } \\
\text { size }\end{array}$ \\
\hline Traditional nursing home & & .5 & .8 & -1.2 & 2.2 & 5 & 0.5 & 0.2 \\
\hline $\begin{array}{l}\text { Regular small-scale living } \\
\text { facility }\end{array}$ & & .3 & .7 & -1.1 & 1.8 & 5 & 0.6 & 0.1 \\
\hline $\begin{array}{l}\text { Qualidem having something } t \\
\text { do }\end{array}$ & $\begin{array}{l}\mathrm{ICC}= \\
0.16\end{array}$ & B & Std. Error B & $\begin{array}{l}95 \% \text { c } \\
\text { interv }\end{array}$ & fidence & & $P$ value & $\begin{array}{l}\text { Effect } \\
\text { size }\end{array}$ \\
\hline Traditional nursing home & & -1.3 & .6 & -2.6 & -.1 & 2 & $0.035^{*}$ & 0.9 \\
\hline $\begin{array}{l}\text { Regular small-scale living } \\
\text { facility }\end{array}$ & & -.3 & .5 & -1.3 & .8 & 2 & 0.6 & 0.2 \\
\hline RISE & $\begin{array}{l}\mathrm{ICC}= \\
0.13\end{array}$ & B & Std. Error B & $\begin{array}{l}95 \% \text { c } \\
\text { interv }\end{array}$ & fidence & & $P$ value & $\begin{array}{l}\text { Effect } \\
\text { size }\end{array}$ \\
\hline Traditional nursing home & & -.9 & .6 & -2.2 & .3 & 3 & 0.1 & 0.5 \\
\hline $\begin{array}{l}\text { Regular small-scale living } \\
\text { facility }\end{array}$ & & -.3 & .5 & -1.4 & .8 & 3 & 0.6 & 0.2 \\
\hline NPI-NH & $\begin{array}{l}\mathrm{ICC}= \\
0.08\end{array}$ & B & Std. Error B & $\begin{array}{l}95 \% \text { c } \\
\text { interv }\end{array}$ & fidence & & $P$ value & $\begin{array}{l}\text { Effect } \\
\text { size }\end{array}$ \\
\hline Traditional nursing home & & 1.4 & 4.7 & -8.9 & 11.6 & 230 & 0.8 & 0.3 \\
\hline $\begin{array}{l}\text { Regular small-scale living } \\
\text { facility }\end{array}$ & & -2.3 & 4.2 & -11.1 & 6.5 & 230 & 0.6 & 0.2 \\
\hline CMAI & $\begin{array}{l}\mathrm{ICC}= \\
0.21\end{array}$ & B & Std. Error B & $\begin{array}{l}95 \% \text { c } \\
\text { interv }\end{array}$ & fidence & & $P$ value & $\begin{array}{l}\text { Effect } \\
\text { size }\end{array}$ \\
\hline Traditional nursing home & & .9 & 4.7 & -9.3 & 11 & 153 & 0.9 & 0.1 \\
\hline $\begin{array}{l}\text { Regular small-scale living } \\
\text { facility }\end{array}$ & & 1.3 & 4.1 & -7.4 & 9.9 & 153 & 0.8 & 0.1 \\
\hline CSDD & $\begin{array}{l}\mathrm{ICC}= \\
0.11\end{array}$ & B & Std. Error B & $\begin{array}{l}95 \% \mathrm{c} \\
\text { interv }\end{array}$ & fidence & & $P$ value & $\begin{array}{l}\text { Effect } \\
\text { size }\end{array}$ \\
\hline Traditional nursing home & & .8 & 1.5 & -2.5 & 4.1 & 22 & 0.6 & 0.2 \\
\hline $\begin{array}{l}\text { Regular small-scale living } \\
\text { facility }\end{array}$ & & .1 & 1.3 & -2.8 & 2.9 & 22 & 0.96 & 0.02 \\
\hline
\end{tabular}

* Significant difference at $\alpha=.05$

\section{DISCUSSION}

The findings of this study indicate that overall quality of care at green care farms is comparable with quality of care at regular small-scale living facilities and traditional nursing homes. Similar scores were found on outcome indicators such as falling incidents and pressure ulcers. In addition, the hours per resident per day did not differ across settings. Lastly, all types of nursing homes had comparable protocols present, and accessibility and content of the protocols differed minimally. Looking at quality of life and related outcomes, some findings suggest that residents of green care farms had a better quality of life than residents of traditional nursing homes.

Limitations of the study must be acknowledged: the cross-sectional design, lack of randomization and the fairly small sample size. The cross-sectional design means that 
we could not determine the causal relationships between type of nursing home and the outcome variables. Ideally there should be a large, randomized controlled study of newly admitted residents covering more nursing homes and following residents over a longer period of time. Although this kind of study would produce more generalizable findings, it has several ethical and practical drawbacks. Randomization of residents to different types of nursing homes is not feasible, as people with dementia and their family caregivers are free to go to the nursing home of their choice. Furthermore, there are still very few green care farms providing 24-hour care, making it impossible to include more green care farm residents. In addition, another limitation has to do with the way data was collected. Green care farms, regular small-scale living facilities and traditional nursing homes all operate within the same health system, with the same legislation, funding, and quality assurance systems (including health care inspectorate visits). ${ }^{14}$ This study shows that all three types of nursing homes adhere to these regulations. However, information gathered in this study on process indicators of quality of care might not paint a reliable picture on the actual care processes at the different types of nursing homes. Future studies should also focus on whether care process guidelines are adhered to in daily care practice by for instance performing observations or conducting interviews with formal caregivers.

The current study suggests a better quality of life at green care farms compared with traditional nursing homes. Difference in the daily life of residents at these different types of nursing homes may influence their quality of life. Previous research indicates that people with dementia at green care farms were more engaged in activities and had more social interaction than people with dementia at regular care facilities, both in daycare and in nursing home care. ${ }^{16,} 31$ Being engaged in activities, and having social interactions are both important factors influencing quality of life. ${ }^{7,} 32$ The green care farms included in this study focus on the remaining capabilities of people with dementia and try to use them as the basis for tailored activities that are integrated into normal daily care. For instance, residents who are still mobile are asked to help with milking the cows and residents who are still able to cook are asked to help with preparing dinner.

Another factor which may explain why residents at green care farms have a better quality of life is the physical environment. The integration of activities and care may be enhanced because the physical environment of green care farms includes, for instance, open doors, large outdoor freely accessible spaces, gardens and stables. Several studies have indicated the importance of the physical environment to people with dementia. ${ }^{32,}$ ${ }^{33}$ Beerens and colleagues (2016) showed that residents who frequently participated in outdoor activities had higher mood scores than residents who went outdoors less often. Furthermore, several reviews indicate that factors such as privacy, autonomy, view, nature, orientation, safety and domesticity are important aspects of the physical environment and can have an effect on people with dementia. ${ }^{33}$ It is plausible that green care farms have a physical environment that has a large potential to be beneficial for their residents. 
However, just making changes to the physical environment of a nursing home is not sufficient to obtain the potential beneficial effects. Nursing staff play an important role in ensuring that the physical environment of a nursing home is used to its full potential. We found no difference in the staff-resident ratio across the different types of nursing homes. Our results suggest that differences in quality of life cannot be explained by staffing levels. There is evidence that improving quantitative measures of staffing is not sufficient to improve care quality; the quality of staff is also important. ${ }^{734}$ Within green care farms and regular small-scale living facilities, care staff has different roles and tasks compared with traditional nursing homes. ${ }^{3}$ Even though many existing nursing homes are moving towards more focus on person-centred care, and engaging people with dementia in meaningful activities, this remains a struggle for many nursing homes. Future research should focus on how we can implement successful factors of innovative nursing homes into other settings by for instance studying on how to integrate the different tasks of staff.

Despite unique features in the physical and organizational environment of green care farms, the current study did not find any differences between green care farms and regular small-scale living facilities regarding quality of life and quality of care. This makes sense, considering they provide care according to the same underlying psychosocial care concept with normalization as an important guiding principle ${ }^{3}$. Although a previous study did found differences on the amount of physical activity of residents of green care farms and regular small-scale living facilities, ${ }^{16}$ the differences in the environment are not translated into quality of life related outcomes.

Our findings have some implications for practice and education. There should be more focus on determining which staff competences are positively associated with care quality and residents' quality of life in nursing homes. There is an increased interest in the concept of psychosocial care, which emphasizes e.g. person-centred care and provision of meaningful activities." ${ }^{3,4}$ However, in practice this remains difficult to achieve. More attention should be paid to finding ways for nursing staff to integrate activities into daily care practices and matching everyday activities to individual residents' preferences and needs. Lastly, it is important to keep different perspectives in mind. This study shows that people with dementia score their quality of life differently than proxies do. Previous research also shows that people with dementia and caregivers do not consider the same domains to be important for their quality of life. $^{35}$ It is important that the perspective of the people with dementia remains the starting point for providing person-centred care. Qualitative studies on the experiences of people with dementia and their informal caregivers can be beneficial for exploring their perspectives on the care provided at different types of nursing homes. 


\section{Conclusions}

In conclusion this study shows that green care farms are a valuable alternative to existing nursing homes. This is important as people with dementia are a heterogeneous group with varying needs. In order to provide tailored care there also is a need for a variety of living environments.

\section{Ethics approval}

According to Dutch law, a study in which participants are not subjected to an intervention or are not required to follow rules of behavior does not require approval by a medical ethical review committee. This study was declared not to be invasive for people with dementia by the medical ethics committee of the Maastricht University Medical Centre (14-05-003). Legal representatives of the residents provided written informed consent and the residents themselves gave assent to participation. 


\section{REFERENCES}

1. Prince M, Wimo A, Guerchet M, Ali G, Wu Y, Prina M. World Alzheimer Report 2015. The global impact of dementia. An analysis of prevalence, incidence, cost \& trends. Alzheimer's Disease International: London. 2015.

2. Graziano Onder M, Finne-Soveri H, Lukas A, Denkinger MD, Carfi A, Vetrano DL et al. Physical Restraint and Antipsychotic Medication Use Among Nursing Home Residents With Dementia. 2016.

3. Verbeek H, van Rossum E, Zwakhalen SM, Kempen GI, Hamers JP. Small, homelike care environments for older people with dementia: a literature review. International Psychogeriatrics 2009;21(02):252-64.

4. Tolson D, Rolland Y, Andrieu S, Aquino J-P, Beard J, Benetos A et al. International Association of Gerontology and Geriatrics: A global agenda for clinical research and quality of care in nursing homes. Journal of the American Medical Directors Association 2011;12(3):184-9.

5. Wolf-Ostermann K, Meyer S, Fleischer-Schlechtiger N, Gräske J, Worch A. Comparison of the nutritional status of residents in shared-housing arrangements and nursing homes. Alzheimer's \& Dementia: The Journal of the Alzheimer's Association 2013;9(4):P606.

6. Kane RA, Lum TY, Cutler LJ, Degenholtz HB, Yu TC. Resident Outcomes in Small-House Nursing Homes: A Longitudinal Evaluation of the Initial Green House Program. Journal of the American Geriatrics Society 2007;55(6):832-9.

7. de Rooij AH, Luijkx KG, Schaafsma J, Declercq AG, Emmerink PM, Schols JM. Quality of life of residents with dementia in traditional versus small-scale long-term care settings: a quasi-experimental study. International Journal of Nursing Studies 2012;49(8):931-40.

8. Verbeek H, Zwakhalen SM, van Rossum E, Ambergen T, Kempen GI, Hamers JP. Dementia care redesigned: Effects of small-scale living facilities on residents, their family caregivers, and staff. Journal of the American Medical Directors Association 2010;11(9):662-70.

9. Onishi J, Suzuki Y, Umegaki H, Endo H, Kawamura T, Imaizumi M et al. Behavioral, psychological and physical symptoms in group homes for older adults with dementia. International Psychogeriatrics 2006;18(01):75-86.

10. de Rooij AH, Luijkx KG, Declercq AG, Schols JM. Quality of life of residents with dementia in long-term care settings in the Netherlands and Belgium: design of a longitudinal comparative study in traditional nursing homes and small-scale living facilities. BMC Geriatrics 2011;11(1):20.

11. Willemse BM, Smit D, de Lange J, Pot AM. Nursing home care for people with dementia and residents' quality of life, quality of care and staff well-being: design of the Living Arrangements for people with Dementia (LAD)-study. BMC Geriatrics 2011;11(1):11.

12. Ausserhofer D, Deschodt M, De Geest S, van Achterberg T, Meyer G, Verbeek H et al. "There's No Place Like Home": A Scoping Review on the Impact of Homelike Residential Care Models on Resident-, Family-, and Staff-Related Outcomes. Journal of the American Medical Directors Association 2016.

13. Hassink J, Grin J, Hulsink W. Multifunctional Agriculture Meets Health Care: Applying the Multi-Level Transition Sciences Perspective to Care Farming in the Netherlands. Sociologia Ruralis 2013;53(2):22345.

14. de Bruin S, de Boer B, Beerens H, Buist Y, Verbeek H. Rethinking Dementia Care: The Value of Green Care Farming. Elsevier; 2017.

15. de Boer B, Hamers J, Beerens H, Zwakhalen S, Tan F, Verbeek H. Living at the farm, innovative nursing home care for people with dementia-study protocol of an observational longitudinal study. BMC Geriatrics 2015;15(1):144.

16. De Boer B, Hamers J, Zwakhalen S, Tan F, Beerens H, Verbeek H. Green Care Farms as Innovative Nursing Homes, Promoting Activities and Social Interaction for People with Dementia. Accepted for publication in: Journal of the American Medical Directors Association. 2016.

17. Donabedian A. The quality of care: how can it be assessed? Journal of the American Medical Association 1988;260(12):1743-8. 


\section{Chapter 6}

18. Nie-Visser NC, Schols JM, Meesterberends E, Lohrmann C, Meijers JM, Halfens RJ. An international prevalence measurement of care problems: study protocol. Journal of Advanced Nursing 2013;69(9):e18-e29.

19. Logsdon RG, Gibbons LE, McCurry SM, Teri L. Quality of life in Alzheimer's disease: patient and caregiver reports. Journal of Mental Health and Aging 1999;5:21-32.

20. Ettema TP, Dröes RM, de Lange J, Mellenbergh GJ, Ribbe MW. QUALIDEM: development and evaluation of a dementia specific quality of life instrument-validation. International Journal of Geriatric Psychiatry 2007;22(5):424-30.

21. Selwood A, Thorgrimsen L, Orrell M. Quality of life in dementia-a one-year follow-up study. International Journal of Geriatric Psychiatry 2005;20(3):232-7.

22. Thorgrimsen L, Selwood A, Spector A, Royan L, de Madariaga Lopez M, Woods R et al. Whose quality of life is it anyway?: The validity and reliability of the Quality of Life-Alzheimer's Disease (QoL-AD) scale. Alzheimer Disease \& Associated Disorders 2003;17(4):201-8.

23. Gerritsen DL, Steverink N, Frijters DH, Hirdes JP, Ooms ME, Ribbe MW. A revised Index for Social Engagement for long-term care. Journal of Gerontological Nursing 2008;34(4):40-8.

24. Lange RT, Hopp GA, Kang N. Psychometric properties and factor structure of the Neuropsychiatric Inventory Nursing Home version in an elderly neuropsychiatric population. International journal of Geriatric Psychiatry 2004;19(5):440-8.

25. Cohen-Mansfield J. Instruction manual for the Cohen-Mansfield agitation inventory (CMAI). Research Institute of the Hebrew Home of Greater Washington. 1991.

26. Finkel SI, Lyons JS, Anderson RL. Reliability and validity of the Cohen-Mansfield agitation inventory in institutionalized elderly. International Journal of Geriatric Psychiatry 1992;7(7):487-90.

27. Alexopoulos GS, Abrams RC, Young RC, Shamoian CA. Cornell scale for depression in dementia. Biological Psychiatry 1988;23(3):271-84.

28. Kørner A, Lauritzen L, Abelskov K, Gulmann N, Marie Brodersen A, Wedervang-Jensen T et al. The geriatric depression scale and the cornell scale for depression in dementia. A validity study. Nordic Journal of Psychiatry 2006;60(5):360-4.

29. Molloy DW, Alemayehu E, Roberts R. Reliability of a standardized mini-mental state examination compared with the traditional mini-mental state examination. American Journal of Psychiatry 1991;148(1):102-5.

30. Collin C, Wade D, Davies S, Horne V. The Barthel ADL Index: a reliability study. International Disability Studies 2009.

31. Bruin SRD, Oosting SJ, Kuin Y, Hoefnagels EC, Blauw YH, Groot LCD et al. Green care farms promote activity among elderly people with dementia. Journal of Housing for the Elderly 2009;23(4):368-89.

32. Beerens $\mathrm{H}$. Adding life to years: quality of life of people with dementia receiving long-term care: Maastricht University; 2016

33. Fleming R, Crookes PA, Sum S. A review of the empirical literature on the design of physical environments for people with dementia. 2008.

34. Backhaus R, van Rossum E, Verbeek H, Halfens R, Tan F, Capezuti E et al. Quantity of Staff and Quality of Care in Dutch Nursing Homes: A Cross-Sectional Study. Journal of Nursing Home Research 2016;2:90-3.

35. Dröes R-M, Boelens-Van Der Knoop EC, Bos J, Meihuizen L, Ettema TP, Gerritsen DL et al. Quality of life in dementia in perspective An explorative study of variations in opinions among people with dementia and their professional caregivers, and in literature. Dementia 2006;5(4):533-58. 


\section{CHAPTER}

\section{Positive and Negative Experiences of Informal Caregivers of People with Dementia Living in Green Care Farms, Small-scale Living}

Facilities, and Traditional Nursing Homes.

This chapter was submitted for publication as: De Boer B, Hamers JPH, Zwakhalen SMG

\& Verbeek H. Positive and Negative Experiences of Informal Caregivers of People with Dementia Living in Green Care Farms, Small-scale Living Facilities, and Traditional Nursing Homes 


\section{ABSTRACT}

Objectives: Little is known about the experiences of informal caregivers within the innovative, small-scale, home-like nursing homes that are developing worldwide. The aim of this study was to explore their positive and negative experiences with regard to green care farms, other small-scale living facilities, and traditional nursing homes.

Methods: Semi-structured interviews with 43 informal caregivers were conducted. Topics discussed were: reasons for choice of a particular type of nursing home; positive and negative experiences within the nursing home. Thematic analysis including an iterative process of open, axial and selective coding, was used.

Results: Person-centeredness, the opportunity to participate in daily activities, and the physical environment/atmosphere played important roles when choosing for green care farms and other small-scale living facilities. Often, informal caregivers actively avoided nursing homes with a clinical, hospital-like atmosphere. At traditional nursing homes less deliberate considerations were made, since usually rapid action was required due to crisis situations. Furthermore, both positive and negative experiences regarding communication and individual staff members appeared across all types of nursing homes.

Conclusion: Person-centeredness, a home-like atmosphere, participation in activities, communication and involvement of staff were considered to be important for people with dementia in all types of nursing homes. Green care farms were considered to be better able to provide residents with a stimulating environment that provides personcentred care. Besides these differences between types of nursing homes, experiences were often related less to the professional competencies of individual nursing staff than to their interpersonal, 'human' qualities.

Keywords: Experiences; Green Care Farms; Informal Caregivers; Nursing Homes; Smallscale Living 


\section{INTRODUCTION}

Dementia not only influences the lives of the people with dementia themselves, it also has an impact on the lives of the family. ${ }^{1}$ Caring for a person with dementia can lead to a significant physical and emotional burden. ${ }^{2}$ A substantial group of people with dementia eventually has to be admitted to a nursing home. ${ }^{3}$

Resolving on a nursing home admission has been described as the most difficult decision for informal caregivers. ${ }^{4}$ In the Netherlands people with dementia and their caregivers are free to choose their own nursing home after admission is indicated. There is a wide array of publicly-funded types of nursing homes which people can choose from, including traditional nursing homes, and various small-scale, home-like facilities. ${ }^{5}$ Traditional nursing homes often have an institutional character and provide care for a group of 20 or more residents on a ward; caregivers have differentiated tasks and daily life is mainly determined by routines and rules of the organisation. Small-scale living facilities have a home-like character and provide care for a group of six to eight residents. Caregivers form a joint household with the residents, meaning they have integrated tasks, and cook, clean, and do other household chores together with the residents $^{6}$. Most recently, green care farms providing 24-hour nursing care have been added to the spectrum of available nursing homes for people with dementia. Green care farms are small-scale facilities providing nursing care for people with dementia in a home-like environment on the terrain of a farm. ${ }^{6}$ Care and agricultural activities are combined, meaning that residents are involved in activities such as gardening, household chores, and other activities that are incorporated into normal daily life.

It is known that perceptions of informal caregivers about their ability to provide care for the person with dementia is a factor influencing nursing home admission. ${ }^{4}$ This is supported by a study by Ducharme and colleagues (2012). They also propose that informal caregivers undertake a cognitive evaluation of the situation before deciding on institutionalisation (modulated by interactions with family members, health care professionals, and visits to prospective living environments). ${ }^{7}$ However, it is questionable whether the decision is always such a rational one, as institutionalisation is often postponed until no other alternative is present and is accompanied with stressors such as emotional burden, struggling with the decision, feelings of guilt, and practical issues (e.g. waiting lists). ${ }^{8-11}$

Furthermore, little is known about why people with dementia and their family members choose a particular type of nursing home. In a study on day care services at green care farms it was suggested people deliberately chose for green care farms because of their dislike of the institutional environment of regular day care facilities. Green care farms were perceived as more useful, more meaningful, and providing more opportunities to be physically active and to go outdoors. ${ }^{12}$ It is not known whether these findings can be transferred to the nursing home sector. Knowledge about why informal caregivers choose a particular type of nursing home, and their experiences 
with these different settings can be of great importance given the increased focus on person-centred care. ${ }^{13}$ Research states that the surroundings of a nursing home should be personalised and that activities should be performed that promote a good life as determined by the needs and preferences of the individual with dementia. ${ }^{13,14}$ This indicates that having a match between the needs and wishes of the person with dementia and the environment can promote the delivery of person-centred care, ${ }^{15}$ which emphasizes the importance of the decision for a particular nursing home environment.

The purpose of this study is to explore from the perspective of the informal caregivers the process of choosing a particular type of nursing home for their relative with dementia. Furthermore, positive and negative experiences of the care environment of informal caregivers of people with dementia living in green care farms, regular small-scale living facilities, and traditional nursing homes are explored.

\section{METHODS}

\section{Design}

This study is part of a larger project that studies the impact of green care farms providing nursing home care for people with dementia $(n=115) .{ }^{6}$ The current study has a qualitative research design and investigates the experiences of the primary informal caregivers of people with dementia living in green care farms, regular small-scale living facilities, and traditional nursing homes for people with dementia. It follows a phenomenological research approach aimed at understanding people's experiences. ${ }^{16}$

\section{Setting}

Eighteen locations divided over three types of nursing homes were included in this study, all located in the southern part of the Netherlands. Table 1 gives a description of the nursing home types. There is a majority of regular small-scale living facilities because these included both stand-alone facilities and small-scale facilities on the terrain of larger nursing homes. 
Table 1. Overview of the included types of nursing homes.

\begin{tabular}{ll}
\hline Nursing home type & Description \\
\hline $\begin{array}{l}\text { Green care farm } \\
\text { (5 locations) }\end{array}$ & $\begin{array}{l}\text { A stand- alone small-scale facility providing in which both care and agricultural } \\
\text { activities are important. Approximately eight residents live together in a house on } \\
\text { the farm. Residents and staff form a joint household. Cooking in the home and a } \\
\text { steady team of caregivers which have integrated tasks }\end{array}$ \\
$\begin{array}{l}\text { Regular small-scale living } \\
\text { facility (9 locations) }\end{array}$ & $\begin{array}{l}\text { Similar to green care farm, with differences in the physical environment. Six to } \\
\text { eight residents, also comprising a joint household with cooking done in the } \\
\text { home. Daily living is mainly determined by the residents and informal caregivers } \\
\text { and the physical environment approaches a home-like situation as much as } \\
\text { possible }{ }^{5} \text {. Small-scale living facilities can be stand-alone in a neighbourhood, or } \\
\text { clustered on the area of a larger nursing home. } \\
\text { At least 20 residents on the ward; often with shared bedrooms, caregivers here } \\
\text { have differentiated tasks and daily life is mainly determined by routines and rules } \\
\text { of the organisation }{ }^{5} .\end{array}$ \\
\hline 4
\end{tabular}

\section{Study population}

A convenience sample ${ }^{16}$ of the informal caregivers of people with dementia participating in the original research project $(n=115)^{6}$ was used in this study. Sampling aimed to include the informal caregiver closest to the person with dementia, who was involved both in the decision making process and in caregiving after admission. Therefore the first contact persons of the resident were asked to participate. If they indicated that someone else was closer to the resident, this person was included. Data collection stopped when themes and categories in the data became repetitive and redundant.

\section{Data collection}

Characteristics of the informal caregivers were gathered (i.e. age, gender, marital status, and relationship to the resident). Semi-structured interviews ${ }^{16}$ were used. Three themes were discussed in each interview: 1) reasons for the choice of a particular type of nursing home, 2) caregivers' positive experiences with the nursing home, and 3) caregivers' negative experiences with the nursing home. Table 2 provides an overview of the topic list with example questions.

Table 2. Topic list and example questions for interview

\begin{tabular}{ll}
\hline Topic & Example questions \\
\hline Reasons for choice & "What factors did you take into consideration when choosing this nursing home?" \\
& "Did you have any expectations about the nursing home?" \\
Positive experiences & "When you look at the nursing home and its direct environment, what do you believe \\
& to be positive aspects of the nursing home?" \\
& "Can you explain why [topic] is important to you? \\
Negative experiences & "What are experiences you had that in hindsight you see as negative experiences? \\
& "You mentioned negative experiences about [topic], what do you think are the causes \\
& of them?"
\end{tabular}




\section{Procedure}

Informal caregivers received an information letter. This letter included an informed consent form. When they agreed to participate in the current study, a date and location for the interview was planned. First, the interviews were practiced within the research team; the first interview was performed by the first author and a trained research assistant, who performed all other interviews. The interviews were recorded and, after the interview, a written transcript was made. In order to increase the credibility and confirmability of the data, a member check was conducted: a summary of a subset of the transcripts was given to the participants in order to check whether they agreed on the content of the particular transcript. ${ }^{16}$ The interviews lasted on average approximately 30 minutes.

\section{Analysis}

The data were analysed using qualitative data analysis software MAXQDA. ${ }^{17} \mathrm{~A}$ thematic analyses approach was used following the steps identified in previous research. ${ }^{18,19}$ The data were systematically searched to identify patterns in order to provide a description of the topics investigated. A combination of open, axial and selective coding was used. ${ }^{16}$ First the researchers read through the transcripts several times and started to create labels for chunks of data that summarised the main message. During this stage it was determined whether chunks of data belonged to 'reasons of choice', 'positive experiences', or 'negative experiences', and a label was given to the chunks of data (e.g. 'reason of choice - close to home', 'positive experience - opportunity to participate in activities', 'negative experience - lack of communication with informal caregivers'. Relationships between codes were identified by means of axial coding. In this stage of the analysis codes that were identified during open coding were linked. Some themes came to the fore as being important factors in the choice of a particular nursing home, and were also often mentioned when talking about positive and negative experiences (e.g. 'activities', 'communication', 'physical environment'). Keeping these main points of interest in mind, selective coding led to the core themes discussed in the current paper. During this last stage, nuances, and differences between the types of nursing homes were identified. Figure 1 shows an overview of the steps taken during the analyses. The whole analysis was an iterative process. The interviews were coded by the first author and independently checked by the last author. 


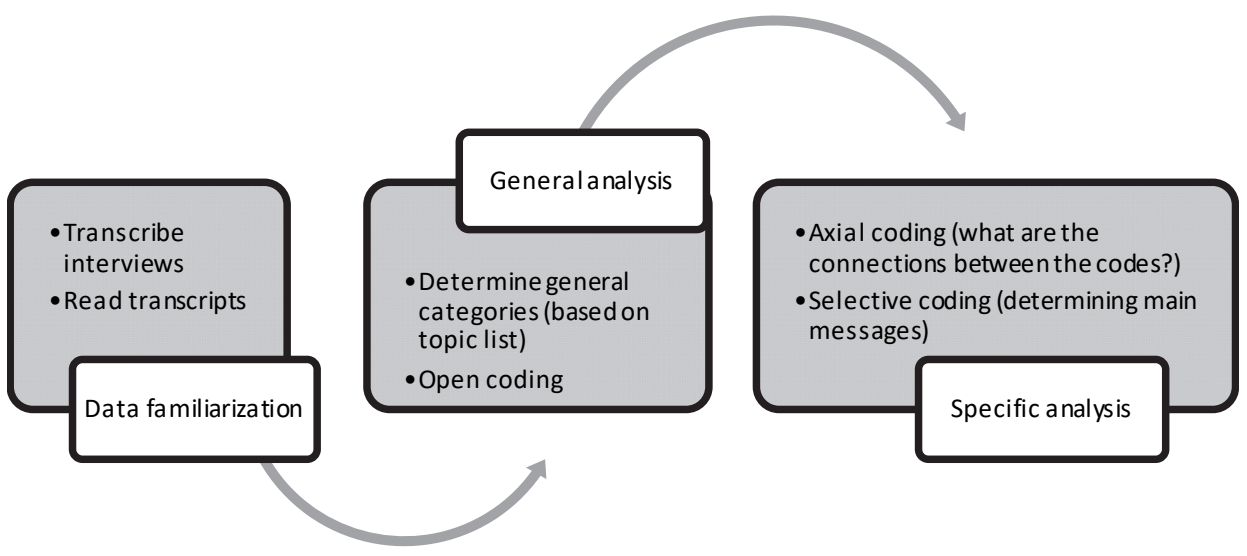

Figure 1. Data analysis process

\section{Ethics}

This study was declared not to be invasive for people with dementia and their informal caregivers by the medical ethics committee of the Maastricht University Medical Centre (14-05-003). Legal representatives of the residents provided written informed consent.

\section{RESULTS}

In total, 85 informal caregivers were approached for an interview, 43 informal caregivers were interviewed (14 informal caregivers declined to participate; the rest were not available at the time of the data collection). Table 3 gives an overview of the sample characteristics of the informal caregivers.

Table 3.Characteristics informal caregivers of nursing home residents

\begin{tabular}{|c|c|c|c|c|c|c|c|c|}
\hline & \multicolumn{2}{|c|}{ Total $(\mathrm{N}=43)$} & \multicolumn{2}{|c|}{$\begin{array}{l}\text { Traditional } \\
\text { nursing home } \\
\text { ward }(\mathrm{N}=11)\end{array}$} & \multicolumn{2}{|c|}{$\begin{array}{l}\text { Green care } \\
\text { Farm }(N=10)\end{array}$} & \multicolumn{2}{|c|}{$\begin{array}{l}\text { Regular small- } \\
\text { scale living } \\
\text { facility }(\mathrm{N}=22)^{*}\end{array}$} \\
\hline \multicolumn{9}{|l|}{ Informal caregiver } \\
\hline Age (SD) & \multicolumn{2}{|c|}{$58(11)$} & \multicolumn{2}{|c|}{$64(13)$} & \multicolumn{2}{|c|}{$54(10)$} & \multicolumn{2}{|c|}{$56(8)$} \\
\hline \multirow[t]{2}{*}{ Gender } & $\mathrm{F}$ & M & $\mathrm{F}$ & M & $\mathrm{F}$ & M & $\mathrm{F}$ & M \\
\hline & 35 & 8 & 7 & 4 & 7 & 3 & 21 & 1 \\
\hline Relationship (\% son/daughter) & \multicolumn{2}{|l|}{$74 \%$} & \multicolumn{2}{|c|}{$45 \%$} & \multicolumn{2}{|c|}{$70 \%$} & \multicolumn{2}{|c|}{$96 \%$} \\
\hline \multicolumn{3}{|l|}{ Marital status informal caregiver (\% married)** 79\% } & \multicolumn{2}{|c|}{$80 \%$} & \multicolumn{2}{|c|}{$88 \%$} & \multicolumn{2}{|c|}{$75 \%$} \\
\hline
\end{tabular}

* Regular small-scale living facilities consist of two types: stand-alone living facilities in a neighbourhood and small-scale living facilities on the terrain of a larger nursing home.

** Five participants did not share their marital status 


\section{Choice of a particular type of nursing home}

The decision on a particular type of nursing home varied across setting. Informal caregivers of people with dementia living in green care farms and regular small-scale living facilities made a deliberate decision for their nursing home, as opposed to informal caregivers choosing traditional nursing homes. When considering green care farms, they had actively looked for a nursing home that matched the preferences, backgrounds, and living experiences of their relatives.

'We chose this care farm because my father has an agricultural background. He grew up on a farm and is familiar with the life of a farmer. He was a sheep breeder, which has been his most important occupation. And because this is a farm where there are a lot of animals and vegetables being cultivated it is like going back to his roots.' [GCF506]

In contrast, at traditional nursing homes, the majority of informal caregivers mentioned practical reasons for their choice, such as the fact that there was a spot available or the referral came via the care organisation. Often rapid action was required because living at home was not possible anymore, and the caregivers did not look further.

'It has to do with the speed at which the decision had to be made. My mother actually had a preference for another nursing home, but we decided to choose this one because there was a spot available'. [TRAD906]

Avoidance of traditional nursing homes with a clinical atmosphere was mentioned as a reason to choose a small-scale, home-like facility or a green care farm. Informal caregivers elaborated on this, stating that they did not want their relative to live in facilities that they often described as 'hospital-like settings'.

'Well, we had a very clear image of what we didn't want. We did not want a large facility in an apartment building with long corridors and large groups of people living together with changing caregivers. Food coming fully prepared from a general kitchen and activities only being performed in large groups. That is what we didn't want. So then you start looking for small-scale facilities.' [GCF1601]

The characteristics of small-scale, living facilities, in which a situation as closest to home is stimulated, was mentioned as an important factor by informal caregivers in choosing this type of nursing home.

'This small-scale living facility is just more home-like (than a traditional nursing home). There are always the same nursing staff, which makes it easier to get to know each other. Furthermore, the residents can also help with cooking, for instance by peeling the potatoes. These things they have done all their lives, and here they can still do this.' [SSL1102] 
In general, across all types of nursing homes, activities were mentioned as an important factor. The fact that people with dementia could continue the lives they had before admission as far as possible was very important in green care farms and regular smallscale living facilities. People chose small-scale living facilities (including green care farms) because of the integration of activities in routines of everyday life. Activities were perceived as meaningful and giving residents the opportunity to contribute something.

'So we also looked at what she could do here, and she can pick up the eggs here, she can get milk from the cows. And if she wants she can work in the garden, or just have a walk outside. There are goats, chickens, rabbits, cows, and the way life is, it is just like a real farm, that's it.' [GCF408]

On the other hand, people opted for a traditional nursing home because they provide residents with a lot of centrally organised activities for entertainment such as music activities or bingo.

\section{Experiences with the care environment}

The positive and negative experiences of informal caregivers with the care environment could be clustered within five themes: (1) physical environment and atmosphere, (2) activities, (3) person-centred care, (4) communication, and (5) staff. In general, informal caregivers agreed upon what they evaluated as positive and negative regarding these themes. For the first three themes, having solely positive (or negative) experiences was related to the type of nursing home.

\section{The physical environment and atmosphere}

Differences between the types of nursing homes were found in experiences with the physical environment and the atmosphere. Informal caregivers of residents in green care farms and regular small-scale living facilities had more positive experiences compared with informal caregivers of residents in traditional nursing homes. They valued the opportunities that the physical environment provided for encouraging residents. Furthermore, the familiar home-like environment was appreciated.

'I really think the small-scale environment is important. It just has a certain look and feel to it. I remember that when I first came here, the only thing reminding me of the fact that this was a 'care facility' was the chair in the shower. But everything else is like entering an ordinary house. So actually this is kind of a 'home'.' [GCF1620]

Regarding traditional nursing homes, informal caregivers mentioned that a home-like feeling was missing. A clinical atmosphere was mentioned as a negative experience of the care environment. 
'The ward doesn't look like a home at all. They have a common living room, which looks like a waiting room in a hospital. They have these large plastic chairs, which doesn't create a home-like feeling.'[TRAD110]

\section{Activities}

All informal caregivers mentioned that activities were important for nursing home residents. However the focus differed across settings. At green care farms informal caregivers were very positive about the amount of activities, and the autonomy residents have with regard to doing activities.

'The fact that people have the freedom. They have a large garden with all sorts of chickens, cows, and goats. And if they want they can go to them. They are occupied in the gardens, with growing vegetables and stuff. People can just do things on their own, without having the feeling they have to ask for permission first. They are free to walk around.'[GCF501]

Furthermore, the way meaningful activities were integrated into daily life was appreciated. Informal caregivers mentioned several concrete examples such as the fact that residents had the opportunity to participate in farm-related activities such as gardening, and feeding the animals, but also in domestic activities such as doing the dishes or cleaning.

At regular small-scale living facilities and in traditional nursing homes, informal caregivers mentioned that there were many centrally-organised activities such as games (bingo), music, or other organized activities.

'Last week they went to the zoo, which was great! And Sunday they had a barbeque, also very nice. And they have something to do almost every day; one day they have bingo, and the next day they have music.' [TRAD1004]

Looking at negative experiences regarding activities, in contrast to green care farms, informal caregivers at traditional nursing homes and regular small-scale living facilities mentioned that residents were still passive for a large proportion of the day, which they perceived as negative. Residents spend a lot of time just sitting in a chair while nothing happens. Furthermore, examples were given of the lack of stimulation to be active, and the fact that activities were organised in an inappropriate way.

'When she wants to get up to clean the table, they tell her to remain seated, and that they [staff] will do it. Whereas, on other wards, I've seen that they ask residents to set and clean the table, to do the dishes, and that kind of stuff.' [SSL301]

'They [staff] take over everything. In the morning they wash and dress him. Then he goes to have breakfast and they ask him what kind of sandwich he wants. So 
he doesn't have to make it himself. Then he goes to his room and just sits there. And around 12 he gets a warm meal which is already made for him. So there is nothing that stimulates him.' [TRAD1015]

\section{Person-centred care}

In general, informal caregivers highly valued experiences of the nursing staff as kind, empathetic, patient, paying personal attention to residents, and taking wishes and preferences of residents into consideration while providing care. Practical examples included when nursing staff took into consideration the way they addressed residents, and when they payed attention to residents' preferences during dinner.

'They approach her the way she wants to be approached. So all that formal stuff like addressing residents by their surname isn't like her. So they address her with her first name.' [SSL301]

'What I really appreciate is that they address people with their last name. Sometimes you hear them using first names, but my mother would not be amused when they would do that to her.' [SSL801]

Differences were found across settings. Informal caregivers at green care farms experienced a higher level of person-centeredness compared with traditional nursing homes and regular small-scale living facilities, where, by contrast, informal caregivers mentioned that staff had a lack of time, and were too busy.

'You get the feeling they really have time for the residents; they are not in a hurry because they need to do other stuff. Probably, in the background they do, but we don't notice it. They just really pay personal attention to people.' [GCF1601]

'They need to pay more attention. Just go to people. Sit with them at the bed when you [staff] have a quiet moment, instead of sitting behind the computer. Just sit with them and get in contact with the people. Just have a chat, and I'm not saying nobody does this, because I noticed it is also related to the person who is working.' [SSL1405]

Furthermore, informal caregivers mentioned that not all nursing staff made the effort to pay personal attention to the preferences and wishes of individual residents. Practical examples included: the way residents drank their coffee, the way they wanted their hair to be made, and what time they want to get out of bed. Nursing staff sometimes kept working according to their routines, without looking at individual needs.

'I know that there are staff here who say: "that's not what I'm here for, and that's not why I chose this profession", and they just don't have time to have a 
one-to-one conversation, or to offer someone a shoulder, or put their arm around someone.' [TRAD1015]

\section{Communication}

The importance of communication between all people involved (informal caregivers, formal caregivers, management) was a topic that was mentioned consistently by informal caregivers as influencing their experience. Both positive and negative experiences were mentioned in all three types of nursing homes.

'Yes! I feel it is important that they [staff] can share anything they want with the family. And I particularly think it is important that we feel we [the family] can share what we think is important for our mother. I think that's the most important thing, if you don't have that kind of contact with each other, then you can't trust each other.' [SSL202]

Participants agreed that good communication was important for gaining trust and getting to know each other, being beneficial for both nursing staff and family of residents. Open, transparent communication was appreciated, as informal caregivers liked to stay up to date on the experiences of their relative.

'Every week our whole family receives a short summary from the manager on what happened during that week. About things that went well, and things that did not go well. And of course, it is about positive and negative things, but I appreciate receiving this information. And we can also reply to these messages, and if I come here and I haven't read the last message. I can just look into the file of my mother.'[GCF408]

Negative experiences with communication had to do with the fact that there was no common communication strategy among nursing staff. Informal caregivers indicated that there are large differences between formal caregivers regarding the information they communicate to the family. Some staff were said to really elaborate on even the smallest details, whereas other failed to share major events.

'Well, it depends on the individual caregiver. Not everyone is involved with the people in the same way. One mentions immediately when my mother has issues with something whereas the other doesn't say anything. With some I have to accidently heard them talking about it and really ask questions about it, otherwise they don't share anything with me.'[SSL704]

Another aspect that was considered negative was poor communication between nursing staff. Informal caregivers mentioned that they repeatedly have to ask multiple caregivers the same questions, whereas nursing staff should communicate with each 
other in order to increase uniformity in the care that is being provided. Otherwise, this can lead to adverse effects.

'At the beginning they said that my mother would remain in bed for one day. But the nurse from today does not know she was in bed the entire day yesterday, and the day before that. So at certain times she stayed in bed for three days a week. Even until 3 o'clock in the afternoon, or until supper. And that is not how it should be. [SSL801]

\section{Staff}

Both positive and negative experiences were mentioned with individual staff members across all settings. Furthermore, informal caregivers at traditional nursing homes and regular small-scale living facilities said not to expect too much from nursing staff because they did the best they could. This was not mentioned at green care farms.

The importance of the staff's role was emphasised in all interviews. Positive and negative experiences regarding communication, activities, and person-centred care appeared related to individual staff members, next to differences across settings. Informal caregivers mentioned that the way nursing staff were able to provide good care had to with what they 'brought to the table' as a human being, instead of a professional. Aspects such as empathy, compassion, and authenticity were felt to be important and some staff members were said to possess these qualities more than others.

'It depends; some nursing staff chooses to do something with the residents when they have a quiet moment, whereas others don't. I actually heard one caregiver say "I'm not trained to occupy the residents, I'm here to care for them."' [SSL704]

'Some nurses completely ignore us when we are here; they hardly say anything to us. But this varies a lot between nurses. Some nurses have more feeling with this than others.' [SSL607]

\section{DISCUSSION}

This study explored the experiences of informal caregivers of people with dementia within different types of nursing homes (green care farms, regular small-scale living facilities, traditional nursing homes). In summary, we made three main findings: (1) Informal caregivers at green care farms and regular small-scale living facilities made more deliberate considerations when deciding upon a nursing home than informal caregivers who had selected traditional nursing homes; (2) Informal caregivers at green 
care farms were more positive about the physical environment, activities, and personcentred care compared with informal caregivers in the other types of nursing homes; (3) Positive and negative experiences were also dependent of individual staff members, irrespective of the type of nursing home.

Some methodological considerations have to be made. We included a relatively small sample of regular small-scale living facilities and traditional nursing homes, which limits generalizability of experiences to similar settings nationally and internationally. Furthermore, as we used a convenience sample, selection bias might have occurred. It is possible that informal caregivers whose experiences were mainly positive were more willing to take part in the study.

The first main outcome indicated that, at green care farms informal caregivers more actively looked for a nursing home that matched the preferences and backgrounds of their relatives, compared with caregivers at traditional settings. This is line with research on why people opt for green care farms as a day-care service. ${ }^{20}$ At green care farms and other small-scale living facilities, the home-like environment was an important component and informal caregivers actively avoided traditional nursing homes due to the more clinical atmosphere and lack of homeliness. In contrast, at traditional nursing homes often rapid action had often been required during the admission process and less deliberate considerations were therefore made. It is important for all informal caregivers to timely start thinking about options for housing with care and when moving to a nursing home may suit the needs of their relative best. Developing a certain amount of health literacy, gaining knowledge about the possibilities for nursing home admission, and having a match between the care environment and the resident can be of great importance for health outcomes and person-centred care. ${ }^{14,15,21}$

Secondly, this study showed that the capacities for especially traditional nursing homes to provide residents with person-centred care in a home-like, familiar atmosphere where residents are stimulated to be active remained a problem. This is in line with previous studies showing that residents of traditional nursing homes spend the majority of their time doing little or nothing, without having social interaction. ${ }^{22-24}$ Furthermore, previous studies also found that informal caregivers of residents in smallscale living facilities expressed positive experiences of their contact with nursing staff, personal attention, and the autonomy of residents at small-scale living facilities. ${ }^{25,26}$

A cultural change towards more person-centred care in nursing homes is occurring. ${ }^{27-29}$ More research is needed on how we can implement successful elements of green care farms and other types of nursing homes, such as taking the preferences and remaining capacities of people with dementia as a starting point, and providing a stimulating environment into traditional nursing homes. ${ }^{31,31}$

Lastly, this study showed that positive and negative experiences were also dependent on individual staff members as well. Previous studies suggest that the educational level and competences of nursing staff play an important role with regard 
to the quality of care at a nursing home. ${ }^{32}$ Considering the increased focus on personcentred care skills such as active listening, emotional recognition, and empathetic ability are becoming increasingly important. ${ }^{33}$ Therefore, more focus is needed, in both research and practice on how to improve the competences and abilities of nursing staff. The leadership of managers, or other role models in a nursing home, might play a key role in this as they are needed to coordinate, coach and evaluate the skills of nursing staff $^{34}$ to optimise care provided.

In conclusion, this study showed that the experiences of informal caregivers with a nursing home are dependent on both the type of nursing home, as well as individual nursing staff. Informal caregivers perceived green care farms as better able to provide residents with a stimulating environment that provides person-centred care, compared with traditional nursing homes. However, experiences were also often related less to the professional competencies of individual nursing staff than to their interpersonal, 'human' qualities. 


\section{REFERENCES}

1. Peeters, J., Francke, A., Beek, S. v., \& Meerveld, J. (2007). Welke groepen mantelzorgers van mensen met dementie ervaren de meeste belasting? Resultaten van de monitor van het Landelijk Dementieprogramma

2. WHO. (2012). Dementia: a public health priority: World Health Organization.

3. Alzheimer's Association. 2015 Alzheimer's disease facts and figures. Alzheimer's \& dementia: the Journal of the Alzheimer's Association 2015;11(3), 332

4. Caron, C. D., Ducharme, F., \& Griffith, J. Deciding on institutionalization for a relative with dementia: the most difficult decision for caregivers. Canadian Journal on Aging 2006;25(02), 193-205. Doi: 10.1353/cja.2006.0033

5. Verbeek, H., van Rossum, E., Zwakhalen, S. M., Kempen, G. I., \& Hamers, J. P. Small, homelike care environments for older people with dementia: a literature review. International Psychogeriatrics 2009;21(02), 252-264. Doi: 10.1017/S104161020800820X

6. de Boer, B., Hamers, J., Beerens, H., Zwakhalen, S., Tan, F., \& Verbeek, H. Living at the farm, innovative nursing home care for people with dementia-study protocol of an observational longitudinal study. BMC Geriatrics 2015;15(1), 144. Doi: 10.1186/s12877-015-0141-x

7. Ducharme, F., Couture, M., \& Lamontagne, J. Decision-making process of family caregivers regarding placement of a cognitively impaired elderly relative. Home Health Care Services Quarterly 2012;31(3), 197-218. Doi: 10.1080/01621424.2012.681572

8. Butcher, H. K., Holkup, P. A., Park, M., \& Maas, M. Thematic analysis of the experience of making a decision to place a family member with Alzheimer's disease in a special care unit. Research in Nursing \& Health 2001;24(6), 470-480. Doi: 10.1002/nur.10005

9. Lieberman, M. A., \& Fisher, L. The effects of nursing home placement on family caregivers of patients with Alzheimer's disease. The Gerontologist 2001;41(6), 819-826. Doi: 10.1093/geront/41.6.819

10. Meiland, F. J., Danse, J. A., Wendte, J. F., Klazinga, N. S., \& Gunning-Schepers, L. J. Caring for relatives with dementia-caregiver experiences of relatives of patients on the waiting list for admission to a psychogeriatric nursing home in The Netherlands. Scandinavian Journal of Public Health 2001;29(2), 113121

11. Sury, L., Burns, K., \& Brodaty, H. Moving in: adjustment of people living with dementia going into a nursing home and their families. International Psychogeriatrics 2013;25(06), 867-876. Doi: 10.1017/S1041610213000057

12. Bruin, S. R. D., Oosting, S. J., Kuin, Y., Hoefnagels, E. C., Blauw, Y. H., Groot, L. C. D., \& Schols, J. M. Green care farms promote activity among elderly people with dementia. Journal of Housing for the Elderly 2009;23(4), 368-389. Doi:10.1080/02763890903327275

13. Brooker, D. What is person-centred care in dementia? Reviews in Clinical Gerontology 2003;13(03), 215222. Doi: $10.1017 /$ S095925980400108X

14. Edvardsson, D., Winblad, B., \& Sandman, P.-O. Person-centred care of people with severe Alzheimer's disease: current status and ways forward. The Lancet Neurology 2008;7(4), 362-367. Doi: 10.1016/S1474-4422(08)70063-2

15. Lawton, M. P. The physical environment of the person with Alzheimer's disease. Aging \& Mental Health 2001;5(sup1), 56-64. Doi: 10.1080/713650004

16. Polit, D. F., \& Beck, C. T. Nursing research: Generating and assessing evidence for nursing practice: Lippincott Williams \& Wilkins. 2008.

17. MAXQDA. Software for qualitative data analysis, VERBI Software - Consult - Sozialforschung GmbH, Berlin, Germany. 2016

18. Braun, V., \& Clarke, V. Using thematic analysis in psychology. Qualitative Research in Psychology 2006;3(2), 77-101. Doi: 10.1191/1478088706qp063oa 
19. Quinn, C., Clare, L., Jelley, H., Bruce, E., \& Woods, B. 'It's in the eyes': how family members and care staff understand awareness in people with severe dementia. Aging \& Mental Health 2014;18(2), 260-268. Doi: 10.1080/13607863.2013.827627

20. de Bruin, S., Oosting, S., Enders-Slegers, M., van der Zijpp, A., \& Schols, J. Caregiver burden in family caregivers of dementia patients attending day care at GCFs or at RDCFs. Sowing in the autumn season. Exploring benefits of green care farms for dementia patients. 2009.

21. Paasche-Orlow, M. K., \& Wolf, M. S. The causal pathways linking health literacy to health outcomes. American Journal of Health Behavior, 2007;31(1), S19-S26. Doi: 10.5555/ajhb.2007.31.supp.S19

22. de Boer, B., Hamers, J. P., Zwakhalen, S. M., Tan, F. E., Beerens, H. C., \& Verbeek, H. Green Care Farms as Innovative Nursing Homes, Promoting Activities and Social Interaction for People With Dementia. Journal of the American Medical Directors Association 2017;18(1), 40-46. Doi: 10.1016/j.jamda.2016.10.013

23. den Ouden, M., Bleijlevens, M. H., Meijers, J. M., Zwakhalen, S. M., Braun, S. M., Tan, F. E., \& Hamers, J. P. Daily (In) Activities of nursing home residents in their wards: an observation study. Journal of the American Medical Directors Association 2015;16(11), 963-968. Doi: 10.1016/j.jamda.2015.05.016

24. Ice, G. H. Daily life in a nursing home: Has it changed in 25 years? Journal of Aging Studies 2002;16(4), 345-359. Doi: 10.1016/S0890-4065(02)00069-5

25. de Rooij, A. H., Luijkx, K. G., Spruytte, N., Emmerink, P. M., Schols, J. M., \& Declercq, A. G. Family caregiver perspectives on social relations of elderly residents with dementia in small-scale versus traditional long-term care settings in the Netherlands and Belgium. Journal of Clinical Nursing 2012;21(21-22), 3106-3116. Doi: 10.1111/j.1365-2702.2012.04110.x

26. Verbeek, H., Zwakhalen, S. M., van Rossum, E., Kempen, G. I., \& Hamers, J. P. Small-scale, homelike facilities in dementia care: a process evaluation into the experiences of family caregivers and nursing staff. International Journal of Nursing Studies 2012;49(1), 21-29. Doi: 10.1016/j.ijnurstu.2011.07.008

27. Koren, M. J. Person-centered care for nursing home residents: The culture-change movement. Health Affairs 2010;29(2), 312-317. Doi:10.1377/hlthaff.2009.0966

28. Zimmerman, S., Shier, V., \& Saliba, D. Transforming nursing home culture: Evidence for practice and policy. The Gerontologist 2014;54(Suppl 1), S1-S5. Doi: 10.1093/geront/gnt161

29. Shier, V., Khodyakov, D., Cohen, L. W., Zimmerman, S., \& Saliba, D. What does the evidence really say about culture change in nursing homes? The Gerontologist 2014;54(Suppl 1), S6-S16. Doi: 10.1093/geront/gnt147

30. Ausserhofer, D., Deschodt, M., De Geest, S., van Achterberg, T., Meyer, G., Verbeek, H., Schlüter, W. "There's No Place Like Home": A Scoping Review on the Impact of Homelike Residential Care Models on Resident-, Family-, and Staff-Related Outcomes. Journal of the American Medical Directors Association 2016;17(8), 685-693. Doi: 10.1016/j.jamda.2016.03.009

31. de Bruin, S., de Boer, B., Beerens, H., Buist, Y., \& Verbeek, H. Rethinking Dementia Care: The Value of Green Care Farming. Journal of the American Medical Directors Association 2017;18(3), 200-203. Doi: 10.1016/j.jamda.2016.11.018

32. Backhaus, R., van Rossum, E., Verbeek, H., Halfens, R., Tan, F., Capezuti, E., \& Hamers, J. Quantity of staff and quality of care in Dutch nursing homes: a cross-sectional study. Journal of Nursing Home Research 2016;2, 90-93. Doi: 10.14283/jnhrs.2016.13

33. Kitwood, T. Dementia reconsidered: The person comes first. Buckingham: Open University Press. 1997.

34. Auerbach, D. I., Staiger, D. O., Muench, U., \& Buerhaus, P. I. The nursing workforce in an era of health care reform. New England Journal of Medicine 2013;368(16), 1470-1472. Doi:10.1056/NEJMp1301694 

CHAPTER

General discussion 

The aim of this dissertation was to study the effects of green care farms that provide 24-hour nursing home care for people with dementia on the daily lives of residents, quality of care, quality of life, and the experiences of informal caregivers. It was investigated whether there were differences between green care farms, traditional nursing homes, and regular small-scale living facilities. Furthermore, the development of a new observation tool to measure the daily lives of people with dementia (MEDLOTool) living in a nursing home was described. In this chapter, the main findings of this dissertation are discussed, and a reflection on methodological and theoretical issues is presented. Furthermore, ideas for future directions regarding both practice and research are given.

\section{MAIN FINDINGS}

The general conclusion of this dissertation is that green care farms are a valuable addition to the existing spectrum of nursing homes for people with dementia. Our observational data showed that residents of green care farms were more active, had more social interaction, and came outside more often than residents of traditional nursing homes. Compared with regular small-scale living facilities, residents of green care farms displayed more physical effort during their days. Furthermore, the observations showed that having social interaction and a positive mood were associated with a better quality of life. Data retrieved from questionnaires were partly in line with the observations as they suggested higher quality of life scores at green care farms, especially on aspects such as positive affect, social relations, and having something to do. Furthermore, the findings showed no differences on neuropsychiatric symptoms, agitation, and depression. No differences were found on quality of care between green care farms and other types of nursing homes. Finally, the interviews with informal caregivers suggested that they experience green care farms as being better able to provide residents with a homelike, familiar, and activating environment compared with traditional nursing homes. This dissertation resulted in the Maastricht Electronic Daily Life Observation tool (MEDLO-tool), a promising tool to gain real time insight into the aspects of the daily lives of nursing home residents with dementia.

\section{METHODOLOGICAL CONSIDERATIONS}

\section{Design}

This dissertation aimed to investigate the effects of green care farms on people with dementia. A randomized controlled trial would be the preferred design for assessing causal effects, in which residents should randomly be allocated to a green care farm or 
control group (i.e. other type of nursing home). However, this was not possible due to ethical considerations, as people themselves decide where they would like to live and receive care. This makes the random allocation of residents to a specific type of nursing home practically impossible. A previous study that tried to randomly assign residents to a nursing home or a special care unit showed that family members had problems with accepting a random group allocation. ${ }^{1}$ Therefore, a quasi-experimental design was chosen, in which green care farms were first compared at a baseline measurement and a 6-month follow-up measurement with traditional nursing homes. In order to determine the possible added value of green care farms and to prevent discussions concerning whether the possible effects were caused only by the scale/size of the nursing home settings, other small-scale, homelike care facilities were also included in the comparison.

In order to determine causality there needs to be an association between the independent (type of living environment) and the dependent variable (outcome for residents), the cause needs to precede the consequence, and alternative explanations have to be dealt with. By including residents from different types of nursing homes in the comparison, and using a matching procedure (explained below), some alternative explanations for possible differences were taken into account. However, because data on quality of care, quality of life, and the experiences of informal caregivers were only collected or reported at baseline, determining causality remains an issue. ${ }^{2}$ For practical reasons, it turned out not to be feasible to collect all data at both the baseline and follow-up measurement points. As the daily life of residents was the primary outcome measure, performing the observations was prioritized above collecting other information. Data on quality of life and related outcomes were collected at two points in time but showed little variance between measurement points. Ideally, all data should be gathered over a longer period of time; a 6-month follow-up is quite short; perhaps a longer follow-up period of, for instance, 12 or 18 months would have provided more insight into developments over time.

\section{Study population}

Previous research has shown that residents in small-scale, homelike care environments had better cognitive and functional abilities at a baseline measurement compared with residents in traditional large-scale nursing home wards. ${ }^{3}$ If residents from one type of nursing home (e.g., traditional nursing homes) had characteristics that differ from those of the residents in another type of nursing home (e.g. green care farms), it constitutes a threat to the internal validity of the study. ${ }^{4}$ It then becomes difficult to determine whether differences can be attributed to real differences between groups (types of nursing homes) or to the differences in capacities of individual residents. Therefore, to increase comparability between residents living in different types of nursing homes, participants in this dissertation were matched on cognition and ADL- capacity. Through 
this matching procedure, the chance of selection bias was decreased. However, it is possible that the matching may limit the external validity of the study as the sample of the traditional nursing homes might not be representative for the whole population in these types of nursing homes.

\section{Measurement}

In this dissertation, both quantitative and qualitative measurement methods were reported. Factors such as quality of care, quality of life, and daily life are complex concepts and require in-depth investigation rather than a single measurement method. A combination of methods was used as it allowed us to provide stronger evidence for a conclusion through the convergence and corroboration of findings. ${ }^{5}$ Quantitative data reported in this dissertation have been complemented by qualitative data (triangulation). ${ }^{2}$ Most of the methods used in this dissertation were in line with the measurements of choice in previous research ${ }^{6}$ and were chosen based on their psychometric properties, the appropriateness for the target population. These measurement methods are almost all proxy measurements, meaning that scores are based on estimates of (in)formal caregivers. Furthermore, the methods used are retrospective and use average values or sum scores (e.g. how often did the resident perform a certain activity during the last two weeks?). All these existing measurement methods each have their own limitations such as recall bias, or only using a single perspective.

Considering these limitations, besides using existing measurement methods, a new tool was developed (the MEDLO-tool) to gather in-depth, real-time information on multiple aspects of daily life within a naturally occurring context of people with dementia living in a nursing home. The MEDLO-tool is based on principles of ecological momentary assessment (EMA). ${ }^{7}$ EMA is characterized by the collection of data in realworld environments; it focuses on individuals' current or very recent states or behaviors, and uses multiple assessments over time. ${ }^{8}$ By using EMA, researchers create a parallel view of activities and reactions to these activities (e.g. how do people feel during activities?). ${ }^{9}$ Multiple momentary assessments provide a more representative assessment than a single static measurement such as a questionnaire. ${ }^{7}$ Studying residents in the context of normal daily life may provide a necessary addition to more conventional research strategies, as experiences during daily life vary over time and consists of a dynamic interplay with the environment, that is is difficult to assess with traditional instruments. ${ }^{10,11}$

\section{Theoretical considerations}

This study has found differences in the daily lives of people with dementia living at green care farms compared with other types of nursing homes. Main differences were 
related to participation in activities, social interaction, time spend outdoors, and physical activity. There are several factors that might explain the differences in daily life between green care farms, traditional nursing homes, and regular small-scale living facilities. Three explanations are provided in this section: the physical and social care environment, the organizational context (leadership/nursing staff), and the match between the residents and the type of nursing home.

First, a noticeable difference between green care farms and many existing nursing homes lies in the physical and social environment. Green care farms take into consideration many aspects of the physical environment that can have a positive influence on people with dementia. This was supported by data concerning the environmental characteristics of the different settings studied in this dissertation, suggesting that green care farms score better on aspects such as privacy and autonomy, view and nature, orientation and routing, and domesticity compared with other types of nursing homes. Many studies have indicated that nature, animals, and related activities can have positive effects on well-being, agitation, and quality of life. ${ }^{12-17}$ Regarding the social environment at green care farms, stimulating home and farm elements are actively used and naturally incorporated in the environment and care provision. Activities are thus not 'especially organized', but are continuously present and fit within normal life. Residents are encouraged to participate in a wide range of meaningful and stimulating activities that increase a sense of autonomy and reciprocity. This is in contrast with traditional nursing homes where it is often a struggle to provide residents with an activating environment and integrate stimulating elements in daily care practice. ${ }^{18,19}$ It is not just the presence of certain elements in a care environment that makes them appreciated elements. For example, there are nursing homes that have beautiful gardens, including animals, and many other facilities, where residents still remain seated in their chairs for a substantial part of their days, doing little or nothing. Furthermore, at traditional nursing homes several interventions are often used to provide residents with activities (e.g. animal-assisted therapy, nature based interventions, recreational activities). Yet, these environmental elements and interventions are not continuously incorporated in daily care practices. ${ }^{20,21}$

Second, the organizational context at green care farms is different from that in traditional nursing homes. Organizational aspects such as working routines at traditional nursing homes appear rigid and are often perceived as unalterable. This complicates implementing person-centered care. Managers and other role models (e.g., nursing staff) play a decisive role in making sure the physical environment is used in an optimal way and that care is provided according to the new psycho-social principles of care. ${ }^{22}$ This is needed to break through the traditional working routines, regulations and care programs. For example, it is not just a matter of leaving the door unlocked so that residents can go outdoors. It goes beyond this; staff should stimulate residents to go outdoors, and be active, and they should accept that is not a problem if they cannot keep an eye on each resident constantly (an aspect that should be endorsed by 
regulations). This example illustrates that implementing certain elements of green care farms into existing (traditional) nursing homes requires serious thought, creativity, vision, and leadership. At green care farms, the farmers (or managers) show leadership through a high degree of personal involvement and motivation in transferring their care vision to their staff. ${ }^{21}$ They focus on the empowerment of staff and residents, ${ }^{23}$ and act as role models by providing practical examples to staff and making them aware of their own behavior. ${ }^{24}$ Nursing staff at green care farms are selected based on competences that support the vision of the green care farm and staff members are continuously guided to provide care according to their care philosophy. Previous research also suggests that the educational level and competences of nursing staff play an important role with regard to the quality of care at nursing homes. ${ }^{25}$ Hypothetically it would be interesting to transfer a complete team of staff from a green care farm (including management) to a traditional nursing home ward and evaluate the effects. One might hypothesize that this new team and leadership would be able to implement considerable change in the way care is provided at the traditional nursing home ward. Even in a more traditional care environment, it could be expected that the team of a green care farm would influence the daily lives of residents, for instance in terms of engagement in meaningful activities, social interactions, and time spent outdoors. This thought experiment would offer the possibility of evaluating the effect of staff on residents, irrespective of the care environment.

Third, the results of this dissertation indicated that the informal caregivers of those at green care farms more actively looked for a nursing home that matched the preferences and backgrounds of their relatives, compared with informal caregivers opting for traditional settings. This is line with current knowledge suggesting that people who chose to use day-care services at green care farms would have chosen to stay at home, rather than going to a regular day-care service, if there were no green care farms providing day-care. This had to do with a dislike of the institutional environment and a lack of useful, meaningful activities at regular care facilities. Research suggests that having a match between a care environment and the background or preferences of people with dementia can influence health outcomes and person-centered care. ${ }^{26-28}$ This is supported by findings indicating that informal caregivers at green care farms were more positive about the physical environment/ atmosphere, activities, and person-centered care compared with other types of nursing homes. There is a wide diversity in types of nursing homes available for people with dementia, which have different views on how to provide person-centered care. It is possible that early orientation and conscious consideration of people with dementia and their informal caregivers with regard to the possible choices of nursing homes and whether they match their needs and wishes will influence the eventual experiences people have after admission. This might explain the more positive experiences of informal caregivers at green care farms compared with other types of nursing homes. Apparently, regular care services (traditional nursing homes) are still not capable of 
providing the person-centered care that is expected by informal caregivers who carefully select a nursing home for their family member with dementia.

\section{FUTURE DIRECTIONS}

\section{Practice}

The results of this dissertation have several implications for future practice.

First, a culture change is occurring within nursing home care. Instead of focusing on the lack of physical capability of people with dementia, there is now a greater focus on the possibilities and remaining capabilities of individual residents. However, these changes need to go beyond the individual level. A similar change needs to occur at all levels of the nursing home care sector. At the organizational level, nursing homes need to stop thinking about barriers and impossibilities (such as too few staff members, not enough money, etc.) and instead start focusing on creative, innovative ways to organize care differently (collaborating with the health care inspectorate, using volunteers, formulating clear tasks for informal caregivers, etc.). At the health system level, the same applies. Instead of focusing on quick fixes, and investing more money in the nursing home sector, more attention needs to be paid to innovative examples of nursing homes that manage to provide care according to the new care vision with the same means provided to all nursing homes. There are several examples of regular nursing homes that implement certain elements of green care farms as well such as greenery, nature, and related activities.

Second, in order to create a good match between the care environment and residents, it is important for people with dementia and their informal caregivers to start thinking about options for nursing homes in a timely manner that may suit their needs and wishes best. At the moment, there is probably not enough diversity in nursing homes so that everyone can go to the nursing home of their choice. Nevertheless, it is important that health care services inform people about the options. Considering that deciding on a nursing home admission is one of the most difficult decisions for informal caregivers, rather than waiting until a crisis situation emerges, more effort should be made to make this process easier. This might influence outcomes such as person centeredness, and satisfaction with the nursing home after admission. ${ }^{26,28}$.

\section{Research}

There remain many unanswered questions about how to provide optimal nursing home care for people with dementia. This dissertation points to several recommendations for future research. 
First, the way in which the effects of new types of nursing home care should be evaluated is changing. Policy and practice are aimed at providing autonomy, personcentered care, and a good quality of life in nursing homes. ${ }^{29,}{ }^{30}$ More emphasis is being put on homelike, small-scale, and familiar care environments. ${ }^{31}$ Green care farms are not the only innovative type of nursing home that exists. Many new small-scale, homelike facilities are developing worldwide. ${ }^{31-35}$ In the Netherlands, innovative initiatives are developing, such as 'Martha Flora', 'de herbergier', and 'het vlinder concept'. Research is needed to gain a better understanding of how to evaluate these new kinds of care facilities. Besides focusing on clinical outcomes, new evaluation methods should focus on aspects such as resident-centered observations, quality of life, atmosphere, staff, activities and should provide information on the daily lives of residents in relation to the context. ${ }^{36,37}$ Nursing homes are complex environments with many interacting components that can affect many outcomes for residents. The MEDLO-tool can be seen as a first step toward assessing aspects of care that are becoming increasingly more important for nursing home residents with dementia. Future studies should focus on measuring quality from the perspective of nursing home residents, taking into consideration relationships and the dynamic between the expectations of residents, informal caregivers, and formal caregivers.

Second, it is necessary to investigate which competences and skills are required for nursing staff and management to provide care according to the psychosocial care concept. This is a decisive element and more research is needed to determine the optimal skill/education mix of nursing staff at nursing homes. Although research indicates that there is no evidence that having more nursing staff leads to better quality of care, these kinds of pseudo-solutions are believed to be valid in practice. Research is needed to bridge these kinds of gaps between research and practice. Conducting research within networks that connect research and practice, such as the Living Lab in Ageing and Long-Term Care is recommended. Furthermore, current findings suggest that informal leadership and supportive supervision can influence both staff and resident outcomes (e.g. satisfaction) in a positive manner. ${ }^{38}$ However, more research is needed to gain insights into the specific leadership practices that are necessary to improve the care provided at a nursing home.

Third, methods aimed at improving the match between nursing home residents and the nursing home should be investigated further. Research should study how to inform people with dementia and their informal caregivers about the options they have regarding their choice of a nursing home. Research shows that unplanned admissions often result in severe health consequences and that a sense of 'feeling at home' in the new place of residence is important for personal resilience and a successful transition. ${ }^{39}$, ${ }^{40}$ Future studies should investigate how to improve the transition process, as many people with dementia and their informal caregivers still have to deal with crisis situations and unplanned admission procedures, influencing their eventual experiences with the nursing home. 


\section{REFERENCES}

1. Maas, M. and K. Buckwalter, Nursing Evaluation Research: Alzheiemer's Care Unit. Alzheimer Disease \& Associated Disorders 1988;2(3): p. 166.

2. Polit, D.F. and C.T. Beck, Nursing research: Generating and assessing evidence for nursing practice. 2008: Lippincott Williams \& Wilkins.

3. Verbeek, H., et al., Small-scale, homelike facilities versus regular psychogeriatric nursing home wards: a cross-sectional study into residents' characteristics. BMC Health Services Research 2010;10(1): p. 30.

4. Gravetter, F.J. and L.-A.B. Forzano, Research methods for the behavioral sciences. 2015: Nelson Education.

5. Johnson, R.B. and A.J. Onwuegbuzie, Mixed methods research: A research paradigm whose time has come. Educational Researcher 2004;33(7): p. 14-26.

6. Moniz-Cook, E., et al., A European consensus on outcome measures for psychosocial intervention research in dementia care. Aging \& Mental Health 2008;12(1): p. 14-29.

7. Shiffman, S., A.A. Stone, and M.R. Hufford, Ecological momentary assessment. Annual Review of Clinical Psychology 2008;4: p. 1-32.

8. Trull, T.J. and U.W. Ebner-Priemer, Using experience sampling methods/ecological momentary assessment (ESM/EMA) in clinical assessment and clinical research: introduction to the special section. 2009.

9. Borell, K., Using the experience sampling method in gerontological social work. Journal of Gerontological Social Work 1999; 30(3-4): p. 183-189.

10. Myin-Germeys, I., et al., Experience sampling research in psychopathology: opening the black box of daily life. Psychological Medicine 2009;39(9): p. 1533.

11. van Knippenberg, R., Experience sampling in dementia care. 2017.

12. Sloane, P.D., et al., The Therapeutic Environment Screening Survey for Nursing Homes (TESS-NH) An Observational Instrument for Assessing the Physical Environment of Institutional Settings for Persons With Dementia. The Journals of Gerontology Series B: Psychological Sciences and Social Sciences 2002;57(2): p. S69-S78.

13. van den Berg, A.E., Health impacts of healing environments. A review of evidence for benefits of nature, daylight, fresh air, and quiet in healthcare settings. Univ. Medical Center Groningen, Wageningen, 2005.

14. Bovenberg, F., et al., Helende omgeving draagt bij aan herstel. Sociale Psychiatrie 2010;29(94): p. 7.

15. Day, K., D. Carreon, and C. Stump, The therapeutic design of environments for people with dementia a review of the empirical research. The Gerontologist 2000;40(4): p. 397-416.

16. Fleming, R. and N. Purandare, Long-term care for people with dementia: environmental design guidelines. International Psychogeriatrics 2010;22(07): p. 1084-1096.

17. Beerens, H.C., et al., The relation between mood, activity, and interaction in long-term dementia care. Aging \& Mental Health 2016;p. 1-7.

18. Ice, G.H., Daily life in a nursing home: Has it changed in 25 years? Journal of Aging Studies 2002;16(4): p. 345-359.

19. den Ouden, M., et al., Daily (In) Activities of nursing home residents in their wards: an observation study. Journal of the American Medical Directors Association 2015;16(11): p. 963-968.

20. De Bruin, S., et al., The concept of green care farms for older people with dementia An integrative framework. Dementia 2010;9(1): p. 79-128.

21. de Bruin, S., et al., Rethinking Dementia Care: The Value of Green Care Farming. 2017, Elsevier.

22. Auerbach, D.I., et al., The nursing workforce in an era of health care reform. New England Journal of Medicine 2013;368(16): p. 1470-1472.

23. Hassink, J., et al., Care farms in the Netherlands: Attractive empowerment-oriented and strengths-based practices in the community. Health \& Place 2010;16(3): p. 423-430.

24. Elings, M. and J. Hassink, Farming for Health in the Netherlands. Farming for Health, 2006: p. 163-179. 
25. Backhaus, R., et al., Quantity of staff and quality of care in Dutch nursing homes: a cross-sectional study. Journal of Nursing Home Research 2016;2: p. 90-93.

26. Edvardsson, D., B. Winblad, and P.-O. Sandman, Person-centred care of people with severe Alzheimer's disease: current status and ways forward. The Lancet Neurology 2008;7(4): p. 362-367.

27. Lawton, M.P., The physical environment of the person with Alzheimer's disease. Aging \& Mental Health 2001;5(sup1): p. 56-64.

28. Paasche-Orlow, M.K. and M.S. Wolf, The causal pathways linking health literacy to health outcomes. American Journal of Health Behavior 2007;31(1): p. S19-S26.

29. Organization, W.H., Dementia: a public health priority. 2012: World Health Organization.

30. Tolson, D., et al., International Association of Gerontology and Geriatrics: A global agenda for clinical research and quality of care in nursing homes. Journal of the American Medical Directors Association 2011;12(3): p. 184-189.

31. Verbeek, H., et al., Small, homelike care environments for older people with dementia: a literature review. International Psychogeriatrics 2009;21(02): p. 252-264.

32. Ausserhofer, D., et al., "There's No Place Like Home": A Scoping Review on the Impact of Homelike Residential Care Models on Resident-, Family-, and Staff-Related Outcomes. Journal of the American Medical Directors Association 2016;17(8): p. 685-693.

33. Atkinson, A., Managing people with dementia: CADE units. Nursing Standard 1995;9(25): p. $29-32$.

34. Angelelli, J., Promising models for transforming long-term care. The Gerontologist 2006;46(4): p. 428430.

35. Ritchie, K., et al., The evaluation of long-term care for the dementing elderly: A comparative study of hospital and collective non-medical care in France. International Journal of Geriatric Psychiatry 1992;7(8): p. 549-557.

36. IGZ. Mystery guests. Caring for Older People: How Can We Do the Right Things Right? 5th European Nursing Congress, Rotterdam, the Netherlands, Journal of Advanced Nursing Special Issue 2016;72(Supplement S1).

37. NIVEL, Evaluatie van een nieuwe vorm van clientgericht toezicht: het Short Observational Framework for Inspection. http://www.nivel.nl, 2015.

38. McGilton, K.S., et al., Outcomes related to effective nurse supervision in long-term care homes: an integrative review. Journal of Nursing Management 2016;24(8): p. 1007-1026.

39. Koppitz, A.L., et al., Relocation experiences with unplanned admission to a nursing home: a qualitative study. International Psychogeriatrics 2017;29(3): p. 517-527.

40. Cooney, A., 'Finding home': a grounded theory on how older people 'find home'in long-term care settings. International Journal of Older People Nursing 2012;7(3): p. 188-199. 

Summary 

The aim of this dissertation is to study the effects of green care farms that provide 24hour nursing home care for people with dementia. It provides insight into whether there are differences between green care farms, traditional nursing homes, and regular small-scale living facilities in terms of the daily lives of residents, quality of care, quality of life, and the experiences of informal caregivers. First, a study aimed at developing an observational tool to measure the daily lives of people with dementia living in a nursing home was conducted (Chapter 3). Second, a longitudinal observational study was carried out, performing over 16,000 observations among 115 residents to compare the daily lives of residents of green care farms with traditional nursing homes and regular small-scale living facilities (Chapter 4). Third, the observational data were used to investigate the associations between aspects of daily life and quality of life (Chapter 5). Fourth, cross-sectional data on quality of care, quality of life, and related outcomes were assessed in the different settings (Chapter 6). Fifth, a qualitative study was conducted to gain insights into the positive and negative experiences of informal caregivers of people with dementia living at green care farms or other types of nursing homes (Chapter 7). The current chapter summarizes all the studies described in this dissertation.

Chapter 1 provides a general introduction to this dissertation. It contains information on dementia, developments within nursing home care, green care farms, daily life at nursing homes, and the relevance of the studies described in this dissertation. Furthermore the outline of this dissertation is specified. The study protocol is described in Chapter 2. Here, the main research questions are formulated and the design of the study is described. Furthermore, the sample, settings, measurement methods, and procedures are discussed.

Chapter 3 describes the development of the Maastricht Electronic Daily Life Observation tool (MEDLO-tool). This tool was developed because appropriate assessment tools for daily life were lacking. Three steps were taken during the development process of the MEDLO-tool: (1) determining relevant aspects of daily life for nursing home residents with dementia based on a literature search and expert interviews; (2) pilot testing observation procedures and operationalizations of the aspects of daily life; (3) exploring the inter-rater reliability and feasibility of the tool in a nursing home facility with 16 residents. The following aspects of daily life can be assessed with the MEDLO-tool: (1) activity (activity performed by the resident, engagement in this activity and the degree of physical effort); (2) physical environment (location of the resident and interaction with the physical environment); (3) social interaction (the level and type of social interaction, and with whom this social interaction took place); (4) emotional well-being (mood and agitation). Each aspect of daily life can be observed and scored using standardized scoring options. Agreement on the aspects has been found to be high, with an average absolute agreement of $86 \%$. Users of the MEDLO- tool indicated that it 
is feasible in practice and contains clear operationalization of the aspects of daily life. Therefore, the MEDLO- tool seems to be a promising tool to gain real time insight into the aspects of the daily lives of nursing home residents with dementia.

Differences in the daily lives of people with dementia living in green care farms, traditional nursing homes and regular small-scale living facilities are discussed in Chapter 4. A longitudinal observational study was conducted in which 16.860 ecological momentary assessments were conducted using the MEDLO-tool. The following aspects of daily life were collected for this study: the activity performed by the participant or occurring in his/her vicinity, engagement in the activity, the level of physical activity during the activity, the physical environment (location where the activity occurred), and the level of social interaction during the activity. Analyses showed that residents of green care farms participated significantly more often in domestic activities and outdoor/nature-related activities, and significantly less often in passive/purposeless activities compared to residents at traditional nursing homes. Furthermore, residents at green care farms had significantly more active engagement, and more social interaction, and came outside significantly more often than residents of traditional nursing homes. Residents of green care farms were significantly more physically active than were residents of regular small-scale living facilities. This indicates that green care farms provide an attractive, homelike environment and activities, which positively influences engagement and social interaction.

Chapter 5 investigated the relationships between aspects of daily life and proxyreported quality of life of people with dementia living in nursing homes. The results revealed that quality of life is associated with frequent social interaction and a positive mood. The association between quality of life and active, expressive, and social activities remained unclear.

Chapter 6 reports on the findings of a cross-sectional study on quality of care, quality of life, and related outcomes at green care farms and other types of nursing homes. Data on quality of care was gathered and consisted of outcome indicators (e.g. falling incidents, pressure ulcers), structure indicators (e.g. hours per resident per day), and process indicators (e.g. presence, accessibility and content of protocols on care delivery). Furthermore, questionnaires on cognition, dependence in activities of daily living, quality of life, social engagement, neuropsychiatric symptoms, agitation, and depression were used. The data showed that quality of care was comparable across settings. No large differences were found on clinical outcome measures, hours per resident per day, or process indicators. Higher quality of life scores were reported for residents of green care farms in comparison with residents of traditional nursing homes. They scored significantly higher on the Quality of Life - Alzheimer's Disease Scale, indicating a better quality of life. In addition, residents of green care farms scored 
higher on three quality of life domains of the Qualidem: positive affect, social relations and having something to do. No differences between green care farms and regular small-scale living facilities were found.

In a qualitative study (Chapter 7), we explored the experiences of informal caregivers with green care farms, small-scale living facilities, and traditional nursing homes. Semistructured interviews were conducted with 43 informal caregivers. Topics discussed were: reasons for choice of a particular type of nursing home; positive and negative experiences within the nursing home. Person-centeredness, the opportunity to participate in daily activities, and the physical environment/atmosphere played important roles when choosing for green care farms and other small-scale living facilities. Often, informal caregivers actively avoided nursing homes with a clinical, hospital-like atmosphere. At traditional nursing homes less deliberate considerations were made, since usually rapid action was required due to crisis situations. Furthermore, both positive and negative experiences regarding communication and individual staff members appeared across all types of nursing homes. Hence, besides differences between types of nursing homes, positive and negative experiences were also often dependent on individual staff members.

Chapter 8 summarizes the main findings of the dissertation. Implications for research and practice, the strengths and limitations of the studies, and possible directions for future research are discussed. 

Samenvatting 

Vroeger leverden verpleeghuizen zorg volgens een medisch model van zorg, waarbij het leveren van fysieke zorg het belangrijkste was. Bewoners woonden samen in grootschalige verpleeghuizen met gedeelde kamers, een institutioneel karakter en de routines van de organisatie bepaalden hoe het dagelijks leven van bewoners eruit zag. Tegenwoordig zien we een verschuiving richting een meer psychosociaal model van zorg waarbij er steeds meer aandacht komt voor aspecten zoals persoonsgerichtheid, autonomie, kwaliteit van leven, en kleinschalig wonen in een herkenbare omgeving. Het doel is nu om bewoners zoveel mogelijk hun leven zoals zij dat hadden voor verpleeghuisopname te laten voortzetten. Hierdoor zien we wereldwijd de ontwikkeling van innovatieve verpleeghuizen. De zorgboerderij is een voorbeeld van een dergelijk innovatief verpleeghuis. Zorgboerderijen leveren kleinschalige zorg op het terrein van een boerderij. Ze combineren agrarische activiteiten met zorgactiviteiten; zorgpersoneel heeft geïntegreerde taken, ze vormen samen met de bewoners een huishouden. Ze koken samen, poetsen samen, en proberen deze activiteiten te integreren in het dagelijks leven van de bewoners. Dit proefschrift beschrijft het eerste onderzoek naar zorgboerderijen die 24-uurs verpleeghuiszorg bieden voor mensen met dementie. Er is onderzocht of er verschillen zijn tussen zorgboerderijen, traditionele verpleeghuizen, en reguliere kleinschalige woonvormen in termen van het dagelijks leven van bewoners, kwaliteit van zorg, kwaliteit van leven, en ervaringen van informele zorgverleners.

Hoofdstuk 1 geeft een algemene introductie van het proefschrift. Het geeft informatie over dementie, ontwikkelingen in de verpleeghuissector, zorgboerderijen, het dagelijks leven in verpleeghuizen, en de relevantie van de studies beschreven in dit proefschrift. Ook wordt de opzet van het proefschrift weergegeven.

Het protocol van de studie wordt beschreven in hoofdstuk 2 . De belangrijkste onderzoeksvragen richten zich op het dagelijks leven van mensen met dementie wonend in verschillende typen verpleeghuizen, de kwaliteit van zorg, en de ervaringen van mantelzorgers. De onderzoeksvragen worden in dit hoofdstuk geformuleerd en het design van de studie wordt beschreven. Tevens worden de steekproef, de setting, de meetmethoden, en de procedures uitgelegd.

Hoofdstuk 3 beschrijft de ontwikkeling van de Maastricht Electronic Daily Life Observation tool (MEDLO-tool). Dit instrument is ontwikkeld om het dagelijks leven van mensen met dementie die in een verpleeghuis wonen in kaart te brengen. Drie stappen zijn genomen gedurende de ontwikkeling van de MEDLO-tool; (1) de relevante aspecten van het dagelijks leven van verpleeghuisbewoners met dementie zijn bepaald op basis van literatuur en expert interviews; (2) de observatie procedures en operationalisaties zijn getest in een pilot-test; (3) de inter-beoordelaars-betrouwbaarheid en de haalbaarheid van de tool zijn onderzocht in een verpleeghuis met 16 bewoners (56\% 
vrouw, gemiddelde leeftijd: 77). De volgende aspecten van het dagelijks leven worden gemeten met de MEDLO-tool: (1) activiteit (activiteit uitgevoerd door de bewoner, betrokkenheid bij de activiteit en de mate van fysieke inspanning; (2) de fysieke omgeving (locatie van de bewoner en de interactie met de fysieke omgeving); (3) sociale interactie (de mate en het type van sociale interactie, en met wie deze interactie plaatsvindt) en (4) emotioneel welbevingen (stemming en agitatie). leder aspect van het dagelijks leven wordt geobserveerd en gescoord met behulp van gestandaardiseerde scoringsopties. Overeenstemming op de aspecten is hoog met een gemiddelde absolute overeenstemming van 86\%. Gebruikers van de MEDLO-tool gaven aan dat de tool haalbaar was in de praktijk en dat de operationalisaties van de aspecten van het dagelijks leven duidelijk waren. Dus, de MEDLO-tool lijkt een veelbelovend instrument te zijn om inzicht te krijgen in aspecten van het dagelijks leven van verpleeghuisbewoners met dementie.

Verschillen in het dagelijks leven tussen mensen met dementie wonende in zorgboerderijen, traditionele verpleeghuizen en reguliere kleinschalige woonvormen worden besproken in hoofdstuk 4. Een longitudinale observationele studie is uitgevoerd waarin 16.680 'ecological momentary assessments' gedaan zijn gebruik makende van de MEDLO-tool. Deze 'ecological momentary assessments' zijn observaties in de context van de dagelijkse zorg. Dit betekend dat gedurende het normale dagelijkse leven in verschillende typen verpleeghuizen op herhaalde willekeurige momenten geobserveerd is wat de bewoners aan het doen waren. De domeinen 'activiteit', 'de fysieke omgeving', en 'sociale interactie' zijn gebruikt tijdens deze studie. Analyses laten zien dat bewoners van zorgboerderijen meer huishoudelijke en buiten/natuur gerelateerde activiteiten uitvoerden, en minder passieve/doelloze activiteiten vergeleken met bewoners van traditionele verpleeghuizen. Verder waren bewoners van zorgboerderijen vaker actief betrokken bij een activiteit, hadden ze meer sociale interacties, en kwamen ze meer buiten dan bewoners van traditionele verpleeghuizen. Bewoners van zorgboerderijen hadden meer fysieke inspanning vergeleken met bewoners van reguliere kleinschalige woonvormen. Deze resultaten geven aan dat zorgboerderijen een aantrekkelijke, huiselijke omgeving en activiteiten bieden, welke een positieve invloed hebben op betrokkenheid en sociale interacties.

Hoofstuk 5 onderzoekt de relatie tussen aspecten van het dagelijks leven en proxygerapporteerde kwaliteit van leven van mensen met dementie in verpleeghuizen. In totaal zijn gegevens verzameld bij 115 bewoners van verschillende typen verpleeghuizen. Resultaten gaven aan dat een betere score op kwaliteit van leven geassocieerd is met een hogere frequentie van sociale interacties en een positieve stemming. Tevens werden indicaties gevonden dat er een associatie was tussen een betere score op kwaliteit van leven en participatie aan actieve, expressieve, en sociale 
activiteiten. Maar wanneer er gecorrigeerd werd voor mogelijke invloeden van bijvoorbeeld leeftijd, geslacht en cognitie verdween deze relatie.

Hoofdstuk 6 rapporteert de bevindingen van een cross- sectionele studie naar de kwaliteit van zorg, kwaliteit van leven, en gerelateerde uitkomsten op zorgboerderijen en andere typen verpleeghuizen. Data over kwaliteit van zorg bestond uit uitkomstindicatoren (bijv. valincidenten, doorligwonden), structuurindicatoren (bijv. uren per bewoner per dag), en procesindicatoren (bijv. aanwezigheid, toegankelijkheid en inhoud van protocollen rondom het leveren van zorg). Daarnaast zijn er vragenlijsten over cognitie, afhankelijkheid in de dagelijkse levensverrichtingen, kwaliteit van leven, sociale betrokkenheid, neuro-psychiatrische symptomen, agitatie, en depressie afgenomen. De data gaven aan dat de kwaliteit van zorg vergelijkbaar was tussen de verschillende typen verpleeghuizen. $\mathrm{Er}$ werden geen grote verschillen gevonden op klinische uitkomstmaten, uren per bewoner per dag, of procesindicatoren. Wel werden er hogere kwaliteit van leven scores gerapporteerd bij bewoners van zorgboerderijen vergeleken met bewoners van traditionele verpleeghuizen. Ze scoorden hoger op de algemene proxy- kwaliteit van leven scores. Tevens scoorden bewoners van zorgboerderijen hoger op drie domeinen van kwaliteit van leven: positief affect, sociale relaties en iets om handen hebben. Er werden geen verschillen gevonden met reguliere kleinschalige woonvormen.

Een kwalitatieve studie naar de ervaringen van informele zorgverleners met zorgboerderijen, kleinschalige woonvormen, en traditionele verpleeghuizen wordt beschreven in Hoofdstuk 7. Semigestructureerde interviews met 43 informele zorgverleners zijn uitgevoerd. De onderwerpen die besproken zijn, waren: redenen voor de keuze voor een bepaald type verpleeghuis en positieve en negatieve ervaringen met een verpleeghuis. Persoonsgerichtheid, de mogelijkheid om deel te nemen aan activiteiten gedurende het dagelijks leven, en de fysieke omgeving/sfeer speelden een belangrijke rol bij het kiezen voor zorgboerderijen en andere vormen van kleinschalig wonen. Vaak gaven informele zorgverleners aan dat ze actief een verpleeghuis meden met een klinische, ziekenhuis-achtige sfeer. Bij traditionele verpleeghuizen werden minder bewuste keuzes gemaakt. Vaak was er snelle actie nodig omdat er sprake was van een crisissituatie. Zowel positieve als negatieve ervaringen met communicatie en individuele zorgverleners werden vermeld in alle typen verpleeghuizen. Naast de verschillen tussen de typen verpleeghuizen, waren ervaringen ook vaak minder gerelateerd aan professionele competenties van personeel, maar vaak aan interpersoonlijke, menselijke kwaliteiten.

Hoofdstuk 8 geeft een samenvatting van de hoofdbevindingen en bediscussieerd implicaties voor zowel onderzoek als praktijk. Sterktes en tekortkomingen van de studies worden besproken en mogelijkheden voor de toekomst worden weergegeven. 
De algemene conclusie is dat zorgboerderijen een waardevolle aanvulling zijn op het bestaande spectrum van verpleeghuizen voor mensen met dementie. Daarnaast heeft dit proefschrift ook bredere implicaties. Hoewel de fysieke omgeving van een verpleeghuis positieve effecten kan hebben op het dagelijks leven van bewoners, heeft de organisatorische context, inclusief routines en competenties van verzorgend personeel ook een doorslaggevende rol. Toekomstig onderzoek zou zich meer op aspecten van het dagelijks leven van bewoners moeten richten waarbij contextuele factoren meegenomen worden. 
Valorization 

This chapter describes the societal impact of the current dissertation. A broader perspective is given on what the research described in this dissertation means for the redesign of care in nursing homes for people with dementia. First, relevant lessons learned from green care farms are highlighted. Second, future directions for research are discussed. Third, activities for the dissemination of this dissertation's findings are elaborated on.

\section{LESSONS LEARNED FROM GREEN CARE FARMS}

In January 2017 a quality framework for nursing homes was published in the Netherlands. It focuses on themes such as person centered care, well-being, providing a meaningful day, and improving quality of care through leadership and staffing. Nursing homes should strive to provide care for people with dementia that suits the wishes, preferences, and needs of their residents. Promoting autonomy, social interactions, and participating in meaningful activities are key ingredients within this developing care vision. These themes also come up when looking at which lessons can be learned from research on green care farms ${ }^{1}$. It shows that people with dementia and their family caregivers consider green care farms to be a valuable variation to the existing long-term care services.

Lesson 1: Take preferences and remaining capacities of people with dementia as a starting point

Rather than focusing on limitations of residents, green care farms take their remaining capacities as a starting point. Green care farms provide residents with a broad spectrum of activities and are able to align these activities with differences in needs and wishes. Although this may sound obvious, this is not always the case in other types of nursing homes. Too often in regular nursing homes routines of the organization determine daily life with little opportunity for individual choice. For example, activities are only offered in a group, with limited or no personal adaptation.

Lesson 2: Ensure that the care environment includes stimulating elements in daily care

Research has identified several valuable elements of green care farms such as the physical environment, and the opportunity to promote meaningful social interactions and activities. The physical environment of a green care farm includes potentially beneficial elements such as outdoor areas, activity areas, stables, gardens, animals, etc.

At green care farms many elements of the environment are naturally incorporated into normal daily life. For instance, some residents get the milk from the cows every

\footnotetext{
${ }^{1}$ De Bruin S., de Boer B., Beerens H.C., Buist Y. \& Verbeek H. Rethinking Dementia Care: The Value of Green Care Farming. Journal of the American Medical Directors Association, 2017:18(3). Doi:10.1016/j.jamda.2016. 11.018
} 
day, set the table in the morning, or help with preparing dinner. At other nursing homes, activities are organized as separate interventions, at fixed moments in time, which prevent them from being integrated into normal daily life. This indicates that existing nursing homes should focus more on providing ways to incorporate activities as part of daily life and care. This can be done by making sure that the physical environment enables residents to initiate an activity, for instance by leaving the dishes in the sink, or having a broom standing outside. The idea is that activities are not organised in a specific area or at a specific moment in time, they should always be present. Furthermore, it is important that nursing homes train their nursing staff on how to engage residents in meaningful activities. It is helpful to provide coaching on the job or by provide example situations (instead of playing a game, or just asking whether a residents wants to join you for a walk, telling them you need help with getting the groceries; or setting the table). It is then also important that staff knows the residents and that they can use this knowledge to provide activities.

Lesson 3: Leadership and vision aimed at implementing a radically different care philosophy

Other nursing homes often also have physical environmental aspects that can be beneficial for residents. Yet, these facilities are not always used. This proves that besides the physical environment, other elements might be more important to promote person centered care. Research suggests that leadership and the care vision at green care farms is a decisive factor as well. Managers at green care farms show that it is important to share a vision within the organization aimed at person centered care, autonomy, and offering fitting activities to individual residents. Furthermore, thinking in possibilities, and being open to ideas from nursing staff, and focusing on providing freedom to both residents and staff is of great importance.

Using an environment to its' full potential also requires creativity of nursing staff. Being able to organize individually tailored activities that are naturally incorporated into normal daily care practices requires certain skills and competences of nursing staff. Managers at green care farms try to create an optimal skill mix by selecting and developing the necessary competences within their team. Furthermore, evaluating whether the care that is being provided is in line with their care philosophy is an ongoing and continuous process.

Continuously evaluating the quality of care within individual teams is something that requires more attention at existing nursing homes. Still, nursing home staff is often working based on routines and habits, without critically evaluating their own behaviour. In the Netherlands, there is now a guideline to discuss staffing issues within teams. The central question in this guideline is: do our knowledge, capabilities, and way of working match with the wishes and desires of the residents? Implementing a continuous 
evaluating culture within teams at nursing homes can influence the care that is being provided.

\section{FUTURE DIRECTIONS}

Many research opportunities follow this dissertation. First, more research is needed on roles, tasks, and competences of nursing staff working in different types of nursing homes. Data gathered during the research described in this dissertation will be used for further studies as there is information available that has not been used yet. For instance, interviews with nursing staff regarding their experiences with different types of nursing homes, and which competences and skills they need working in a particular type of nursing home will be used for further research.

Second, studies on how to implement successful elements of innovative nursing homes into regular nursing homes are needed. There might be several facilitating factors and barriers when implementing elements into regular nursing homes. These need to be identified, in order to improve the implementation process.

Third, investigating how to improve the match between a nursing home and their residents is of great importance. People with dementia are a heterogeneous group which calls for a heterogeneous spectrum of nursing homes that fit individual preferences, needs, and wishes. Research on improving the transition from home towards a nursing home is therefore necessary. It is important to include informal caregivers when investigating possible changes in the transition process. As they are the ones that are confronted with these complex situations, and studying how to improve the transition process for them is important.

\section{OBSERVING THE DAILY LIVES OF NURSING HOME RESIDENTS AS A MEASURE OF QUALITY}

In line with recent policy developments with regard to evaluating the quality of nursing homes, the daily life of nursing home residents was the primary outcome of this dissertation. Instead of only focusing on clinical outcomes, the health care inspectorate in the Netherlands started to focus more on the residents' perspective of care, and is pilot testing observational methods to do this. The Maastricht Electronic Daily Life Observation Tool (MEDLO-Tool) used in this dissertation can be seen as a first step of getting insights into the perspective of the residents. The MEDLO-Tool was developed for the research purposes of this dissertation, and has received considerable attention since then. It is now being used by other national and international research teams and will be developed further in the future. In Germany, a study is being conducted that will 
provide more information regarding the usability, the reliability and validity of the tool. In Norway, the MEDLO-tool is being used to assess the daily lives of people with dementia going to green care farms providing day care services in comparison with regular day care services.

It is important to keep spending attention to new ways for evaluating quality of care, as they should be focused on the perspective of the residents. By using observations, research and practice can get a grasp on what it is like to be a resident in a particular nursing home. Experiencing the boredom and tension, but also the joy during a day at a nursing home provides rich information that can be used to improve daily practice.

\section{DISSEMINATION OF THIS DISSERTATION'S FINDINGS.}

Findings of this dissertation are disseminated for the scientific audience through articles published in peer-reviewed, international journals, and presentations gives at several national and international conferences. Furthermore, the project has received attention in the media as well. Articles within newsletters from the International Psychogeriatric Association and the American Medical Directors Association were published. Interviews were given, and published within Trouw and de Limburger. Also, a radio interview was broadcasted on L1 Radio. Smaller collumns have been written in several magazines. The German magazine Pro Alter has published an extensive article about the project.

In order to disseminate the findings of this dissertation further, several steps will be taken. First, a summary factsheet of the results from this dissertation will be distributed among all long-term care organizations who are a member of the Living Lab in Ageing \& Long-Term Care in the province of Limburg. In addition, the factsheet will also appear on their website (http://www.academischewerkplaatsouderenzorg.nl).

Furthermore, together with the National Institute for Public Health and the Environment a short (Dutch) report entitled 'Zorgboerderijen als innovatieve zorgomgeving voor mensen met dementie, welke elementen kunnen worden overgenomen?' has been published recently and will also be available in the website of the Living Lab. This report provides information on which lessons can be learned from green care farms, and gives a first impression on how successful elements of green care farms should be implemented in regular long term care services.

The MEDLO-Tool including a Dutch, German, and English manual is also freely accessible on the website of the Living Lab. 
Dankwoord 

Daar ligt hij dan... het proefschrift, opeens is hij af. En dan mag je een dankwoord schrijven. Aangezien ik mezelf als een man van weinig woorden zou willen beschrijven was dit niet eenvoudig, toch heb ik een poging gewaagd. Dit proefschrift had er nooit gelegen zonder de hulp van te veel mensen om op te noemen. Ik wil graag een aantal mensen in het bijzonder bedanken.

Allereerst wil ik alle directe deelnemers aan het onderzoek bedanken: alle bewoners van zorghoeve de Port, zorgboerderij Dn Bolle Akker, en de deelnemende locaties van MeanderGroep. Ook dank aan hun familie en verzorgenden, en alle managers/ directeuren, en andere 'experts uit het veld' die ik heb mogen spreken tijdens mijn onderzoek. Heel erg bedankt voor jullie geduld tijdens het invullen van alle vragenlijsten, interviews, en het tolereren van mijn aanwezigheid tijdens de vele uren van observeren op alle locaties! Ik weet zeker dat ik wel eens in de weg gelopen heb, maar iedereen bleef altijd super vriendelijk! Maar bij deze toch mijn excuses;)

En dan natuurlijk mijn promotieteam! Jan, Hilde en Sandra, jullie waren echt top! Dank jullie wel! Dankzij jullie heb ik met veel vertrouwen en plezier aan het onderzoek gewerkt. Ik heb ontzettend veel van jullie geleerd, waaronder dat een 'volle agenda' ook relatief is. Ik hoop dat ik de komende jaren nog vaak met jullie mag samenwerken. Beste Hilde, bedankt, bedankt, bedankt. Ik kan het niet vaak genoeg zeggen. Jouw manier van werken spreekt mij ontzettend aan, en vanaf mijn eerste dag had ik het gevoel dat wij een goede match waren. Je stond altijd voor me klaar en hielp mij de hoofdzaken van bijzaken te onderscheiden, vaak ging dit gepaard met de zin 'ik chargeer even hé'. Beste Sandra, ook bij jou stond de deur altijd open. De rust die jij uitstraalt is iets dat ik als voorbeeld zie. Bedankt voor de gedetailleerde feedback op mijn stukken. Hierdoor kon ik altijd mooi de puntjes op de i zetten. Beste Jan, officieel sprak ik jou iedere drie weken, waarbij je tijdens ons overleg altijd nuttige feedback op mijn werk had. Maar tussen de bedrijven door was je ook altijd geïnteresseerd in hoe het verder met me ging, en hebben we ook veel leuke niet werk-gerelateerde gesprekken gehad, dank daarvoor!

De leden van de beoordelingscommissie, Prof. Frans Verhey, Prof. Jos Schols, Prof. Katrien Luijkx, en Prof Karin Wolf-Ostermann, onder voorzitterschap van Prof. Gerjo Kok, wil ik graag bedanken voor het kritisch beoordelen van dit proefschrift en het opponeren tijdens mijn verdediging. Dit laatste geld ook voor dr. ir. Simone de Bruin, bedankt!

Gedurende de afgelopen 4 jaar heb ik mijn kamer gedeeld met 4 collega's.

Reza, you were my first roommate at Maastricht University, and what a roommate you were! Thank you for showing me the ropes during the start of my PhD. I really enjoyed our talks about (our sometimes different) views on culture and politics. After finishing your PhD you went back home to Isfahan. I hope you and your family are doing well, and who knows, maybe we will meet again!

Susanne, hoewel wij maar kort onze kamer gedeeld hebben wil ik ook jou bedanken voor de gezelligheid. 
Hanneke en Ramona, ik ben erg blij dat jullie mijn paranimfen willen zijn! Allebei hebben jullie mij laten zien hoe je het proefschrift hoort te verdedigen, en ik hoop dat ik het net zo goed doe!

Hanneke, met veel plezier heb ik met jou samengewerkt en heel wat verpleeghuizen af mogen reizen. Ik vond het altijd gezellig met je op de kamer, zo nu en dan kwam je weer met een kookadvies, wat mij dan weer te lang duurde (het verbaasde mij altijd hoe jij naast je werk ook nog tijd had om uren te sporten, en ook nog zo uitgebreid kon koken). Ook de onenigheden over wat onder de Nederlandse taal viel, blijven mij bij (wat is sjoenkelen?). Inmiddels ben je gestart met je nieuwe baan, en ik wil je kei veel succes wensen!

Beste Ramona, wij delen nu onze 'droge ogen' kamer. Ik vergeet nooit dat je half ondersteboven onder het bureau lag om de laatste druppels uit je spray te krijgen. Soms lijkt het wel alsof jij van iedereen die je ooit ontmoet hebt, de naam en functie onthouden hebt. Een competentie die ik graag zou willen leren! Wij delen nu een tijdje een kamer en ik kon me geen betere kamergenoot wensen. We mogen nu gezamenlijk aan nieuwe projecten werken, en ik heb alle vertrouwen dat dit helemaal goed gaat komen!

Natuurlijk wil ik ook alle andere collega's van HSR bedanken voor de fijne tijd die ik gehad heb. Ik ben erg blij dat ik met jullie de afgelopen jaren van gedachte heb mogen wisselen over ons werk. Daarnaast was het natuurlijk ook gewoon gezellig in de pauzes waarbij we regelmatig naar buiten gingen om een wandeling te maken, bedankt!

Beste vrienden en vriendinnen, naast het werk is genieten van de vrije tijd natuurlijk erg belangrijk, en dit is mij de afgelopen vier jaar altijd goed gelukt dankzij jullie. Of het nu was door uit eten te gaan, te sporten, te gamen, samen een filmpje kijken, of door ons als idioten te gedragen tijdens carnaval. Jullie hebben altijd voor de nodige afleiding gezorgd, dank daarvoor!

Lieve familie, zo nu en dan vroegen jullie hoe het met mijn studie ging, en dan moest ik weer uitleggen dat promoveren toch net iets anders is... Desalniettemin waren jullie altijd geïnteresseerd in waar ik mee bezig was! Bedankt daarvoor! Een extra dankwoord voor alle oma's en opa's. Hedy, Sjeng, Lily, Leo en Tiny. Jullie zijn allemaal voorbeelden die laten zien hoe actief te blijven op latere leeftijd, en hoe te blijven genieten van het leven. Ik hoop dat ik later op dezelfde manier in het leven sta! Bedankt voor dit mooie voorbeeld.

Monique en Jo, ik was 15 toen ik heel nerveus bij Anouk voor de deur stond, en jullie hebben ervoor gezorgd dat ik me vanaf het eerste moment ook bij jullie thuis voelde. Betere schoonouders kan ik me niet wensen. Bedankt daarvoor, en vooral ook voor de vele lekkere en gezellige etentjes van de afgelopen jaren! Die houden we er zeker in! Joey, vroeger liet ik jou zien hoe je moest sporten, maar tegenwoordig zijn die rollen wel omgedraaid! Ook jij vroeg me altijd hoe het op het werk met me ging, bedankt daarvoor! Inmiddels ben je begonnen aan de opleiding die je altijd al wilde volgen, heel veel succes! 
Pap en mam, zonder jullie was ik nooit gekomen waar ik nu sta. Jullie hebben mij altijd gesteund en het is ongelofelijk hoeveel jullie voor me gedaan hebben. Allereerst bedankt daarvoor! Het was leuk om te zien hoe trots jullie op me waren als ik thuiskwam met nieuws over een artikel dat gepubliceerd was, of met een abstract dat geaccepteerd was bij een internationaal congres. Voordat ik het wist, wist de hele familie al dat ik naar Amerika zou gaan om een presentatie te houden! Jullie hebben me meegegeven dat het belangrijk is om te genieten van het leven, en je niet gek te laten maken. Jullie zijn en blijven een voorbeeld van hoe ik in het leven wil staan. Bedankt!

Robin, bedankt voor de vele trainingsuren, spierpijn, blessures, goede (en slechte) serie/film adviezen, en hulp van de afgelopen jaren. Je staat altijd voor iedereen klaar en bent een top broer! Samen met jou sporten heeft altijd voor de nodige afleiding gezorgd, en je bent samen met Kim een voorbeeld van wat veerkracht is, hiervoor heb ik enorme respect. Bedankt dat jullie altijd voor me klaar staan!

Anouk, de afgelopen jaren heb ik nog het meest genoten van na het werk bij jou thuis komen. Wij zijn al meer dan twaalf en een half jaar samen en wonen sinds kort in ons eigen huisje. Ik weet zeker dat wij de rest van ons leven samen gelukkig zullen blijven. Ik hoop dat we jouw 'YOLO' motto voor altijd kunnen vasthouden. Bedankt voor al het geluk dat jij mij geeft! Ik hou van jou! 



\section{About the author}

Bram de Boer, born May 31st, 1990, studied psychology at Maastricht University. In 2011 he finished his bachelor cognitive psychology, after which he chose the Master social \& health psychology, which he finished a year later. During his study Bram worked as a tutor/trainer for various psychology courses within the problem based learning system in Maastricht. Furthermore, he worked as a research assistant at the faculty of psychology and neuroscience (FPN). He continued these jobs after graduation until July 2013. Since August $15^{\text {th }} 2013$ Bram worked as a PhD candidate at Maastricht University. He worked at the department of Health Services Research (HSR) within the CAPHRI School for Public Health and Primary Care. His project investigates green care farms as an alternative for traditional nursing home care for people with dementia. It is a longitudinal comparative study with the primary goal of gaining insight into the effects and feasibility of green care farms as an alternative for existing nursing home care facilities. The project focusses on a) the quality of care, b) the effects for the residents and c) the experiences of the people who are directly involved in the care process. The concept of green care farming is being compared with traditional nursing home wards and other types of small scale living facilities. Bram now works as a researcher within the Living Lab in Ageing and Long- Term Care, where he participates in projects aimed at quality of care and quality of life within long term care for people with dementia. 



\section{List of publications}





\section{ARTICLES}

De Boer B., Beerens H.C., Katterbach M., Viduka M., Willemse B.M. \& Verbeek H. The Physical Environment of Nursing Homes for People with Dementia: Traditional Nursing Homes, Small-Scale Living Facilities, and Green Care Farms. Submitted to the Journal of Healthcare Engineering.

Buist Y., Verbeek H., de Boer B. \& de Bruin S. Innovating Dementia Care; Implementing Characteristics of Green Care Farms in Other Long-Term Care Settings. Submitted to International Psychogeriatrics

De Boer B., Hamers J.P.H., Zwakhalen S.M.G. \& Verbeek H. Positive and Negative Experiences of Informal Caregivers of People with Dementia Living in Green Care Farms, Small-Scale Living Facilities, and Traditional Nursing Homes. Submitted to Aging \& Mental Health

De Boer B., Hamers J.P.H., Zwakhalen S.M.G., Tan F.E.S. \& Verbeek H. Quality of Care and Quality of Life of People with Dementia Living at Green Care Farms: a CrossSectional Study. BMC Geriatrics, 2017:17(1):155. Doi: 10.1186/s12877-017-0550-0

De Bruin S., de Boer B., Beerens H.C., Buist Y. \& Verbeek H. Rethinking Dementia Care: The Value of Green Care Farming. Journal of the American Medical Directors Association, 2017:18(3). Doi:10.1016/j.jamda.2016.11.018

De Boer B., Hamers J.P.H., Zwakhalen S.M.G., Tan F.E.S., Beerens, H.C. \& Verbeek H. Green Care Farms as Innovative Nursing Homes, Promoting Activities and Social Interaction for People with Dementia. Journal of the American Medical Directors Association, 2017:18(1) . Doi:10.1016/j.jamda.2016.10.013

Beerens H.C., Zwakhalen S.M.G., Verbeek H., Tan F.E.S., Jolani S., Downs M., de Boer B., Ruwaard D. \& Hamers J.P.H. The Relation Between Mood, Activity, and Interaction in Long-Term Dementia Care. Aging \& Mental Health, 2016. Doi:10.1080/13607863. 2016.1227766

De Boer B,. Beerens H.C., Zwakhalen S.M.G., Tan F.E.S., Hamers J.P.H. \& Verbeek H. Daily Lives of Residents with Dementia in Nursing Homes: Development of The Maastricht Electronic Daily Life Observation Tool. International Psychogeriatrics, 2016:1. Doi:10.1017/S1041610216000478

Beerens H.C., de Boer B., Zwakhalen S.M.G., Tan F.E.S., Ruwaard D., Hamers J.P.H. \& Verbeek H. The Association Between Aspects of Daily Life and Quality of Life of People with Dementia Living in Long-Term Care Facilities: A Momentary Assessment Study. International Psychogeriatrics, 2016. Doi: 10.1017/S1041610216000478

De Boer B., Hamers J.P.H., Beerens H.C., Zwakhalen S.M.G., Tan F.E.S. \& Verbeek H. Living at The Farm, Innovative Nursing Home Care for People with Dementia-Study Protocol of an Observational Longitudinal Study. BMC geriatrics 2015; 15(1): 144. Doi: 10.1186/s12877-015-0141-x 


\section{CONFERENCE ABSTRACTS}

De Boer B., Beerens H.C., Hamers J.P.H. \& Verbeek H. Alternatives to Traditional Nursing Home Care: The Case of Green Care Farms. IPA European regional meeting, December 3-5, 2014, Brussels, Belgium.

De Boer B., Hamers J.P.H., Zwakhalen S.M.G. \& Verbeek H. Green Care Farms as Nursing Homes: Quality of Life and Social Interactions. IAGG World congress, July 23-27, 2017, San Fransisco, CA, USA.

De Boer B., Hamers J.P.H., Zwakhalen S.M.G. \& Verbeek H. The Physical Environment of Green Care Farms: A Comparison With Existing Nursing Homes. IAGG World congress, July 23-27, 2017, San Fransisco, CA, USA.

De Boer B., Hamers J.P.H., Zwakhalen S.M.G. \& Verbeek H. Wonen op de Zorgboerderij, Ervaringen van Mantelzorgers met een Innovatieve Vorm van Verpleeghuiszorg. Nationaal Gerontologiecongres, 3 november, 2017, Ede, Nederland.

De Boer B., Beerens H.C., Zwakhalen S.M.G., Hamers J.P.H. \& Verbeek H. Evaluating The Daily Lives of Residents as a Measure of Quality: Development of a New Observation Tool. GSA Annual Scientific Meeting, November 16-20, New Orleans, LA, USA.

De Boer B., Beerens H.C. \& Verbeek H. 24-Hour Nursing Home Care: Comparing Living at a Farm with Living in Other Types of Facilities. GSA Annual Scientific Meeting, November 16-20, New Orleans, LA, USA.

De Boer B., Hamers J.P.H., Zwakhalen S.M.G., Tan F.E.S., Beerens H.C., \& Verbeek H. Green Care Farms Providing Nursing Home Care: Promoting Activities and Social Interaction. European Nursing Congress, October 4-7, Rotterdam, the Netherlands.

De Boer B., Beerens H.C., Zwakhalen S.M.G., Hamers J.P.H. \& Verbeek H. Daily Lives of People with Dementia: Development of The Maastricht Electronic Daily Life Observation tool. IPA International Congress, October, 13-16, Berlin, Germany.

De Boer B., Beerens H.C., Hamers J.P.H. \& Verbeek H. Green Care Farm for People with Dementia: an Alternative to Nursing Home care?. IAGG European Region Congress, April 23-26, Dublin, Ireland.

\section{MANUALS}

De Boer B, Hamers J.P.H., Zwakhalen S.M.G., Beerens H.C. \& Verbeek H. (2016): Maastricht Electronic Daily Life Observation Tool Handleiding. Maastricht.

De Boer B, Hamers J.P.H., Zwakhalen S.M.G., Beerens H.C. \& Verbeek H. (2016): Maastricht Electronic Daily Life Observation Tool Manual. Maastricht. 
Dichter M. N., de Boer B., Verbeek H., Halek, M. (2017): (2017): Benutzerhandbuch für die deutschsprachige Maastricht Electronic Daily Life Observation Tool (MEDLO-Tool) Version 1.0. Witten. 

Living lab in ageing and long -term care 


\section{LIVING LAB IN AGEING AND LONG-TERM CARE}

This thesis is part of the Living Lab in Ageing and Long-Term Care, a formal and structural multidisciplinary network consisting of Maastricht University, seven long-term care organizations (Cicero Zorggroep, Envida, Mosae Zorggroep, MeanderGroep ZuidLimburg, Sevagram, Vivantes and Zuyderland) and Zuyd University of Applied Sciences, all located in the southern part of the Netherlands. In the Living Lab we aim to improve the quality of care and quality of life for older people via a structural multidisciplinary collaboration between research, policy, education and practice. Practitioners (such as nurses, physicians, psychologists, physio- and occupational therapists), work together with managers, researchers, students, teachers and older people themselves to develop and test innovations in long-term care.

\section{ACADEMISCHE WERKPLAATS OUDERENZORG ZUID- LIMBURG}

Dit proefschrift is onderdeel van de Academische Werkplaats Ouderenzorg ZuidLimburg, een structureel, mulitdisciplinair samenwerkingsverband tussen de Universiteit Maastricht, zeven zorgorganisaties (Cicero Zorggroep, Envida, Mosae Zorggroep, MeanderGroep Zuid- Limburg, Sevagram, Vivantes en Zuyderland) en Zuyd Hogeschool. In de werkplaats draait het om het verbeteren van de kwaliteit van leven en zorg voor ouderen. Zorgverleners (zoals verpleegkundigen, verzorgenden, artsen, psychologen, fysio- en ergotherapeuten), beleidsmakers, onderzoekers, studenten en ouderen zelf wisselen kennis en ervaring uit. Daarnaast toetsen en evalueren we vernieuwingen in de dagelijkse zorg. Praktijk, beleid, onderzoek en onderwijs gaan hierbij hand in hand. 


\section{PHD-THESES LIVING LAB IN AGEING AND LONG-TERM CARE / PROEFSCHRIFTEN ACADEMISCHE WERKPLAATS OUDERENZORG ZUIDLIMBURG}

Bram de Boer. Living at the farm. An innovative alternative for regular nursing home care for people with dementia. 2017

Nienke Kuk. Moving forward in nursing home practice. Supporting nursing staff in implementing innovations. 2017

Ramona Backhaus. Thinking beyond numbers. Nursing staff and quality of care in nursing homes. 2017

Irma Everink. Geriatric rehabilitation. Development, implementation and evaluation of an integrated care pathway for older patients with complex health problems. 2017

Martin Van Leen. Prevention of pressure ulcers in nursing homes, a big challenge. 2017 Mariëlle Daamen-Van der Velden. Heart failure in nursing home residents. Prevalence, diagniosis and treatment. 2016

Armand Rondas. Prevalence and assessment of (infected) chronic wounds. 2016

Hanneke Beerens. Adding life to years. Quality of life of people with dementia receiving long-term care. 2016 (Cum Laude)

Donja Mijnarends. Sarcopenia: a rising geriatric giant. Health and economic outcomes of community-dwelling older adults with sarcopenia. 2016

Tanja Dorresteijn. A home-based program to manage concerns about falls. Feasibility, effects and costs of a cognitive behavioral approach in community-dwelling, frail older people. 2016

Basema Afram. From home towards the nursing home in dementia. Informal caregivers' perspectives on why admission happens and what they need. 2015

Noemi Van Nie-Visser. Malnutrition in nursing home residents in the Netherlands, Germany and Austria. Exploring and comparing influencing factors. 2014

Esther Meesterberends. Pressure ulcer care in the Netherlands versus Germany 0- 1. What makes the difference? 2013

Math Gulpers. EXBELT: expelling belt restraints from psychogeriatric nursing homes. 2013 Hilde

Hilde Verbeek. Redesigning dementia care. An evaluation of small-scale homelike care environments. 2011176

Judith Meijers. Awareness of malnutrition in health care, the Dutch perspective. 2009

Ans Bouman. A home visiting program for older people with poor health. 2009.

Monique Du Moulin. Urinary incontinence in primary care, diagnosis and interventions. 2008 
Anna Huizing. Towards restraint free care for psychogeriatric nursing home residents. 2008

Pascalle Van Bilsen. Care for the elderly, an exploration of perceived needs, demands and service use. 2008

Rixt Zijlstra. Managing concerns about falls. Fear of falling and avoidance of activity in older people. 2007

Sandra Zwakhalen. Pain assessment in nursing home residents with dementia. 2007 
